\title{
Effects of concept mapping on learning anatomy and transfer of anatomy knowledge to kinesiology in health sciences students
}

Frances E. Huber

West Virginia University

Follow this and additional works at: https://researchrepository.wvu.edu/etd

\section{Recommended Citation}

Huber, Frances E., "Effects of concept mapping on learning anatomy and transfer of anatomy knowledge to kinesiology in health sciences students" (2001). Graduate Theses, Dissertations, and Problem Reports. 2394.

https://researchrepository.wvu.edu/etd/2394

This Dissertation is protected by copyright and/or related rights. It has been brought to you by the The Research Repository @ WVU with permission from the rights-holder(s). You are free to use this Dissertation in any way that is permitted by the copyright and related rights legislation that applies to your use. For other uses you must obtain permission from the rights-holder(s) directly, unless additional rights are indicated by a Creative Commons license in the record and/ or on the work itself. This Dissertation has been accepted for inclusion in WVU Graduate Theses, Dissertations, and Problem Reports collection by an authorized administrator of The Research Repository @ WVU.

For more information, please contact researchrepository@mail.wvu.edu. 


\title{
Effects of Concept Mapping on Learning Anatomy and Transfer of Anatomy Knowledge to Kinesiology in Health Sciences Students
}

\author{
Frances E. Huber
}

\author{
Dissertation submitted to \\ College of Human Resources and Education at \\ West Virginia University \\ in partial fulfillment of the requirements for the degree of \\ Doctor of Education \\ in \\ Curriculum and Instruction \\ James Rye, $\mathrm{PhD}$, Chair \\ Anne Nardi, PhD \\ Corrie Mancinelli, $\mathrm{PhD}$ \\ Judy Abbott, $\mathrm{PhD}$ \\ Elizabeth Walker, PhD \\ Andy Katayama, $\mathrm{PhD}$ \\ Department of Education Theory and Practice \\ Morgantown, West Virginia \\ 2001
}

Key words: Anatomy, kinesiology, concept map

Copyright 2001 Frances E. Huber 


\begin{abstract}
Effects of Concept Mapping on Learning Anatomy and Transfer of Anatomy Knowledge to Kinesiology in Health Sciences Students
\end{abstract}

Frances E. Huber

Purpose: The purpose of this study was to determine the effects of concept mapping on academic achievement in anatomy and transfer of anatomy knowledge to kinesiology and to describe the participants' experience with this new study strategy. Methods: Thirtyeight junior physical therapy and occupational therapy students volunteered to participate in this study in the fall of 2000. Thirty students matriculated into the spring semester and completed the study. All participants signed informed consents. Participants were randomly assigned to a control group or concept mapping group. The concept mappers were instructed with concept mapping. Members of the concept mapping group were given a copy of Inspiration ${ }^{\circledR}$ software to install on their home computers for participating in the study. Control group members received $\$ 30$ for participating in the study. Concept mappers were required to submit weekly concept maps for seven weeks in the fall semester. No concept maps were required in the spring semester. All participants maintained a record of the time and method for studying for anatomy in the fall and kinesiology in the spring. Participants were tested prior to instruction and immediately after in anatomy on upper extremity topics. A Learning Styles and Study Strategy Inventory (LASSI) was also collected at the start of the study, at the start of the spring semester and upon completion of the study in the midterm of the spring semester. The participants were tested on kinesiology knowledge pre and post classroom instruction. Grades for the anatomy and kinesiology courses were also collected. Results: No statistically significant differences $(p<.05)$ were found between groups on measures of anatomy knowledge, kinesiology knowledge or LASSI. Significant correlations $(p<.01)$ were found between anatomy course grade average and kinesiology course grade average $(r=.547)$. Qualitative findings revealed differences in acceptance of concept mapping as a new strategy depending on the participants' overall metacognitive approach to learning. Conclusions: Concept mapping in anatomy did not improve scores of academic performance for anatomy or kinesiology. However, the intent of the student to use the concept mapping strategy as a rote learning method may have influenced the results.The effectiveness of concept mapping as a learning strategy may depend on metacognitive level of the student using the technique. 
Table of Contents

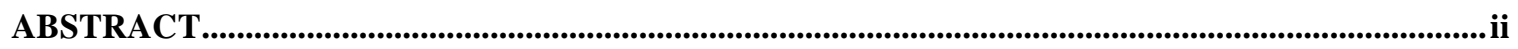

TABLE OF CONTENTS .......................................................................................................................................ii

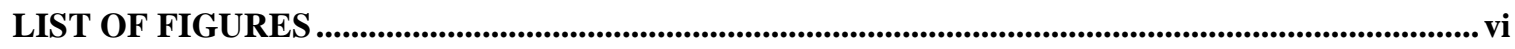

LIST OF TABLES ............................................................................................................................................................. vii

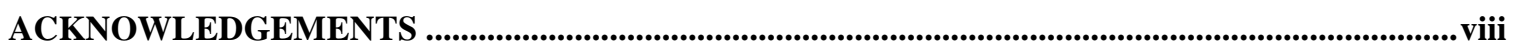

CHAPTER ONE INTRODUCTION ................................................................................................... 1

PURPOSE

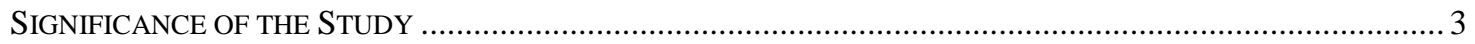

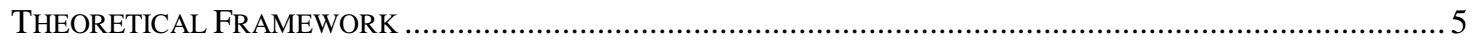

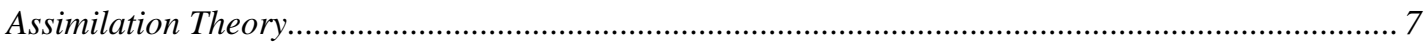

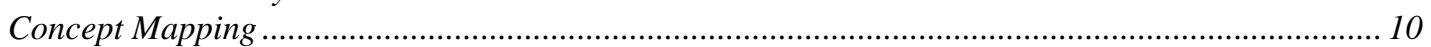

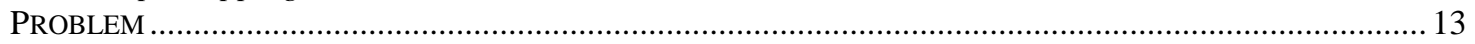

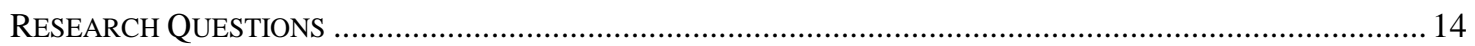

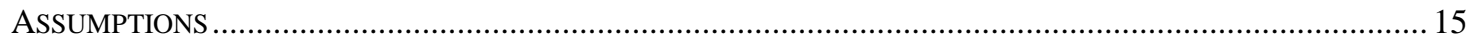

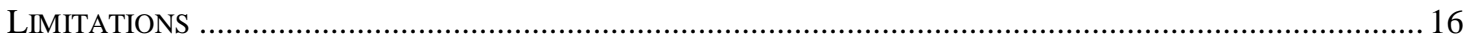

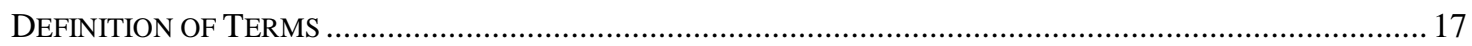

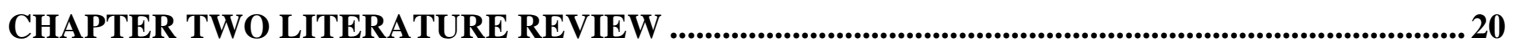

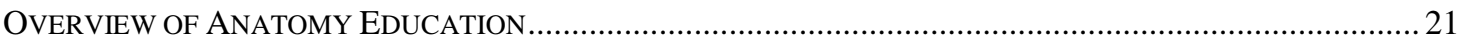

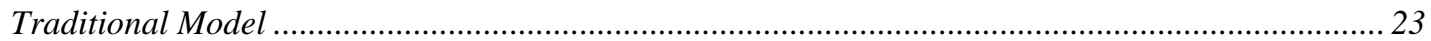

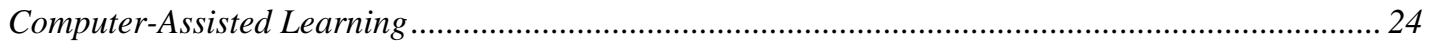

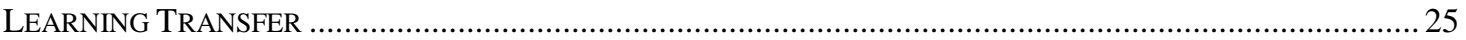

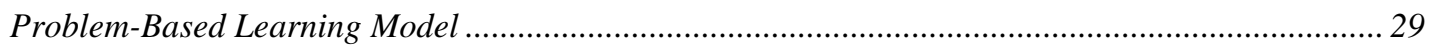

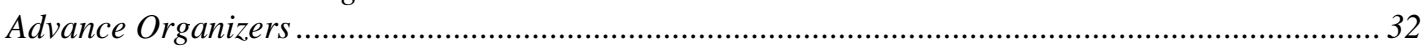

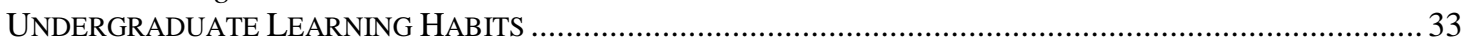

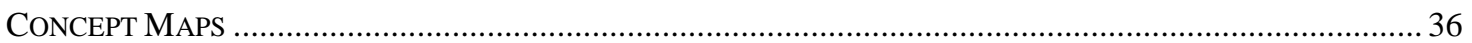

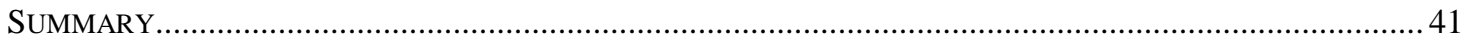

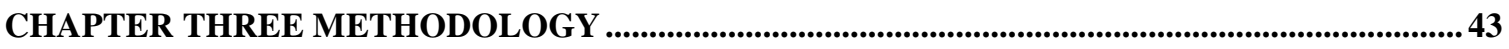

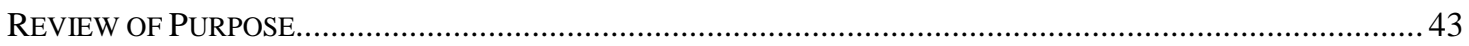

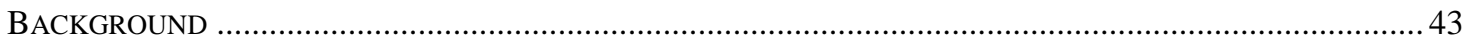

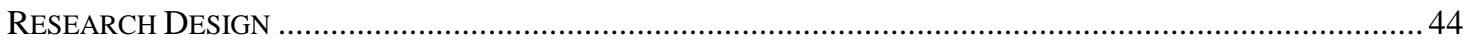

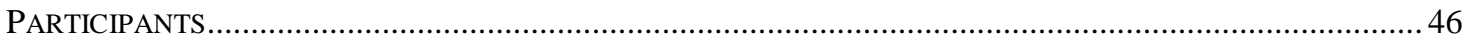

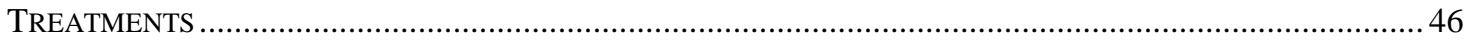

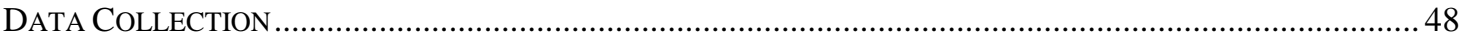

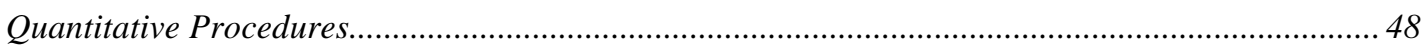

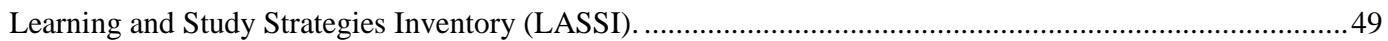

Anatomy and kinesiology test construction.....................................................................................5

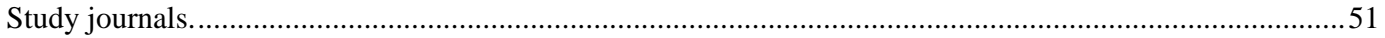

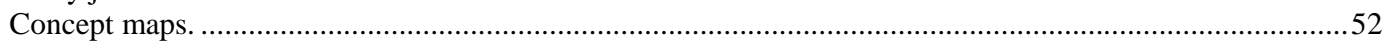

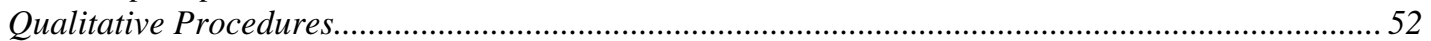

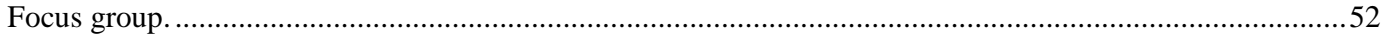

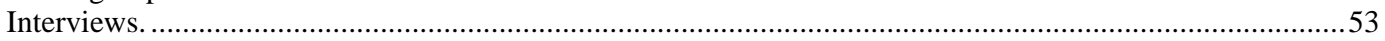

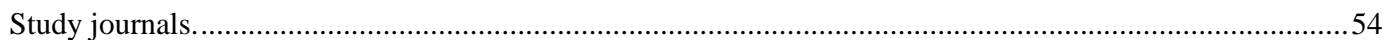

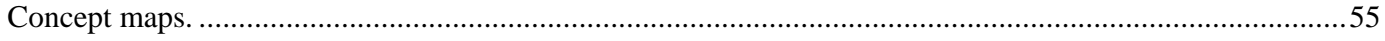

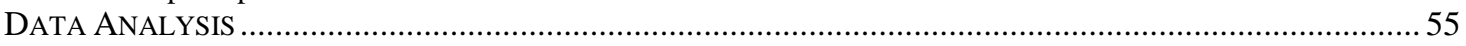

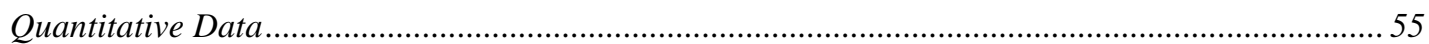




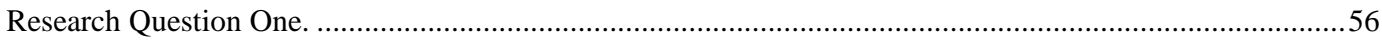

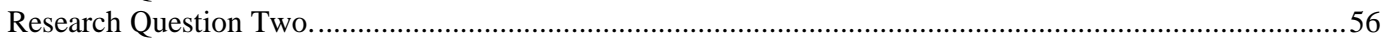

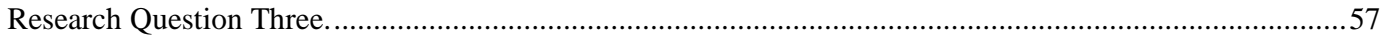

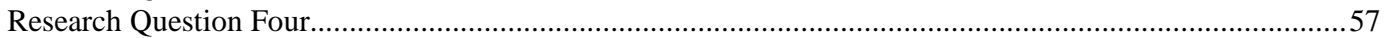

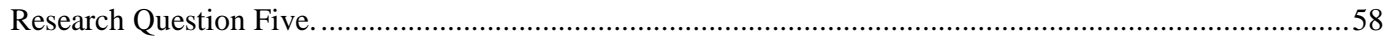

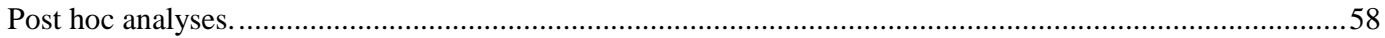

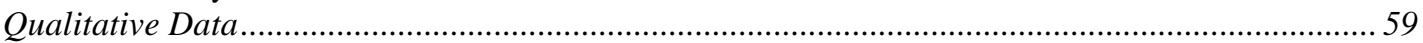

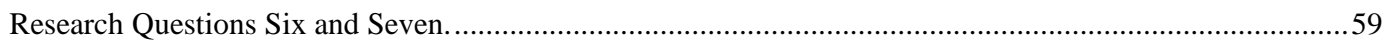

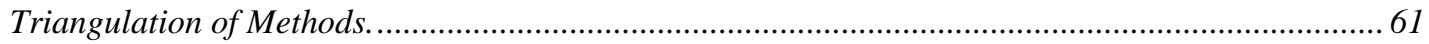

CHAPTER FOUR RESULTS FOR RESEARCH QUESTIONS ONE THROUGH FIVE ..................63

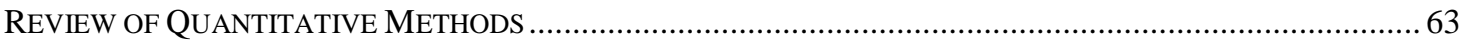

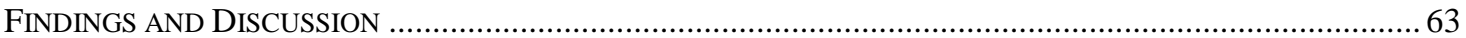

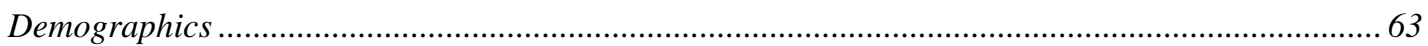

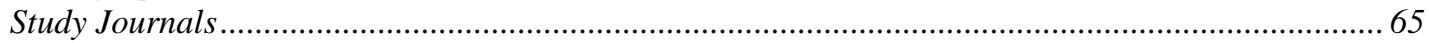

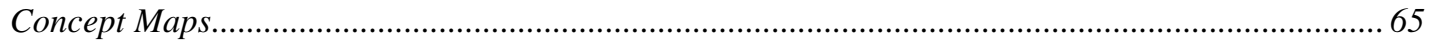

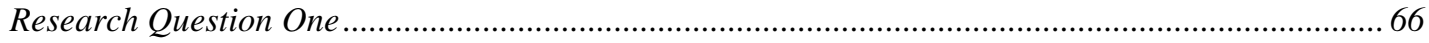

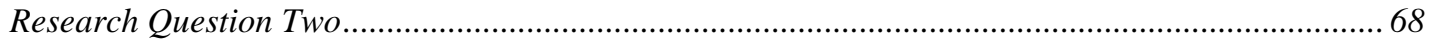

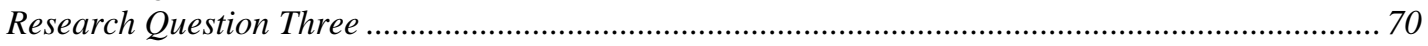

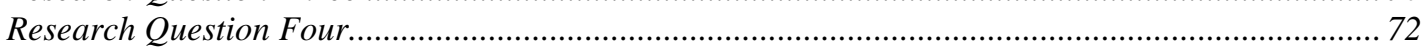

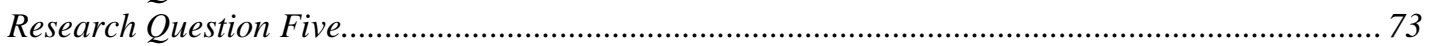

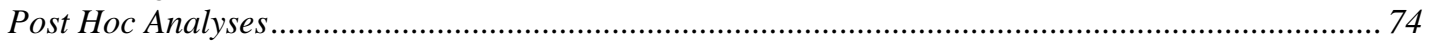

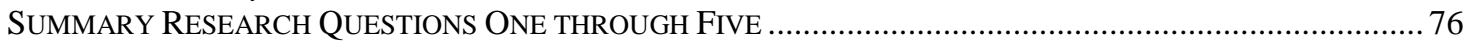

CHAPTER FIVE QUALITATIVE FINDINGS AND DISCUSSION ..................................................78

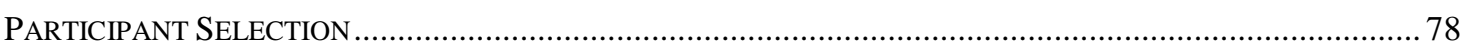

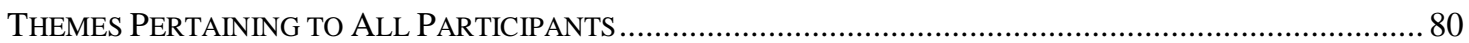

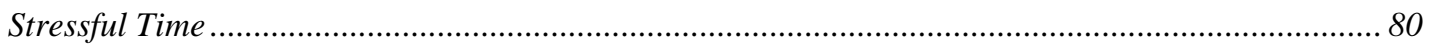

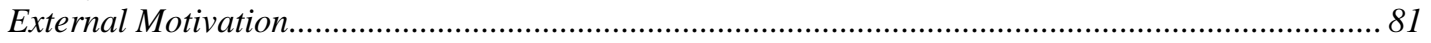

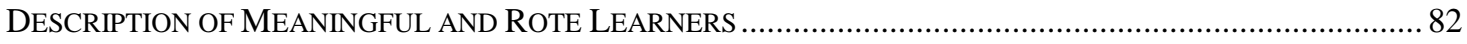

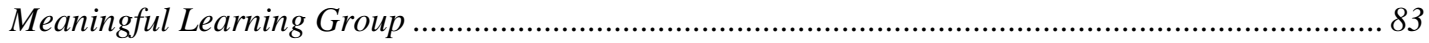

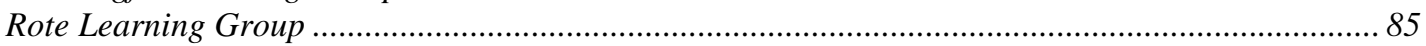

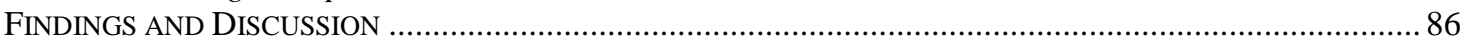

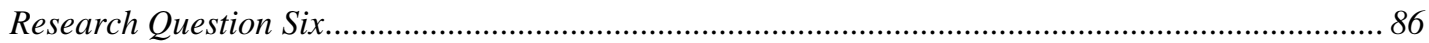

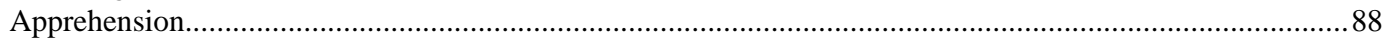

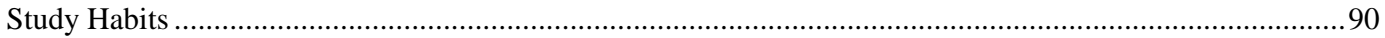

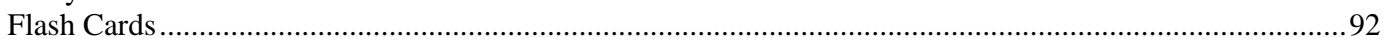

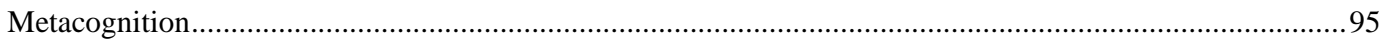

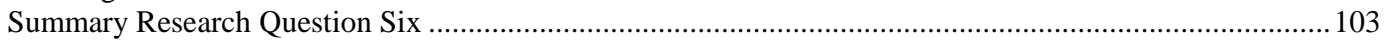

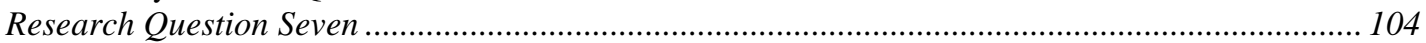

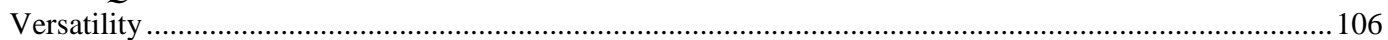

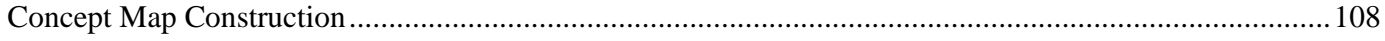

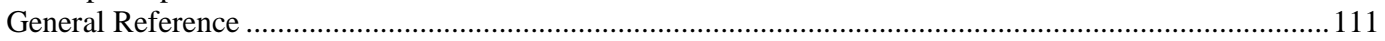

Time Commitment.

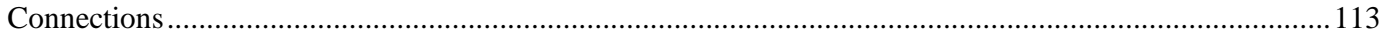

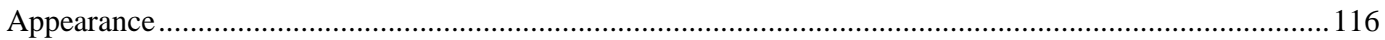

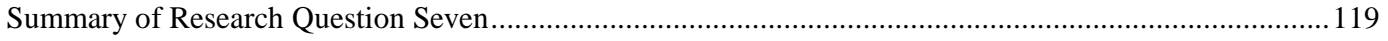

Triangulation of Methods ................................................................................................ 120

CHAPTER SIX SUMMARY, CONCLUSIONS, IMPLICATIONS, AND RECOMMENDATIONS

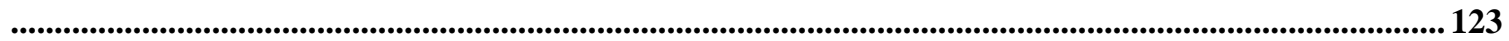

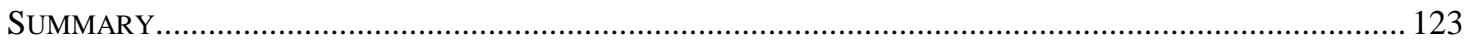

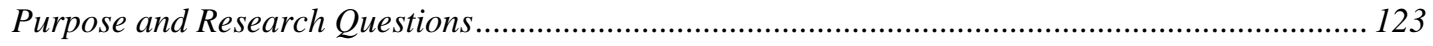

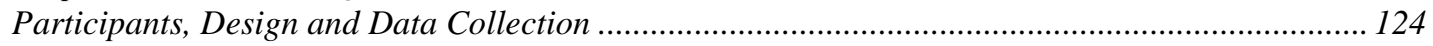

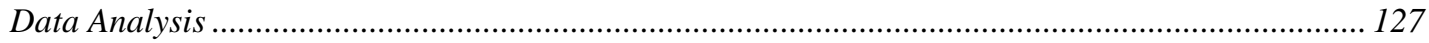

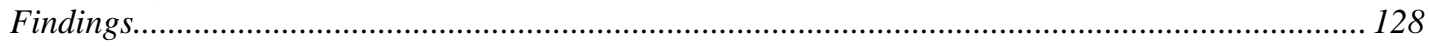

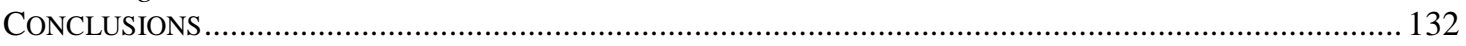

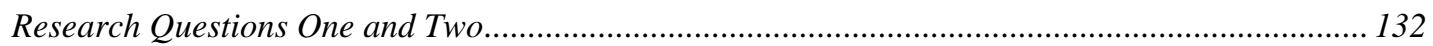


Research Question Three

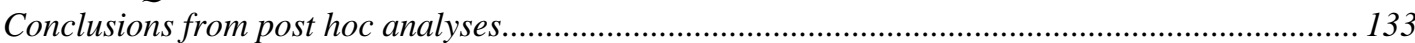

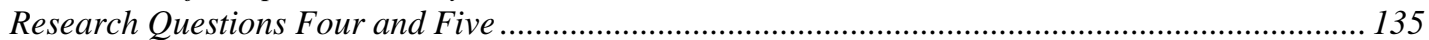

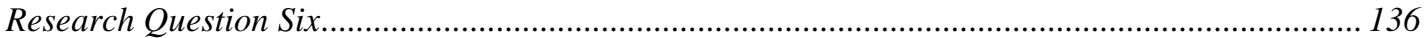

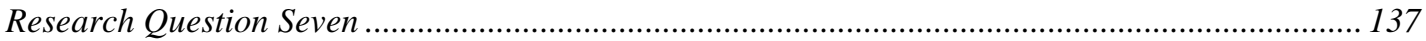

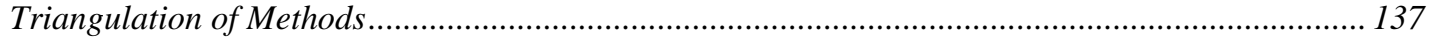

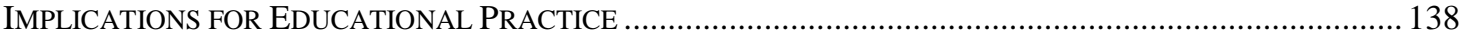

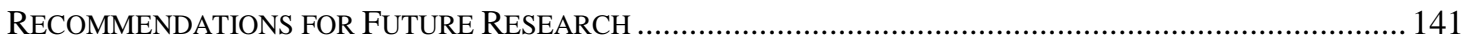

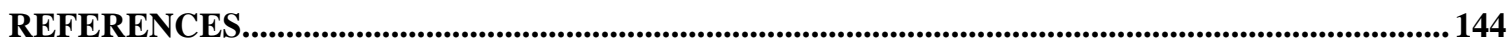

APPENDIX A: EXAMPLE OF CONCEPT MAP WITH FEEDBACK ….......................................... 155

APPENDIX B: TEST MATRIX AND OBJECTIVES FOR RESEARCHER-CONSTRUCTED

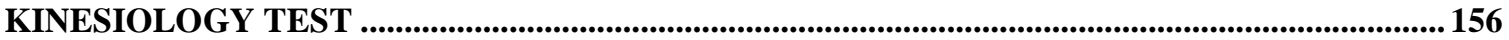

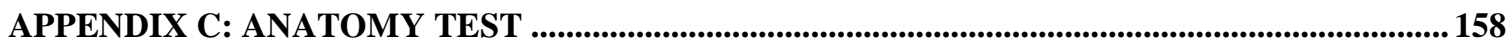

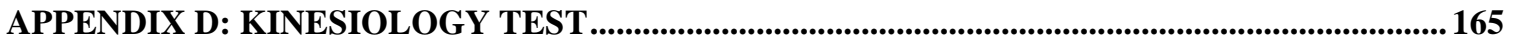

APPENDIX E: STUDY JOURNAL EXAMPLE ........................................................................................173

APPENDIX F: EXAMPLE OF STUDY JOURNAL COMPLETED BY PARTICIPANT ................ 175

APPENDIX G: TABLES OF RESULTS FOR QUANTITATIVE ANALYSES ................................177

APPENDIX H: EXAMPLE OF CODED TRANSCRIPT FROM INTERVIEW (INDUCTIVE

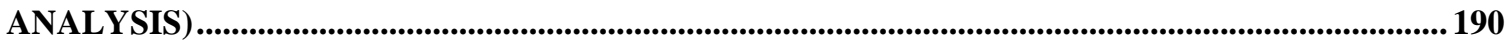

APPENDIX I: EXAMPLE MATRIX FOR LOGICAL ANALYSIS (RESEARCH QUESTION SIX) 198

APPENDIX J: CONCEPT MAP EXAMPLES FROM PARTICIPANTS ......................................215 


\section{List of Figures}

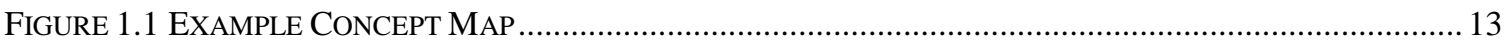

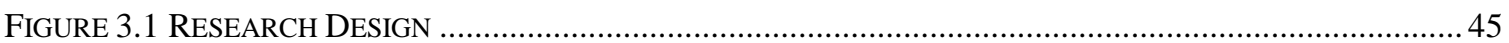

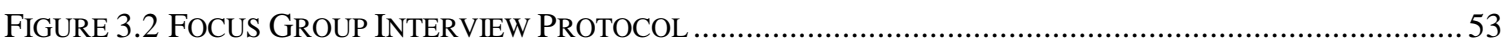

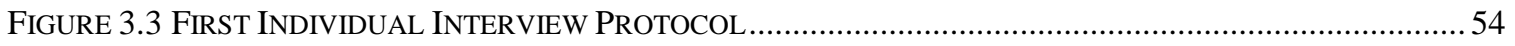

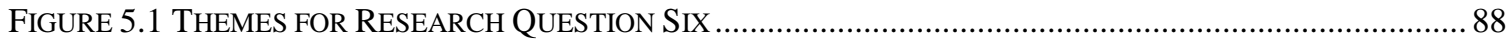

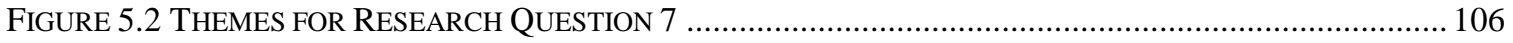

FIGURE J1CONCEPT MAP CONSTRUCTED BY JA (MEANINGFUL LEARNER) ..........................................215

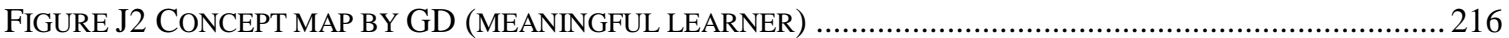

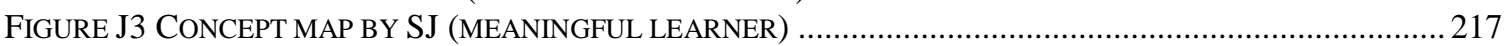

FIGURE J4 CONCEPT MAP CREATED BY CG (MEANINGFUL LEARNER).................................................2 218

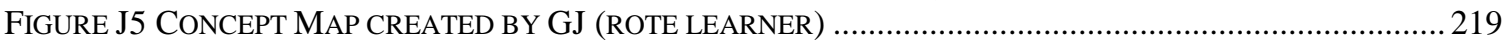

FIGURE J6 CONCEPT MAP CREATED BY DK (ROTE LEARNER) ....................................................220 


\section{List of Tables}

TABLE G1 DesCRIPTIVE STATISTICS AND INDEPENDENT T TEST RESUlTS FOR DEMOGRAPHIC DATA ......... 177 TABLE G2 DESCRIPTIVE STATISTICS AND INDEPENDENT $T$ TEST RESULTS FOR LASSI PRETEST SUBSCALES

TABLE G3 TOTAL STUDY TIME (IN HOURS) FOR ANATOMY AND KINESIOLOGY ……................................ 179

TABLE G4 DESCRIPTIVE STATISTICS FOR ANATOMY CONCEPT MAP SCORES ……..................................... 179

TABLE G5 2X3 ANOVA WITH REPEATED MEASURES FOR RESEARCHER-CONSTRUCTED ANATOMY TEST 180

TABLE G6 KRUSKAL-WALLIS ANALYSIS OF INSTRUCTOR-CONSTRUCTED ANATOMY TESTS........................ 180

TABLE G7 MANN-WhITNEY $U$ ANALYSIS OF FINAL ANATOMY COURSE GRADE AvERAGE............................ 181

TABLE G8 2X2 ANOVA WITH REPEATED MEASURES FOR RESEARCHER-CONSTRUCTED KINESIOLOGY TEST

TABLE G9 INDEPENDENT T TEST ANALYSIS FOR FINAL KINESIOLOGY COURSE GRADE AVERAGE .............. 181

TABLE G10 2X3 ANOVA WITH REPEATED MEASURES FOR LASSI SUBSCALE ANXIETY ...........................182

TABLE G11 2X3 ANOVA wITH REPEATED MEASURES FOR LASSI SUBSCALE ATTITUDE ..............................182

TABLE G12 2X3 ANOVA WITH REPEATED MEASURES FOR LASSI SUBSCALE CONCENTRATION .............. 183

TABLE G13 2X3 ANOVA WITH REPEATED MEASURES FOR LASSI SUBSCALE INFORMATION PROCESSING

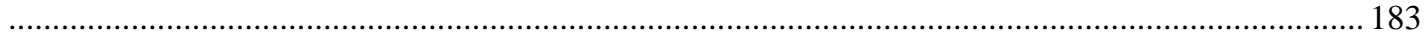

TABLE G14 2X3 ANOVA wITH REPEATED MEASURES FOR LASSI SUBSCALE MotIVATION...................... 184

TABLE G15 ANCOVA FOR LASSI SUBSCALE SELECTING MAIN IDEAS ................................................... 184

TABLE G16 2X3 ANOVA wITH REPEATED MEASURES FOR LASSI SUBSCALE SELF TESTING ................... 185

TABLE G17 2X3 ANOVA wITH REPEATED MEASURES FOR LASSI SUBSCALE STUDY AIDS ..................... 185

TABLE G18 2X3 ANOVA wITH REPEATED MEASURES FOR LASSI SUBSCALE TEST STRATEGIES ............. 186

TABLE G19 2X3 ANOVA WITH REPEATED MEASURES FOR LASSI SUBSCALE TIME MANAGEMENT ......... 186

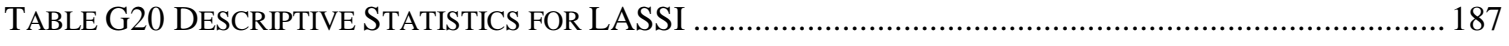

TABLE G21 2X2X2 ANOVA with REPEATED MEASURES FOR KinESIOLOGY High ITEMS VERSUS LOW

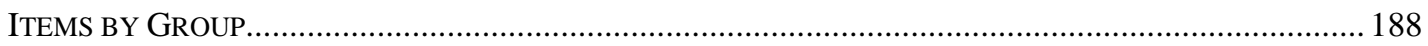

TABle G22 DesCRIPTIVE STATISTICS FOR KinESIOLOGY High ITEMS VERSUS LOW ITEMS By PER CENT .. 189 


\section{Acknowledgements}

So many people were helpful to me while I was "doing the dissertation." First and foremost, I want to express my love and appreciation to Chrissie for all she does.

I give my appreciation to Jim Rye who was an excellent advisor and committee chair, one whom I plan to emulate in the future should I ever have a doctoral student.

To all my committee members I am grateful for the time and expertise they supplied. I might have been afraid to say it before, but I can say now that they all made this process enjoyable as a learning experience. That is the way it should be.

I acknowledge and thank those at my two places of employment throughout this process who encouraged me (Andrea, Cathy, Martha, Mary, MaryBeth), set fine examples (Jane and Rege), helped me manage my schedule and priorities, and otherwise gave support (Diane and Jerry). Special thanks goes to my research mentors Paula and Perri, and the rest of the mock defense team (Ingrid, Linda, and Rick) for giving great feedback.

I also thank those other sources of moral support, friends (especially PhD.org and the Fuel and Fuddle gang) and family. 


\section{Chapter One Introduction}

The education to become a physical therapist (PT) or occupational therapist (OT) spans several years. The coursework includes basic and applied sciences, such as anatomy and kinesiology, usually followed by clinical coursework that emphasizes evaluation and treatment procedures. Each semester builds upon the previous one and lays the groundwork for the learning that will take place subsequently. Students would benefit from learning the earlier content so that it is retrievable and useful to them in later courses and during their clinical work. Also, as health care practitioners in the information age, a solid cognitive framework of foundation knowledge will allow for new information to be easily integrated with previously learned information. Pressure is placed upon allied health schools to graduate new practitioners who can be immediately effective as therapists. Developing a cognitive framework with which one can assimilate and transfer information would facilitate the transition from student to practitioner.

Meaningful learning has been defined by Ausubel as learning that occurs in a framework of prior knowledge such that new information may be related, or anchored to prior knowledge (Ausubel, 1968). In the education of a health professional who will be responsible in part for the well-being of patients or clients, the ability to learn information in a meaningful way is critical. During a health care session, the professional will have to assimilate new findings from the examination and problem solve by incorporating a vast array of knowledge in order to improve the patient's condition.

To accomplish the goal of increased clinical efficiency early in the practitioner's career, some learning that traditionally took place during clinical experience, such as 
critical thinking and problem-solving, must now be delegated to the classroom. This requires an exploration of new paradigms for teaching in health care curricula to improve the educational experience for the students. Since these curricula generally begin with scientific concepts, the best place to begin seems to be within this realm.

Anatomy and kinesiology are pre-requisites for the clinically-oriented courses of both PT and OT students. Often the anatomy course with cadaver dissection is among the most challenging courses that students have met in their college experience. Many students find that the study methods that have been helpful in the past no longer yield the desired results in anatomy. One of the most daunting parts of the anatomy course is the volume of information that one is expected to know. How students approach the task of learning this volume of information may determine how well prepared they are to use anatomical information in courses such as kinesiology and subsequent clinically-oriented courses.

\section{$\underline{\text { Purpose }}$}

The primary purpose of this study was to explore the use of concept mapping as a method for promoting meaningful learning in anatomy to facilitate transfer of anatomical information to kinesiology. This study links many areas including how PT and OT students study for their classes, what conditions must be in place in order for them to alter their studying strategies, and how concept mapping was perceived. Since PT and OT students begin their professional education after two or more years of undergraduate coursework, they often have well-entrenched study methods with which they have been successful. The usefulness of any novel strategy will be partially determined by how it is perceived by the student and how much benefit is derived from its use. 
The specific purposes of this study were to determine the effects of concept mapping on (a) academic performance in anatomy, (b) transfer of anatomy knowledge to kinesiology and biomechanics in a subsequent semester, and (c) learning and studying strategies. Since many factors may determine academic performance, this study also sought to determine if there was (d) a relationship between kinesiology course grade and anatomy course grade and concept mapping, and (e) a relationship among kinesiology course grade, anatomy course grade, concept mapping, SAT scores and Quality Point Average (QPA). Since there is some literature to suggest that it may be difficult for experienced students to make a substantive change in study habits (Santhanam, Leach, \& Dawson, 1998), additional purposes of this study were to (f) describe the experience of students when learning with a new strategy and (g) describe the students' overall perspective about concept mapping.

\section{$\underline{\text { Significance of the Study }}$}

Practicing physical and occupational therapists are aware daily of the enormous breadth of information necessary to evaluate and treat patients. It can be overwhelming. Entry-level education is intended to provide a strong foundation on which to build and incorporate new learning. Practicing clinicians become more effective through experience and interactions with patients or clients and other therapists. However, entry-level education might be structured in a way that would better facilitate learning in practice. A search of the literature found no studies that sought to describe teaching or learning methods that enhanced the ability of the PT or OT student to both learn anatomy information and transfer it to other courses in the curriculum. 
It seems that instructors in the curriculum subsequent to anatomy hold one of two assumptions about anatomy information. The first is that students will remember or review the relevant anatomy and the second is that they will not. There are flaws with both these assumptions. The first assumption puts the onus on the student to make up for an educational deficit in which they did not learn the necessary anatomy information in a way that is permanent or useful to them. The second assumption puts the onus on the subsequent instructors to take time out of their already packed-with-content classes to review information that the students have already had! Both of these scenarios might be avoided if students develop a sound cognitive framework of anatomy information that can be retained and retrieved in a usable way in subsequent classes.

In order to achieve that effect, a study strategy must be employed to help the student to build a cognitive framework that will allow for anatomy information to become meaningful to the student. Concept mapping is a study strategy that has been used to help promote meaningful learning (Novak \& Gowin, 1984). Developed by Novak and Gowin (1984) based on learning theory by Ausubel, concept maps have several purposes within the higher education classroom. Concept maps have been used to assess learning (Beissner, 1992; Bolte, 1999; Heinze-Fry \& Novak, 1990; Markow \& Lonning, 1998; Okebukola, 1990), identify misconceptions (Bolte, 1999), show conceptual change (Graham, 1994, 1996; Trowbridge \& Wandersee, 1994; Wallace \& Mintzes, 1990), and organize instruction and learning (Cliburn, 1985). In this study, concept maps were chosen for their role in promoting meaningful learning and metacognition.

"Metacognition is defined as the knowledge and control one has over one's thinking and learning activities" (Swanson, 1990, p. 306). Metacognition has 
applications in both education and practice for the PT and OT. Metacognition allows students to scrutinize their own thinking processes while learning. Metacognition may also allow therapists to assess themselves while evaluating and treating patients.

A strategy that promotes both meaningful learning and metacognition could have powerful implications in the education and practice of the PT or OT. The earlier that a PT or OT can begin to develop these learning skills, the greater benefit will be derived from the remainder of the education. One way this benefit may be seen is through an enhanced ability to transfer newly learned information to a novel learning environment. This dissertation will study the effects of a meaningful learning strategy, concept mapping, employed with anatomy content on the performance in the anatomy course as well as a subsequent course in the curriculum, kinesiology.

\section{$\underline{\text { Theoretical Framework }}$}

Since the curriculum for entry into a health care profession is founded in the basic sciences, science education is at the core of the professional education. Changing views on the nature of learning and the proliferation of technology to support that learning have led to a close examination of science education in recent years. New standards have been established on how science should be taught and learned, and what the outcomes of a successful science and technology education should be (National Research Council, 1996; Schrum, 1999). Although these standards are mainly directed at primary and secondary science education reform, they also have implications for teaching and learning at the college level.

The National Science Education Standards require science teachers to utilize inquiry-based constructivist methodologies and technology in the classroom (Layman, 
1996; National Research Council, 2000). These standards shift science education from a teacher-centered activity to a learner-centered activity that focuses on students understanding and using knowledge rather than just acquiring information (National Research Council, 1996). These standards correspond to a constructivist curriculum that "focuses on only a handful of central concepts, the relationships among those concepts, and connections between those concepts and the objects and events of the natural world. In this view the primary objective of school science is quality over quantity, meaning over memorizing, and understanding over awareness" (Mintzes \& Wandersee, 1998). This statement applies to the science of anatomy learned in the initial phase of the health professional curriculum. Students must have a broad understanding of anatomy and the relationship between anatomy and injury or disease. However, students must also have a strong cognitive framework of broad principles in order to learn the details related to anatomy that will be important to them in clinical practice.

Constructivists consider learning to be an individual process by which the learner attributes meaning to knowledge. Constructivism is a theory of learning that allows for knowledge structure to be based on personal experience, resembling Rosse's “internalized understanding” of anatomy knowledge (Rosse, 1995).

Human Constructivists reject the view that knowledge is a product that can be faithfully conveyed by teachers. Instead we substitute the idea that knowledge is an idiosyncratic, dynamic construction of human beings; that education attempts to bridge differences among people and that teachers are ‘middlemen’ or negotiators of meaning (Mintzes \& Wandersee, 1998, p. 50). 
There are many theorists within the realm of constructivism. Ausubel described a constructivist learning theory that emphasized the organization of one's knowledge in a mental framework of hierarchy.

\section{Assimilation Theory}

Ausubel's Assimilation Theory supports the main tenets of constructivism and serves as the basis for the research in this study. Ausubel theorized that learning takes place through the assimilation of new information into previously formed knowledge structures (Ausubel, 1968; Novak, 1992). This theory is easily integrated with the constructivist view that knowledge is individually constructed by the learner. In particular, three aspects of the theory are relevant to this discussion: assimilation, rote or meaningful learning and reception or discovery learning.

Assimilation is the integration of new information under a category that has been previously learned and held in a hierarchical cognitive framework. The new information would be subordinate to the broader, more encompassing concept on a superior level in the hierarchy. Using assimilation, educational experiences should be planned so that general, more inclusive concepts are presented first to promote cognitive organization. Then new subordinate information can be presented or subsumed into the structure. The new meanings may be derivative subsumptions or specific examples of the concept. Commonly the new concepts are attained through correlative subsumption which "is an extension, elaboration, modification, or qualification of previously learned propositions" (Ausubel, 1968, p. 52). By the process of assimilation the anchoring concept, or original knowledge, becomes linked with the subsuming concept by the nature of the meaning or relationship between the concepts. 
Obliterative subsumption may eventually result when a new concept loses its dissociation from the anchoring concept and both concepts are recalled or structured cognitively as one.

The less stable (and more specific) meaning of a subordinate idea, is gradually incorporated within or reduced to the more stable ( and more inclusive) meaning of the specifically relevant idea in cognitive structure that assimilates it and the less stable (and more specific) meaning of a combinatorial idea is similarly incorporated within or reduced to the more stable (and more generalized) meanings of the wider, less specifically relevant body of ideas in cognitive structure to which it is related (Ausubel, 1968, p. 95).

With obliterative subsumption the framework of the entire concept becomes stronger in the cognitive structure, but the specifics or details are lost (Mintzes \& Wandersee, 1998). Obliterative subsumption might be troublesome to the anatomy student when details are important to remember. On the other hand, a strong framework of anatomical knowledge may allow a student to compare and contrast among concepts in order to maintain differences within the cognitive structure.

Another important principle in assimilation theory is the difference between rote and meaningful learning. Ausubel describes the difference in the following: ... meaningful learning takes place if the learning task can be related in nonarbitrary, substantive (nonverbatim) fashion to what the learner already knows, and the learner adopts a corresponding learning set to do so. Rote learning, on the other hand, occurs if the learning task consists of 
purely arbitrary associations, ...; if the learner lacks the relevant prior knowledge necessary for making the learning task potentially meaningful; and also (regardless of how much potential meaning the task has), if the learner adopts a set merely to internalize it in an arbitrary, verbatim fashion ..." (Ausubel, 1968, p. 24).

Furthermore, Ausubel goes on to say "Meaningfully- and rotely-learned materials are learned and retained in qualitatively different ways because potentially meaningful learning tasks are, by definition, relatable and anchorable to relevant established ideas in cognitive structure" (Ausubel, 1968, p. 108). This implies that rotely learned material is $n o t$ anchored and therefore is tenuously grasped by the learner making retrieval and transfer of the information extremely difficult. Ausubel insisted that an important factor for new learning is an established cognitive structure on which to anchor new information (Ausubel, 1968). The assimilation of new information is dependent on the characteristics of the original framework so that the more secure and inclusive the framework is the better the new information will be linked to it. Meaningful learning is thought to strengthen the original framework to allow for future learning.

Finally, Ausubel distinguishes between reception and discovery learning as methods for acquiring knowledge. Reception learning occurs when a topic is presented to the learner in its complete form. Traditional lectures are examples of reception learning. With discovery learning, the learner ascertains the important elements of the topic. Problem-based learning is a curriculum model based on discovery learning. Ausubel refutes the common misconception that reception learning by definition cannot be meaningful. Rather, Ausubel asserts that meaning is attributed by the learner through 
internalization of the knowledge. These two types of learning involve very different processes and meaningful learning may result from either (Ausubel, 1968).

\section{Concept Mapping}

Ausubel's theory served as the framework from which concept mapping was developed. Concept maps were first designed as a way for researchers to illustrate an individual's cognitive structure for a particular topic as gleaned from verbatim transcripts of clinical interviews. Concept maps were constructed from and then compared to interview transcripts and revised until the maps were valid representations of how the individuals mentally structured knowledge. The concept maps derived from the interview transcripts were found to be reliable when researchers who independently mapped interviews produced very similar concept maps (Novak \& Musonda, 1991). Eventually, concept maps developed into tools to be used for a variety of applications including teaching and research.

In the college setting, concept maps have been used to assess conceptual change (Graham, 1994, 1996; Trowbridge \& Wandersee, 1994; Wallace \& Mintzes, 1990), identify student misconceptions (Bolte, 1999), and assess student performance in a variety of content areas (Beissner, 1992; Bolte, 1999; Heinze-Fry \& Novak, 1990; Markow \& Lonning, 1998; Okebukola, 1990). It was found that the effort on the part of the student to construct an individual concept map helped the student retain and recall information in a psychology course better than studying an expert-constructed concept map (McCagg \& Dansereau, 1991). This enhanced learning can take place even when constructing a network (concept map) mentally and not on paper (De Simone, Oka, \& Tischer, 1999). In addition, a comparison of high-directed concept maps (i.e., fill-in the 
blanks) to low-directed maps (i.e., students construct from scratch) found that the lowdirected maps revealed more about student knowledge and structure of knowledge (RuizPrimo, Schultz, Li, \& Shavelson, 2001). Based on this premise, the investigator for the present study chose to have the students construct their own maps of anatomy topics based on the method described by Novak and Gowin (1984). For concept map construction, students first choose a topic and then brainstorm for important concepts within that topic. The brainstorming is followed by organizing the concepts in a hierarchical pattern and constructing the concept map from the hierarchy. Finally, the concept mapper places crosslinks within the map to establish connections among the concepts in different vertical threads of the map (Novak \& Gowin, 1984).

As the product of both technology and constructivism, electronic concept mapping may have applications in learning for the student in health sciences. The drive to incorporate computer technology into education reaches beyond enhancement of the educational experience to become, in some instances, a required skill for the job market. Increasingly, physical and occupational therapists find the need for technology skills in daily application of their professional knowledge (Agho \& Williams, 1995; Hammel \& Smith, 1993; Kanny \& Anson, 1998; McNurlen, Gilkeson, \& Drake, 1996; Williams, Agho, \& Holm, 1996; Williams, Agho, \& McCloy, 1996). Computers have been used as adjuncts to the traditional education model. However, the use of computers in education can also help to support constructivism by allowing students to use the computer to manipulate and organize knowledge in an individualized, and therefore meaningful, manner (Jonassen, 2000). 
Electronic concept maps may be used to facilitate critical thinking through an intellectual partnership between the learner and the computer (Jonassen, 2000). In an intellectual partnership, the learner and the computer each do the work for which they are especially well-suited. The computer retrieves and stores information and the learner recognizes patterns, organizes information, and restructures knowledge into a meaningful representation. Through this partnership, the learner must reflectively and deeply engage the content using critical thinking to see patterns and make judgements (Jonassen, 2000). Concept mapping software extends the mapper's capability beyond two dimensional displays of knowledge to multi-dimensional semantic networks. The concept maps may be used as a way for students to show what they know, as a way to reflect on learning, and as a way to present information to others (Anderson-Inman \& Ditson, 1999).

Figure 1.1 shows an example of how a concept map might be used to integrate information in anatomy. The figure also shows the components of a concept map. The main idea, or highest level of the hierarchy, is in a cloud symbol. The second level of hierarchy is shown by rectangular symbols and the third level with oval symbols. Links are labeled with plain text showing the relationship between concepts. Crosslinks, links that connect concepts from different vertical threads, are italicized and underlined. The figure also shows some of the features of Inspiration $^{\circledR}$ software that may support the constructivist role of computers in education: the variety of symbols available, the straight and curved links and crosslinks that allow for different arrangement of the symbols, and the variations of text fonts and styles. 


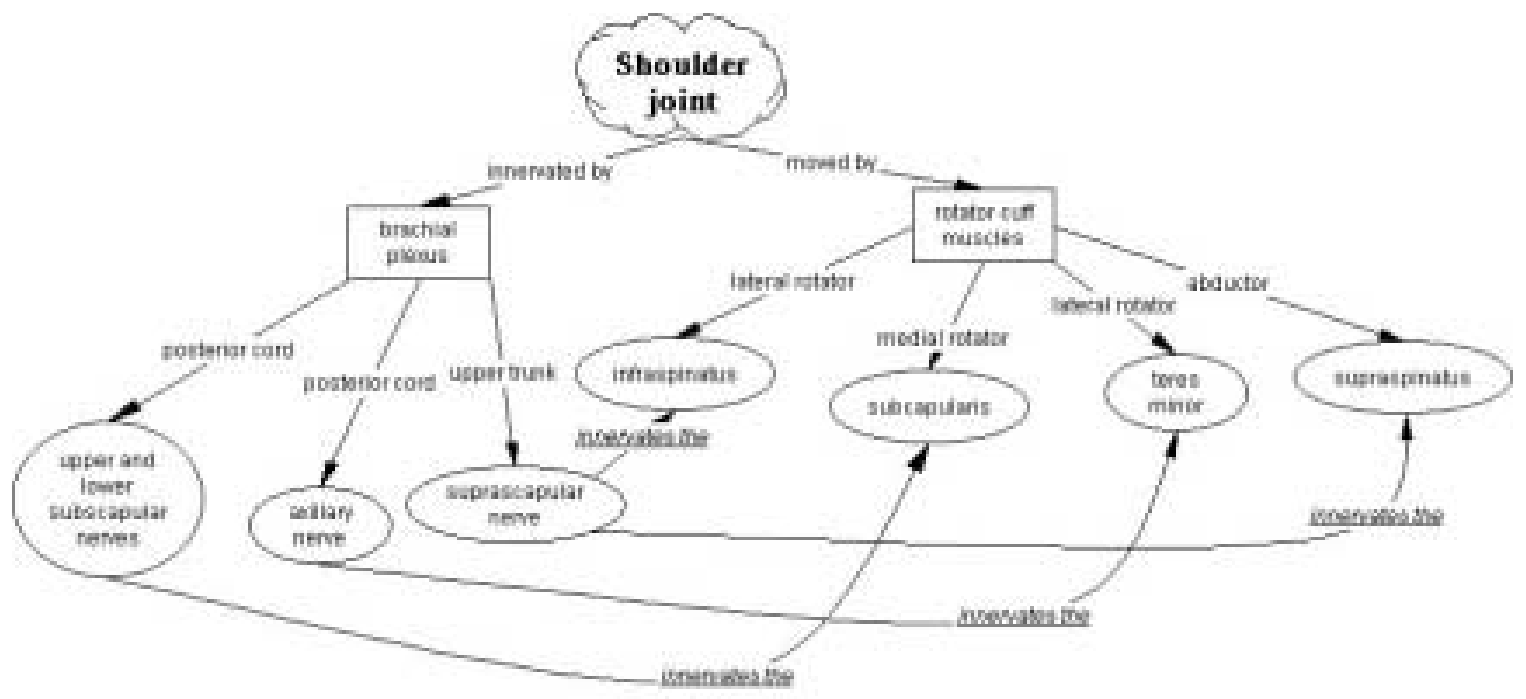

$\underline{\text { Problem }}$

Anatomy and kinesiology are foundational courses in the PT and OT curricula.

The clinical courses that follow anatomy are based in part on the expectation that students know and are able to apply anatomical information to solve clinical problems. Therefore, effectively learning this information not only predisposes one to success in the anatomy course, but also theoretically facilitates learning in the remainder of the curriculum. Kinesiology, the study of movement, spans the gap between basic and clinical sciences. For example, in anatomy a muscle may be learned as an individual entity. In kinesiology, the student learns how that muscle may function with others to produce a specific movement. Learning normal movement in kinesiology then progresses to learning how to assess and rehabilitate abnormal movement, a significant component of PT and OT practice.

If students learn anatomy facts with intention only to pass an examination, then they may be successful in the anatomy class. However, if a student intends to learn so 
that anatomy information is available when necessary for understanding kinesiological concepts, then the student benefits. Using concept maps may promote metacognition and enhance retention to enable transfer of anatomical concepts to kinesiology and reduce the demand on subsequent learning. Concept maps may also be useful to students to see the "whole picture" by allowing them to integrate previous learning and concurrent learning in related courses.

Finally, PT and OT curriculum are particularly thick with information. A mechanism that enhances learning transfer will allow faculty members to feel confident that they no longer need to pack the curriculum to the brim. Learning transfer would allow for faculty to focus on main concepts with the confidence that the student will learn them in such a way that he or she may re-configure the knowledge when necessary to suit the situation.

\section{$\underline{\text { Research Questions }}$}

There were a total of seven research questions posed in this study. The overall purpose of the study encompassed both quantitative and qualitative perspectives. The first five questions were quantitative in nature. The last two were qualitative.

1. Does the use of concept mapping significantly improve $(p<.05)$ academic performance on tests of anatomy knowledge?

2. Does the use of concept mapping in anatomy significantly improve $(p<.05)$ academic performance on tests of kinesiology knowledge?

3. Does the use of concept mapping significantly improve $(p<.05)$ scores on the Learning and Study Strategies Inventory (LASSI)? 
4. Is there a statistically significant relationship $(p<.05)$ between kinesiology course grade average and anatomy course grade average and concept mapping?

5. Is there a statistically significant relationship $(p<.01)$ between anatomy course grade average, kinesiology course grade average and ACT/SAT equivalent scores, GPA, initial LASSI scores, study time and concept mapping time?

6. How do students describe their experience learning with a novel strategy?

7. What are students' perceptions regarding concept mapping as a study tool?

\section{Assumptions}

There were several assumptions on which this research project was based. First was the assumption that the concept mapping group kept the concept mapping techniques and software confidential throughout the length of the study. The students attended a variety of classes together and had formed close friendships among their classmates. The investigator explained the importance of keeping the concept maps confidential and the students in the treatment group signed an oath to that effect.

The second assumption was that the students made candid responses to questions on the study journals and in the focus groups and interviews. The investigator encouraged the students to be candid and assured them that any responses would be kept anonymous and confidential. The students also signed a consent form that assured them that their grades or class standing would not be affected by participation or refusal to participate in this study.

Finally, the investigator assumed that the students who participated in this study were motivated to be successful in the courses that were being studied. Since these 
courses represent the entry into professional education for PT and OT students, the investigator assumed that the students strongly wanted to perform well on examinations and also to learn the content as a basis for future learning.

\section{$\underline{\text { Limitations }}$}

There were several limitations within the context of this study. First, the sample was one of convenience based on the number of students who volunteered to participate in the study. The volunteers were randomly assigned to treatment and control groups. However, there was not a random sample selected from the entire anatomy class and therefore the present study was not a true experimental design.

There was attrition between the first and second semesters of the study. Six participants were lost from the treatment group and two from the control group. This attrition occurred because of an academic policy within the School. Students are required to pass a course with a grade of $\mathrm{C}$ or better in order to continue with the curriculum. Any $\mathrm{D}$ or $\mathrm{F}$ grade in a course must be repeated when the course is next offered. Since the courses are held only one semester each year, anyone earning a D or F grade must wait until the following year. None of the students who dropped out of the study earned a D or F in the anatomy class, but in another course held concurrently in the fall semester.

The group of students who participated in this study were a relatively homogenous group with a narrow range of QPA and SAT scores. Only one person in the study, a non-traditional student returning to school after a 16 year absence, had a QPA of less than 3.0. The total SAT scores ranged from 930 total points to 1500 total points, a large disparity, but only three students scored less than 1000 points on the SAT and only one student scored greater than 1350 total. Therefore, 34 of the 38 participants had a total 
SAT score in the 1000 to 1350 point range. This homogeneity may have presented a limitation in the event of a small effect size of the intervention.

The PT and OT students had different laboratory experiences in kinesiology. Although this may have affected the scores of the OT students when compared to the PT students overall, there was a relatively even number of OT and PT students in the treatment and control groups. Therefore, any advantage or disadvantage as the result of different laboratory experiences would have been distributed evenly between the two groups.

\section{Definition of Terms}

Concept map: A concept map is a two-dimensional representation of knowledge using links to describe the relationships between and among concepts.

Conceptual change: Conceptual change is "broadly defined as learning that changes some existing conception" (Chi, Slotta, \& Leeuw, 1994, p. 27). This includes the change of a concept from one defining category to another.

Constructivism: Constructivism is based on the principle that learning is an individual process by which the learner attributes meaning to the knowledge based on personal experience and previous learning.

Crosslink: A crosslink is a line on a concept map drawn between concepts on two different vertical threads. Many crosslinks on a map indicate that the concept mapper recognizes the relationship among the concepts.

Focus group interview: A focus group interview is "an interview with a small group of people on a specific topic" (Patton, 1990, p. 335). 
Kinesiology: Kinesiology is "the study of human movement from the point of view of the physical sciences" (Luttgens \& Hamilton, 1997 (p. 2)) In particular the physical sciences include biomechanics, musculoskeletal anatomy and neuromuscular physiology.

LASSI: The Learning and Study Strategies Inventory (LASSI) is an instrument for measuring "students' use of learning and study strategies and methods" (Weinstein, 1987, p. 2) and can be used to evaluate the success of interventions designed to improve study habits.

Link: A link is a line drawn between two concepts on a concept map to describe the relationship between the two concepts.

Meaningful learning: Meaningful learning occurs when the learner is able to relate and anchor new information to relevant knowledge already in a cognitive framework (Ausubel, 1968).

Metacognition: Metacognition is "defined as the knowledge and control one has over one's thinking and learning activities" (Swanson, 1990, p. 306).

QPA: Quality Point Average (QPA) is the ratio between the sum of the grades received (range $\mathrm{A}=4.0$ to $\mathrm{F}=0.0$ ) and the sum of the quality points (credits) received. It is calculated in the same way that grade point average is.

Rote learning: Rote learning is an arbitrary, non-substantive method of learning in which new learning is not anchored or connected with previous learning (Ausubel, 1968).

Study journal: A study journal was a log kept by the students to record the amount of time spent studying for anatomy (in the fall semester) and kinesiology (in the spring 
semester). The study journal was also used to record answers to various questions related to studying.

Transfer of learning: Transfer of learning is "the process of using knowledge acquired in one situation in some new or novel situation" (Alexander \& Murphy, 1999, p.561) 


\section{Chapter Two Literature Review}

The purpose of this research is to examine the usefulness of concept maps as a meaningful learning strategy for PT and OT students. The students who participated in this study were in their third year of college. In this year, basic science and clinical science topics, including anatomy and kinesiology, are taught as foundations for further learning in the health sciences curriculum. Study strategies, such as concept mapping, that promote meaningful learning may allow PT and OT students to become proficient in transferring foundation knowledge to clinical practice. This literature review discusses the various dimensions of the present study that influence meaningful learning for anatomy and kinesiology.

The review begins with an overview of anatomy education as it applies to the preparation of health care professionals. The basic sciences, including anatomy, differ from the clinical sciences in that they do not necessarily have a direct impact on patient care, but rather serve as a foundation on which understanding of the decision-making process in patient care is based. Content knowledge in the basic sciences provides the PT or OT student with information that must be transferred or used in novel situations. In the case of this research, gross anatomy content knowledge is used to support learning and understanding concepts in kinesiology. For health professionals to effectively use basic science information to guide practice, they must be able to transfer the learning from the classroom or laboratory setting to the clinic.

The importance of learning transfer becomes apparent when one considers a few important factors. First, there is an enormous body of relevant information that is necessary for the health care practitioner to safely and effectively treat patients. Second, 
that body of information is not static but rapidly growing and changing. Third, each patient will have a multitude of individual characteristics that will require the practitioner to problem-solve creatively using a variety of information sources. All of these factors support the idea of learning transfer as a desirable skill for the PT or OT.

There are many methods that address the need for promoting transfer of information. There have been wholesale curriculum changes such as with problem-based learning. There have also been methods that have addressed the issue on a smaller scale, for example the use of advance organizers in individual courses. In addition to characteristics of the school or class, ability to learn content and transfer that knowledge to a new setting is dependent upon individual learner characteristics. These characteristics may include metacognition and approach to studying. Both these areas are included in this literature review. Finally, since concept maps were used as a way to promote meaningful learning in hopes of improving learning transfer from gross human anatomy to kinesiology, concept maps are discussed primarily with attention to their application in higher education.

\section{Overview of Anatomy Education}

Anatomy is viewed as an essential body of knowledge for the practicing physical therapist or occupational therapist. Human anatomy provides an important basic science foundation for classes held later in the curriculum such as kinesiology and classes where clinical evaluation and treatment skills are taught. For physical therapy students it is thought that a strong foundation in anatomy is crucial to adequately learn further information (Anderson \& Conley, 2000; Buchanan, 1992; Fiebert \& Waggoner, 1996; Mattingly \& Barnes, 1994). 
In addition to learning the content of human anatomy, a successful student will also develop "anatomical reasoning" (Rosse, 1995). Anatomical reasoning is the ability to apply cognitive skills and knowledge in anatomy to solve clinical problems. This would be essential for clinical tasks such as performing a physical examination and interpreting the results, distinguishing between normal and pathological tissue, selecting appropriate diagnostic tests and prescribing treatment (Rosse, 1995). Whether a student can develop anatomical reasoning depends on the ability of the student to develop "an implicit and fully internalized understanding of the three-dimensional (3-D) dynamic structure of the living body" (Rosse, 1995, p.499). What Rosse refers to as an “internalized understanding" can also be thought of as the student's cognitive structure of the anatomy knowledge.

The literature is rich with research related to anatomy instruction. The Management Committee of the Anatomical Society of Great Britain and Ireland found that anatomy educators from basic science and from medical practice backgrounds did not differ significantly in their description of the optimal anatomy curriculum for medical students. This indicates that there is some commonality between what classic anatomists believe to be important in learning anatomy and what medical doctors also see as relevant (Fitzgerald, 1992). Other researchers have done surveys that address the issues of what, when, and how much is being taught in anatomy classes in both physical therapy and medical schools (Berube, Murray, \& Schultze, 1999; Fitzgerald, 1992; Mattingly \& Barnes, 1994; Painter, 1994). The surveys are designed to collect information about textbooks, time spent in lecture and in laboratory activities, and the role of technology. The surveys often fail to ask about the instructional approach used to ensure that students 
learn anatomy in a way that will promote transfer. Since there is some consensus about what role anatomy plays in practice and the relative importance of anatomy as a discipline, the central question remains how to teach it better.

Two main approaches to teaching and learning anatomy have emerged that coincide with what Ausubel (1968) describes as reception learning (i.e., the traditional model) and discovery learning (i.e., the problem-based learning model). In addition to addressing curricular issues, computer technology has made an impact on anatomy education and will also be addressed.

\section{Traditional Model}

Gross anatomy has traditionally been taught by the "time-honored" method of lecture and cadaver dissection (McCracken \& Spurgeon, 1991; Nnodim, 1990). The influx of greater numbers of students into medical schools which increased the number of students to each cadaver caused educators to consider alternative methods of anatomy education (Nnodim, 1990). In a survey of physical therapy curricula, researchers found a variety of methods being used to teach and learn anatomy. Cadaver dissection held steady as a popular method with over $96 \%$ of respondents indicating this method as very effective for learning anatomy (Berube et al., 1999).

One approach to improving the traditional model of anatomy education involves incorporating computer technology. Much of the literature examines the role of the computer as a supplement or replacement for cadaver dissection as a cost and/or time saving measure (Bacro, Murphy, \& Reeves, 1997; Berube et al., 1999; Boucher, Hunter, \& Henry, 1999; Croninger, Tumiel, \& Sowa, 1995; Guy \& Frisby, 1992; McCracken \& 
Spurgeon, 1991; Rosse, 1995; Sundsten, Kastella, \& Conley, 1991; Toth-Cohen, 1995;

Walsh \& Bohn, 1990).

\section{Computer-Assisted Learning}

A survey of physical therapy curricula reported that over $60 \%$ of the respondent schools employed some form of computer-assisted instruction (CAI) in delivery of anatomy content (Berube et al., 1999). This represented an increase from the $18.4 \%$ reported by Mattingly and Barnes in an earlier survey (Berube et al., 1999; Mattingly \& Barnes, 1994). Computer use for anatomy education has taken many forms, but seldom has the computer been used to replace cadaver dissection or lecture as the primary mode of content delivery (Berube et al., 1999).

The computer is particularly well-suited for visual-rich content such as anatomy, kinesiology and biomechanics (Bacro et al., 1997; Boucher et al., 1999; Croninger et al., 1995; Toth-Cohen, 1995). There have been many attempts to develop computer programs with interactive capabilities to be used as adjuncts to traditional curricula (Bacro et al., 1997; Boucher et al., 1999; Croninger et al., 1995; Guy \& Frisby, 1992; McCracken \& Spurgeon, 1991; Rosse, 1995; Sundsten et al., 1991; Toth-Cohen, 1995; Walsh \& Bohn, 1990). To some extent, the developers of these programs tapped the multimedia capabilities of computer assisted instruction to display the three dimensional aspects of anatomy (McCracken \& Spurgeon, 1991; Sundsten et al., 1991) However, many anatomy educators prefer cadaver dissection to promote learning relationships and threedimensional understanding of human anatomy (Berube et al., 1999) and therefore use computers as a supplement rather than the primary mode of education. Anderson and 
Conley (1996) found no differences in retention of anatomical detail in students who had cadaver dissection or computer-assisted learning.

Whether the traditional model of anatomy education is supplemented with computer-assisted instruction or not, the underlying premise is one of reception learning. There are elements of discovery learning inherent in the cadaver dissection, but the bulk of the content is delivered to the students in a complete package. A common approach to studying anatomy from a student perspective is to memorize the details, such as origins and insertions of muscles. However, rote memorization does not readily allow for transfer of that knowledge to new situations such as clinical patient problems. The Problem-based learning model is designed to avoid rote learning by presenting basic science information (including anatomy) in the context of a patient problem. Before presenting a description of how Problem-based learning attempts to promote learning transfer, background on the latter will be discussed.

\section{$\underline{\text { Learning Transfer }}$}

In order for health care professional students to be successful in the transition from the classroom to the clinic, they must be able to transfer knowledge and skills. Transfer is "the process of using knowledge acquired in one situation in some new or novel situation" (Alexander \& Murphy, 1999). Detterman (as cited in Alexander and Murphy, 1999) said "if you want people to learn something, teach it to them." However, "it is impossible to convey even the most basic of academic knowledge and skills in all their potential iterations" (Alexander \& Murphy, 1999, p. 563). Considering that every patient will have unique circumstances to accompany her or his primary diagnosis, we can accept that it is impossible to directly learn everything that a practicing health care 
provider might need to know on any given day in the clinic. Learning transfer provides the means to apply information learned in one context to new tasks.

Salomon and Perkins (1989) describe two types of transfer that impact this dissertation research. These are high-road and low-road transfer. Low-road transfer is a function of varied practice and automatization. This differs from simply learning which may take place without varying practice. Low-road transfer does not require a large cognitive investment on the part of the learner. "Broadly speaking, low-road transfer is the trend when a performance is unintentional, implicit, based on modeling and driven by reinforcement" (Salomon \& Perkins, 1989, p. 122). This description bears a remarkable resemblance to rote learning. On the other hand, high-road transfer requires "mindful abstraction" (Salomon \& Perkins, 1989). Mindful abstraction requires a considerable investment on the part of the learner to ensure that the abstraction is understood. The abstraction "yields a representation that subsumes [italics added] a greater range of cases" (Salomon \& Perkins, 1989, p. 125). However, the more an abstraction subsumes, the more likely that details are lost (Salomon \& Perkins, 1989). Ausubel refers to this phenomenon as obliterative subsumption (Ausubel, 1968).

In a review of transfer of training, Baldwin and Ford (1988) provide a framework for learning transfer that incorporates training inputs, outcomes and conditions of transfer. Outcomes are what is learned and retained from the educational experience. The conditions of transfer include the ability to generalize learning to new situations and maintain changes in behavior based on the transfer of learning. Of particular importance to this research project is the issue of training inputs. Training inputs include three 
different elements: design of the training or instruction, characteristics of the learner, and the environment in which the transfer takes place.

When considering the training design or instruction to enhance transfer, there are three elements to address: principles of learning, sequencing, and content (Baldwin \& Ford, 1988). Any course that is considered a prerequisite course for future applications should by definition have an overall objective of learning transfer. In other words, there must be intent to transfer built in (Alexander \& Murphy, 1999; Kember, 1996; Salomon \& Perkins, 1989; Simons, 1999). In addition, courses should include certain elements such as access to skills that foster learning and application of content knowledge in work or clinical conditions in which the knowledge will be used (Alexander \& Murphy, 1999; Kember, 1996; Simons, 1999). The latter elements are often present in the PT and OT curricula, but seldom during the basic science education phase. Usually settings that include patient care are reserved for clinical application courses.

Transfer of learning content was compared to reasoning ability to see which made a greater impact on achievement scores in expository or inquiry courses in biology. The authors found that the number of previous biology courses taken by the students did not predict achievement in this (or theoretically) subsequent courses (Johnson \& Lawson, 1998).

This finding seems to fly in the face of the collective wisdom of many college instructors who worry about course prerequisites, and who worry about covering many topics in introductory college survey courses presumably to make certain that students are adequately prepared for subsequent courses (Johnson \& Lawson, 1998). 
The authors cautioned against the propensity to cover too many topics in one course, making the courses a "mile wide and an inch deep" (Johnson \& Lawson, 1998), referred to by others as "mentioning versus teaching" (Alexander \& Murphy, 1999). If learning transfer is an objective of the course, then it is detrimental for instructors to spend valuable classroom time running through details rather than emphasizing key concepts. With that in mind, it is essential that instructors choose topics with care and ensure that topics are sequenced in science curriculum with the emphasis on reducing the total number of topics that are to be learned (Mintzes \& Wandersee, 1998).

In Baldwin and Ford's model, another important element for transfer is the learner (Baldwin \& Ford, 1988). Simons (1999) reports that transfer in the learning environment involves several paradoxes for the learner: finding and using prior knowledge, acknowledging tacit knowledge, recognizing relevant situations and conditions, eliciting near or far transfer, and deciding what to transfer (Simons, 1999). With respect to the latter, one may transfer content knowledge or skills such as problem-solving or selfregulation of learning. If a learner intends to actually change her or his thinking process, the learner may be classified as self-regulating (Hadwin \& Winne, 1996). Self-regulation, or metacognition, can have a powerful effect on learning transfer.

Lin, Newby and Glenn (1994) found that metacognition improves ability to transfer problem solving to situations dissimilar from the learned conditions. On a posttest of far (high road) transfer, there were significantly better scores among the students who had used metacognitive cues than those students who had not. Students indicated that they used the metacognitive techniques, primarily questioning, to solve the far transfer problem, and had the cues not been introduced, they probably would not have 
used the method (Lin, Newby, \& Glenn, 1994). Other researchers found that a group that practiced self-reflection scored higher on far transfer tests than groups that had not (Shih, Shyu, \& Chen, 1997). However, students do not always practice self-regulation to monitor how well they are learning (Garner \& Alexander, 1989). Strategies that facilitate this self-monitoring may promote the practice.

There are many aspects of learning that may, or more commonly, may not transfer. In order for a student to be successful, he or she requires three things: knowledge of the content, a willingness to learn, and strategies for learning (Alexander \& Murphy, 1999). The strategies for learning include the ability to transfer learning skills and knowledge. These findings seem to suggest that the ability to transfer learning is related first to acquiring the knowledge but then, more importantly, to being aware of

how that knowledge may be manipulated to solve new problems. In a study of $4^{\text {th }}$ and $5^{\text {th }}$ graders, it was found that students with higher metacognitive abilities performed better academically than low-metacognitive students of even higher general aptitude (Swanson, 1990). These metacognitive skills may not be developed in undergraduates to the extent that they are needed. There have been attempts at both the curriculum and classroom levels to promote development of these cognitive skills. Problem-based learning and advance organizers, respectively, are examples of each.

\section{$\underline{\text { Problem-Based Learning Model }}$}

Problem-based learning (PBL) is a model that espouses the discovery approach to learning. Students are introduced to common patient problems very early in the curriculum. The students work in groups to make assessments of their own knowledge and develop a plan to address deficiencies. A faculty tutor guides but does not direct the 
students through the procedure. The underlying premise of PBL is that through inquiry, self-directed study and small group interaction with peers, students learn relevant basic science information and develop problem-solving skills to be used in clinical assessment and treatment of patients (Norman, Patel, \& Schmidt, 1990). One of the founding tenets of PBL is the notion of self-directed learning in which students assume "responsibility for their own learning" (Boshuizen, van der Vleuten, Schmidt, \& Maciels-Bongaerts, 1997, p. 115). Taking responsibility for learning is supposed to establish lifelong learning skills that will help students to solve novel problems in future clinical settings. This concept seems to have promise for developing the clinical reasoning skills that are necessary for practice, although these skills do not necessarily have anything to do with the application of basic science knowledge (Boshuizen et al., 1997).

Balla, Biggs, Gibson \& Chang (1990) concluded that experienced clinicians visualize the appropriate anatomy when given a clinical case. However, medical students in a PBL curriculum demonstrated no relationship between scores on an anatomy knowledge test and ability to form a diagnosis, concluding that "organization of concepts is indeed the key to good clinical diagnosis" and not strictly anatomy knowledge (Balla, Biggs, Gibson, \& Chang, 1990, p. 144). Finally, the conclusion is drawn then, that "experts conceptualize at a much higher level than novices so that this alters the actual nature of the knowledge and not just the structure of memory" (Balla et al., 1990, p. 144). Knowledge of basic science information seems to undergo a conceptual change through the process of clinical practice.

Presumably, acquiring basic science knowledge is only a portion of the skill needed for solving clinical problems. In a review of the literature, there was found "no 
evidence indicating that one curriculum or another, problem-based or otherwise, is able to enhance students' problem-solving skills independent of their acquisition of knowledge" (Norman \& Schmidt, 1992). However, discussion of the problem during PBL sessions did appear to provide the groundwork for acquiring knowledge including the use of prior knowledge to enhance the learning of new information and the elaboration of concepts during problem analysis when students challenge each other to explain newly acquired information (Norman \& Schmidt, 1992). PBL has been shown to promote conceptual change during group interactions by promoting the processing of information at a deep rather than surface level (De Grave, Boshuizen, \& Schmidt, 1996).

When compared to students from a traditional lecture-based curriculum, students from a PBL curriculum were found to have a more positive attitude toward basic sciences in general perhaps because the basic sciences were learned in the context of clinical problems (Kaufman \& Mann, 1997). However, even though students had a positive attitude toward PBL, they continued to rate traditional curricula better in the area of knowledge acquisition (Bernstein, Tipping, Bercovitz, \& Skinner, 1995). Specifically, students expressed a concern, shared by faculty members (Vernon, 1995; Vernon \& Hosokawa, 1996), that PBL will allow for knowledge gaps to occur in the basic sciences. This concern was supported somewhat by a study comparing the scores of students from PBL and conventional curricula on the National Board of Medical Examiners Parts I, II, and III. PBL students score lower on the Part I examination which has an emphasis on basic science recall in the multiple choice format. However, PBL students then went on to score significantly higher on the Part III exam which has more clinical application questions (Mennin, Friedman, Skipper, Kalishman, \& Snyder, 1993). 
Overall, PBL has had mixed results with respect to test scores and clinical performance (Colliver, 2000). In light of this and the fact that PBL requires a significant change from the traditional curriculum and often a change in philosophy of teaching and learning for all of the participants, it may be advisable to look for alternatives to achieve the type of learning that is desirable. A method of learning is required that will allow for students to develop a strong cognitive structure of basic science (e.g., anatomy) knowledge that will allow for application to clinical problems within a traditional curriculum.

\section{$\underline{\text { Advance Organizers }}$}

Prior learning may be made more explicit in anticipation of transfer with use of advance organizers. Ausubel introduced the idea of advance organizers as a way to "bridge the gap between what the learner already knows and what he needs to know before he can successfully learn the task at hand" (Ausubel, 1968, p. 148) by showing the underlying structure of a body of knowledge. Concept maps have been touted as possible tools to help facilitate the discernment and selection of central concepts that "constitute the 'big picture' or pervasive principles at the core of scientific disciplines" (Trowbridge \& Wandersee, 1998, p. 116). In his dissertation, Cliburn (1985) compared student performance in two classes of human anatomy and physiology. One class was structured with concept maps as advance organizers and the other class was structured in the traditional way by textbooks. Based on scores from a multiple-choice posttest, he found a marginal facilitating effect on learning in the group with concept mapping. There was a statistically significant effect $(p<.01)$ on retention in the advance organizer group suggesting that expository organizers, such as concept maps, may have a delayed effect 
on learning by helping to establish structure for students when the content is new (Cliburn, 1985). In other words, instructing students with new content while using a device that shows how the new content fits in with the big picture or contributes to the framework for future application improved the students' ability to retain the information.

Advance organizers and PBL address the issue of learning transfer on a relatively large scale. However, one's ability to transfer learning may be largely dependent on personal characteristics such as metacognition. Metacognition may be developed through careful application of study strategies that help the student to reflect on the process of learning and not just the content of learning. Some of the benefits of incorporating these strategies and barriers are addressed in the following section.

\section{Undergraduate Learning Habits}

Learning strategies most commonly used are those with which the learner is most familiar (Garner \& Alexander, 1989; Kember, 1996; Lonka, Lindblom-Ylanne, \& Maury, 1994). For example, even if a student initially intends to study to understand content, when faced with an anxiety-inducing testing situation, the student is prone to revert to familiar learning strategies that have been successful in the past (e.g., memorization) (Garner \& Alexander, 1989; Kember, 1996). This may be a reflection of an educational system that rewards students who learn for reproduction of the content (Kember, 1996), as study strategies are often employed for effect and in response to the type of assessment that is anticipated (e.g., multiple choice test or essay test) (Thomas \& Bain, 1984). Effective strategies are applicable to the type of learning expected to take place, the content and context in which that content is to be used (Tait \& Entwistle, 1996). 
Therefore, for a novel study strategy to become a habit, the strategy must be shown to be of benefit and superior to other strategies (Garner \& Alexander, 1989).

Some researchers have used the terms "surface-level reproduction" or "deep-level processing" (Lonka \& Lindblom-Ylanne, 1996; Marton \& Saljo, 1976) to describe study strategies. These categories correspond to Ausubel's rote and meaningful classifications respectively (Ausubel, 1968). Deep-level processing or meaningful learning involves a transformation or restructuring of knowledge in order to glean an understanding. This may include comparing and contrasting, using analogies and linking new information to old. Reproductive learning is bound by the context in which the material is learned. In reproductive learning the emphasis is on remembering and not the re-structuring of knowledge. A comparison of deep and surface approaches in $8^{\text {th }}$ graders learning science found that deep level processors generated spontaneous ideas and had more elaborate and precise answers. The deep processors also asked questions that led to conceptual understanding rather than surface processors who asked questions related to knowledge or procedure (Chin \& Brown, 2000). Deep and surface level information processing may occur together in varying combinations (Thomas \& Bain, 1984).

In a qualitative study, Vermunt (1996) found four approaches to studying that differ in five areas: "the strategies students use to process learning contents, the strategies they use to regulate their learning, the affective processes that occur during studying, and the mental models of learning and learning orientations of students" (Vermunt, 1996, p. 46). The four learning styles are categorized according to purpose for learning. They include undirected, meaning directed, reproduction directed, and application directed. It is important for teachers to find ways to minimize dependence on undirected and 
reproduction directed learning styles (or surface-level reproduction) and encourage meaning and application styles (or deep-level transformation) (Lonka \& LindblomYlanne, 1996) which seem to be more applicable to the general goals of higher education (Vermunt, 1996).

With regard to learning style, however, there seems to be some evidence that there is a progression from a superficial nature of study to a deep nature as education progresses (Graham, 1996; Lonka \& Lindblom-Ylanne, 1996). In this transformation, newer students go from a dualist nature with external regulation of learning and surface approach, to a more relativist, self-regulating, and deep approach to study (Lonka \& Lindblom-Ylanne, 1996). One researcher pointed out that students seldom engage in learning conceptual information initially (Markow \& Lonning, 1998) and this may lead to an emphasis on learning detailed information rather than concepts. Another study found that logical thinking skills of physical therapy students improved within the first year of the professional program indicating that students undergo cognitive change. However, logical thinking ability scores were not related to success within the program or identification of "at-risk" students (Norman \& Boonyawiroj, 1997). Graham (1994) developed a model of conceptual development in physical therapy students and reported that roadblocks to conceptual development include memorization, lack of time for study, and inability to see relevance of the concept (Graham, 1994). A study method that overcomes these roadblocks will facilitate conceptual development. One example of a study method to address this need is the concept map. 


\section{Concept Maps}

Concept maps have been developed as a study method that may assist students in meaningful learning (Novak, 1990). Based on assimilation theory, concept maps are twodimensional representations of knowledge using links to describe the relationships between and among concepts. When constructing a concept map, the concept mapper first selects key concepts from a topic. Then he or she prioritizes the concepts such that the most inclusive concept is listed first and the least inclusive listed last. The concept map is arranged according the hierarchical list and the concepts are linked with appropriate words to describe the relationship between the concepts. Finally, the concept mapper inserts crosslinks, connecting different vertical threads of the concept map. The crosslinking step is important for showing an integrated understanding of the various aspects of the topic. The mapper receives feedback on the map at this point with advice to reconstruct as needed (Novak \& Gowin, 1984). One study examined the use of expertgenerated maps to help direct learning for students to generate their own maps as study aids. When the students began to construct their own maps on general psychology content, they were found to have better recall and retention than those students who did not (McCagg \& Dansereau, 1991). Although an expert-generated map may serve as an advance organizer, the exercise of concept mapping is valuable to the student for constructing meaning.

Concept maps have been used to assess student performance on class-related test scores (Beissner, 1992; Bolte, 1999; De Simone et al., 1999; Heinze-Fry \& Novak, 1990; Markow \& Lonning, 1998; Okebukola, 1990). All of these researchers used classroom achievement measures to assess the effects of concept mapping on performance with 
varying results. In a college chemistry course, students used concept maps to illustrate their understanding of chemical concepts in the lecture and laboratory portions of the course. No statistically significant differences were found in test scores between those who had used concept maps and those who had not (Markow \& Lonning, 1998). In a study involving biology majors, Okebukola (1990) found a significant improvement in posttest scores for both genetics and ecology in students constructing concept maps. The dependent measure was a test constructed to assess knowledge at the comprehension level and beyond. The researcher concluded that concept maps may be a way to have students see that "concepts do not exist in isolation" (Okebukola, 1990, p. 501). In the case of Beissner, the specific aim was to improve scores on problem-solving measures. She found that PT and athletic training students who constructed concept maps scored significantly better on treatment-planning problem-solving questions than students who did not (Beissner, 1992). Heinze-Fry and Novak (1990) found no significant difference in test scores but better conceptual understanding of biology in students who concept mapped for an autotutorial course.

Concept maps have been used to demonstrate conceptual change in college students (Graham, 1994; Trowbridge \& Wandersee, 1994; Wallace \& Mintzes, 1990) which has shed some light on the validity of concept mapping as an assessment tool. Trowbridge and Wandersee (1994) used concept maps to identify "critical junctures" in a course on evolution. After finding that students were unable to agree on the superordinate concept for two particular lectures, the researchers conferred with the course instructor who confirmed that those concepts were traditionally difficult for students to understand. The validity of concept maps was further assessed in a study of conceptual change in 
biology. There was an underlying assumption that those students with more knowledge would construct better quality concept maps than those with less knowledge. The concept maps were able to detect changes in learning and structuring of new information. It was concluded that concept maps are useful for showing not only what a student knows, but also how that knowledge is organized (Wallace \& Mintzes, 1990). In addition, Bolte (1999) found that scores on concept maps accompanied by interpretive essays correlated significantly with other measures of achievement in a mathematics course such as examination scores and final grade for the course.

Some studies have been done to assess students' perceptions and attitudes toward concept mapping (Bolte, 1999; Markow \& Lonning, 1998; Santhanam et al., 1998). The main complaint of the students when using concept mapping is the time commitment that is involved in generating a quality map (Bolte, 1999). Learning something rotely may be viewed as a time-saving method with immediate results when given the demands of busy undergraduates. If it is true that in the long run (negating the benefits of immediate gratification) meaningful learning is ultimately more beneficial than rote learning, then students must come to appreciate the efforts that are placed in that type of learning. That may be difficult when measures of student performance (i.e., examinations) are based largely on rote learning of topics (Bolte, 1999; Markow \& Lonning, 1998).

Acknowledging that students may not have been willing to address comments of a negative nature to the course instructor, students in one study perceived that concept mapping helped them to clarify concepts and add focus to the lecture topics (Bolte, 1999; Markow \& Lonning, 1998). In a study of spontaneous learning strategies used by high school students on a medical school entrance examination, concept mapping was more 
often employed by students who achieved higher scores on critical review of a text passage. Concept mapping in particular was noted to be of benefit since it encourages and requires one to integrate information from various parts of the text into a coherent whole that is connected with previous knowledge, a metacognitive activity (Lonka et al., 1994).

Santhanam et al. (1998) suggests that one of the most important factors related to the use of concept mapping in the undergraduate years, assuming that the strategy is new to them, is the timing and method of the introduction. They found that when given the opportunity, students chose not to use concept mapping as a learning tool, favoring instead memorization as the study habit of choice (Santhanam et al., 1998). Even as an extra credit assignment in one study only $47 \%$ of the class on average regularly participated in concept mapping activities (Trowbridge \& Wandersee, 1994). Students perceived that thinking that promotes integrating concepts is more important in the later years of the curriculum (Santhanam et al., 1998). Graham (1994) also found that younger students seem to initiate studying with memorization and rote learning strategies before branching into more meaningful learning techniques as a conceptually intense course, such as kinesiology, progresses.

Hadwin and Winne (1996) made recommendations specifically for concept mapping after a literature review of study techniques used by college students.

On the basis of these four studies, we tentatively conclude that concept mapping is a potentially effective tactic. We are tentative because these results suggest that the context within which students study can affect the effectiveness and the utility of concept mapping. Three qualifications can be suggested. First, concept mapping is useful if courses require 'deep 
thinking' rather than memorization for retaining facts. Second, the benefits of concept mapping are more pronounced for students who persist in using the tactic. Third, students with low content knowledge may feel insecure about concept mapping (p. 702).

The first qualification may be addressed by the instructor by choosing testing methods that encourage meaningful learning as an external motivation. The student with internal motivation can address all three qualifications.

Concept maps have been used in a variety of ways in schools to facilitate critical thinking, cooperative learning, active learning and reflection on knowledge. Electronic concept maps may be used to facilitate critical thinking through an intellectual partnership between the learner and the computer (Jonassen, 2000). In an intellectual partnership, the learner and the computer each do the work for which they are especially well-suited; the computer retrieves and stores information and the learner recognizes patterns, organizes information, and restructures knowledge into a meaningful representation. Through this partnership, the learner must reflectively and deeply engage the content using critical thinking to see patterns and make judgements (Jonassen, 2000). In addition to the intellectual partnership that may develop, there are advantages to using electronic concept map programs over paper and pencil versions. With the software, students can use a variety of images to illustrate their concept maps adding an element of individuality and creativity. Also, the software allows for manipulation of concepts so that revisions may be made as new learning occurs. Finally, the maps are not confined to the size of the paper and can be easily expanded (Anderson-Inman \& Ditson, 1999). Inspiration ${ }^{\circledR}$ software (Inspiration Software, Inc.) enables the user to develop 
electronic concept maps using a variety of graphics for illustrating purposes. It also has several features that enhance the user's ability to show learning including an outline feature, a place to embed notes and graphics, and a mechanism to facilitate brainstorming activities. The software extends the concept mapper's capability beyond two dimensional displays of knowledge to multi-dimensional semantic networks. The concept maps may be used as a way for students to show what they know, as a way to reflect on learning, and as a way to present information to others (Anderson-Inman \& Ditson, 1999). All of these objectives are especially applicable to the PT and OT student in anticipation of a strenuous curriculum and challenging practice.

\section{Summary}

In summary, it is widely accepted that anatomy is an important introductory course on which future learning is based. Retention of anatomy facts alone does not ensure success in subsequent coursework. Anatomical reasoning, a product of meaningful learning, must also be present in order to glean a complete educational experience for health professionals. At least one curriculum model, PBL, has been developed as a way to help students learn information in the context of clinical problem solving in an attempt to enhance meaningful learning and learning transfer. However, this framework often requires a complete overhaul of the curriculum. An advance organizer is an example of a strategy that may be employed in the classroom. However, use of advance organizers puts the onus on the instructor rather than the student to draw connections among topics.

A useful tool that may not only coincide with traditional curriculum but also encourage meaningful learning on the part of the student is the concept map. The concept map was developed to illustrate assimilation principles. The use of electronic concept 
mapping may encourage students to use technology to extend and organize their thinking from a constructivist perspective. Concept mapping may also facilitate transfer of learning by promoting metacognition. Introducing a new study strategy may be problematic for undergraduates with years of success with other methods. However, if the study strategy can be shown to be of benefit to not only enhance academic performance but also to facilitate learning in the remainder of the curriculum, students may be more inclined to use the strategy. 


\section{Chapter Three Methodology}

\section{$\underline{\text { Review of Purpose }}$}

The overall purpose of this study was to investigate the use of concept mapping to promote meaningful learning in anatomy and transfer of anatomy knowledge to kinesiology. The complete investigation of that purpose was also supported by questions about the effects of concept mapping on performance on tests of anatomy and kinesiology knowledge and changing study habits in undergraduates. These questions lent themselves well to quantitative methods and analyses. As the participants were successful undergraduate students in their junior year, the effects of introducing a novel study strategy was investigated from a qualitative perspective to see how the students reacted to a new learning technique.

\section{Background}

At the investigator's institution, the anatomy course for physical therapy and occupational therapy students is a two semester course offered over the fall and spring terms. The anatomy class falls under the classification of a traditional gross anatomy course and includes six hours weekly of lecture and four hours weekly of cadaver dissection. The investigator served as a laboratory assistant and also presented some lectures for the course. In the fall semester the students are introduced to anatomic terminology and topics such as the superficial back, upper extremity and thorax. The anatomy course during the fall 2000 semester enrolled approximately 130 students from four different disciplines (occupational therapy, physical therapy, perfusion technology and physician assistant). 
In the spring semester, a one-semester kinesiology course is taken by both physical therapy and occupational therapy students concurrently with the second half of the anatomy course. The kinesiology class covers the kinesiology and biomechanics of the major joints of the body. The focus in the kinesiology course is on developing skills that enable the students to analyze normal human motion. The researcher had no involvement with the kinesiology course. However, the researcher has taught kinesiology in the past and informed the participants of that fact. This study was designed to focus testing on knowledge related to anatomy and kinesiology of the upper extremity (UE). Testing and data collection were scheduled around those topics in the fall semester anatomy and spring semester kinesiology courses.

\section{$\underline{\text { Research Design }}$}

This study was a mixed methods design employing both qualitative and quantitative data collection and analysis techniques. The quantitative portion was a quasiexperimental pretest-posttest control-group design, or a one-variable (i.e., concept mapping) multiple-condition (i.e., in anatomy and in kinesiology) design (Gall, Borg, \& Gall, 1996). The qualitative portion of the study was a phenomenological design that sought to elicit the experience of the participants as they interacted with a new phenomenon (i.e., concept mapping) (Patton, 1990). The overall design of the entire study is diagrammed in Figure 3.1. 
Figure 3.1 Research Design

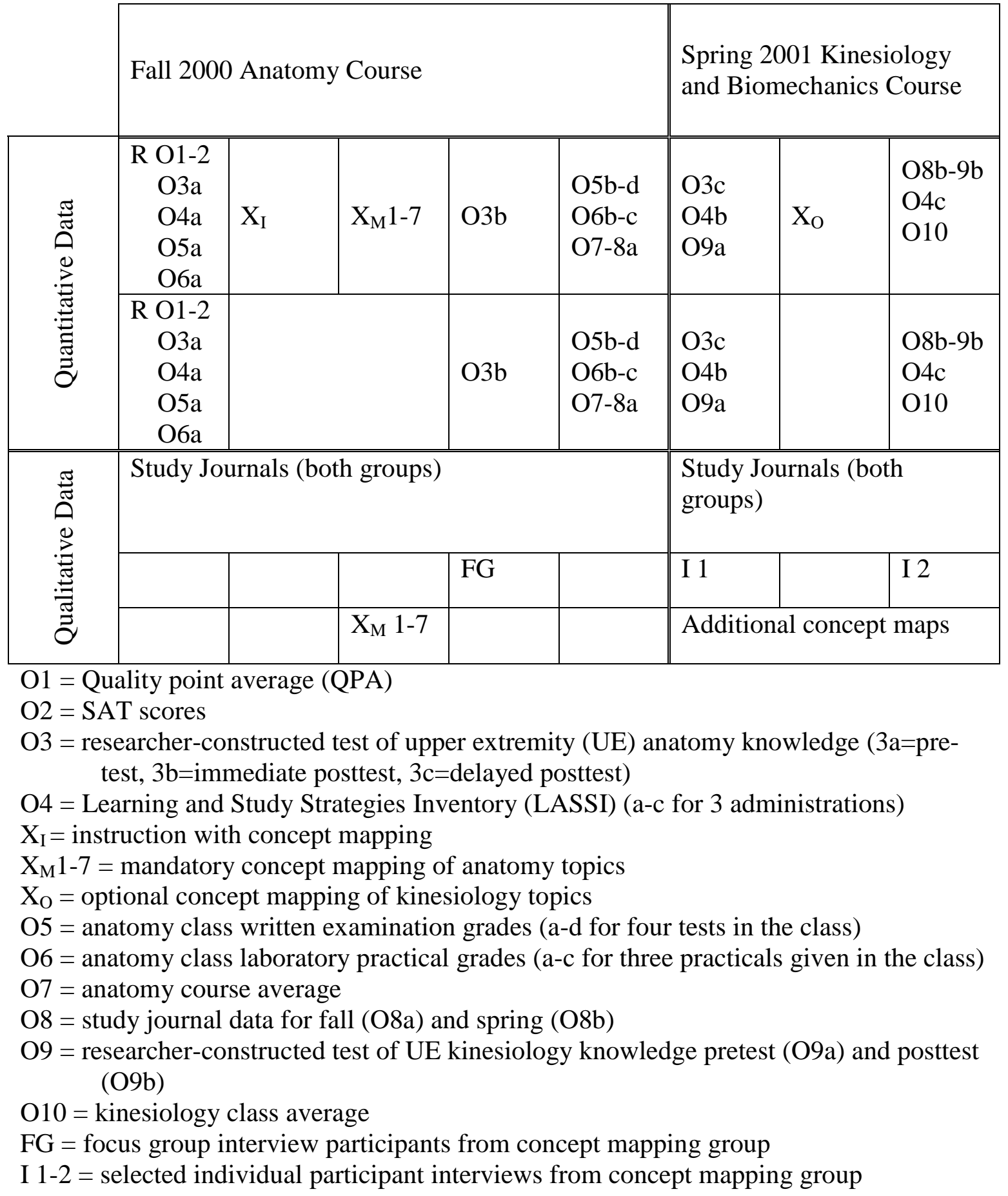




\section{$\underline{\text { Participants }}$}

The participants were volunteers $(\mathrm{n}=38)$ from all third year physical therapy and occupational therapy students enrolled in an anatomy course at Duquesne University. There were a total of 38 physical therapy and 42 occupational therapy students enrolled in the fall semester anatomy course. At the $5^{\text {th }}$ week of fall semester classes, participants were recruited through an announcement in the anatomy laboratory. Students were assured that the decision to participate or not participate would have no effect on their grade in either the anatomy or kinesiology course as the researcher was not involved with assigning scores on lecture or laboratory examinations, or on the final course grade. Volunteers were randomly assigned to either a treatment group for concept mapping or a control group. Members of the concept mapping group received a complimentary copy of the Inspiration ${ }^{\circledR}$ software to install on their own computers. Members of the control group received $\$ 30$ at the end of the study. This amount is equivalent to the cost for each copy of the Inspiration ${ }^{\circledR}$ software. The students signed an informed consent. This study received approval from the Institutional Review Boards for expedited review at both Duquesne University and West Virginia University.

\section{$\underline{\text { Treatments }}$}

Students in the treatment group were instructed how to construct concept maps during the fall semester using the method described by Novak and Gowin (1984). The students were asked to select key concepts from a topic that had been taught in anatomy. The students prioritized the concepts such that the most inclusive concept was listed first and the least inclusive listed last. Next, each student constructed a concept map using the 
hierarchical list and filled in appropriate linking words to illustrate the relationships between the concepts. Finally, the students inserted appropriate crosslinks (i.e., links that connected or defined a relationship between concepts on different vertical threads of the map) on the concept map. The researcher gave the students feedback on the map with advice to reconstruct as needed (Novak \& Gowin, 1984). The researcher especially encouraged the students to draw connections and links among the anatomy topics. See Appendix A for an example of a concept map constructed by a participant with the feedback given by the researcher.

The instruction took place in a computer laboratory with Inspiration ${ }^{\circledR}$ software installed on each machine. Each student constructed the initial concept map with the software. Students had time to explore those aspects of the software that were not explicitly described during the instruction. The concept mapping instruction took approximately 90 minutes. The researcher encouraged the students to use the concept mapping software as often as they liked and for whatever courses they wished. However, they were specifically encouraged to use concept mapping to study anatomy information. The members of the concept mapping group were given a schedule for submitting the required concept maps with suggested topics for mapping that corresponded to the topics being presented in class. The treatment group was asked not to share the concept map software or discuss concept mapping with any other class members. The treatment group signed a statement promising not to speak to other students about the concept mapping procedure.

After the pretest of anatomy knowledge, the participants in the treatment group submitted concept maps, one per week, for topics being covered in the anatomy course. 
The researcher gave feedback on each of the maps including questions that prompted reflection on the organization of the map and possibilities for including more crosslinks and linking words or phrases. In the spring semester, the treatment group participants were encouraged to concept map kinesiology topics. However, these concept maps were not mandatory.

\section{$\underline{\text { Data Collection }}$}

\section{Quantitative Procedures}

The volunteers were randomly assigned to a treatment group or a control group. Current quality point average (QPA) and SAT scores were obtained from the dean's office for members of both groups. Quality point average is calculated in the same way as grade point average (i.e., multiplying credit hours by the value of the grade received and dividing by total number of credit hours taken). The first testing session took place during the 10th week of the fall semester prior to instruction on upper extremity topics in the anatomy course. Members of both the treatment and control groups took the Learning and Study Strategies Inventory (LASSI) and a researcher-constructed and validated test on anatomical concepts related to the upper extremity. Members of both treatment and control groups were instructed with how to keep study journals to record the amount of time spent studying for anatomy and the study methods used. The study journals were collected weekly for the remainder of the research project.

After the UE content was studied in the anatomy course, members of both groups were given the researcher-constructed anatomy test as a posttest. The immediate posttest took place in the same week as the anatomy course test on the same topics (i.e., shoulder 
and arm regions). At the end of the fall semester, the anatomy course grades were collected from the course instructor for all the participants. These grades included the final anatomy course average, the written examinations developed by the anatomy course instructor (one pre-treatment and two post-treatment tests), and the laboratory practical examination scores (one pre-treatment and two post-treatment tests). Laboratory practical examinations are timed tests that take place in the dissection laboratory where students identify anatomical structures that have been labeled on the cadavers.

In the second week of the spring term, members of both groups took the researcher-constructed anatomy test (delayed posttest), the first administration of the researcher-constructed kinesiology test and the second administration of the LASSI. Also, each participant was instructed to monitor the time spent studying kinesiology in a weekly study journal. After the upper extremity topics were covered in the kinesiology course, the investigator administered the researcher-constructed kinesiology test for the second time and final LASSI. At the end of the spring semester, the grades for the kinesiology course were collected from the course instructor for all of the participants.

\section{Learning and Study Strategies Inventory (LASSI).}

Since concept mapping may be a mechanism to help promote conceptual change and metacognition, an inventory of study strategies is an appropriate dependent measure. The investigator chose the self-scoring paper version of the Learning and Study Strategies Inventory (LASSI) for college students. The LASSI was developed as an assessment tool for student study methods. The LASSI measures thought processes and behaviors that affect learning and may be altered through educational intervention. The inventory has been widely used by academic and other institutions since its development 
in the late 1980's. Research done on the test has found it to be helpful in providing teachers and students with information to improve study skills and strategies (Haught, Hill, Walls, \& Nardi, 1998; Talbot, 1994). The LASSI has 10 scales including Attitude, Motivation, Time Management, Anxiety, Concentration, Information Processing, Selecting Main Ideas, Study Aids, Self Testing, and Test Strategies (Weinstein, 1987).

\section{$\underline{\text { Anatomy and kinesiology test construction. }}$}

One of the instruments used to assess anatomy knowledge of the upper extremity was a 40-item multiple-choice instrument constructed by the researcher using test items from a variety of published sources (Chung, 1995; Gest, Burkel, \& Waanders, 1993; Wilson, 1991). The researcher also constructed a 50-item test used to assess kinesiology knowledge with the specific purpose of assessing the effects of concept mapping at levels of cognitive ability beyond knowledge and comprehension into the application, analysis and synthesis levels of learning in the cognitive domain (Shepard \& Jensen, 1997). The instrument was constructed according to the methods described in various publications (Gall et al., 1996; Gredler, 1999; Rice, Ryan, \& Samson, 1998). The researcher constructed objectives for the kinesiology topics related to the upper extremity. Then the researcher created a matrix with the cognitive skills levels in a column on the left and various topics to be addressed (i.e., upper extremity anatomy or kinesiology) as a row across the top. Then, the researcher constructed or selected multiple-choice test items to address each of the topics for each of the cognitive domain levels (Gredler, 1999; Rice et al., 1998). See Appendix B for the kinesiology objectives and test construction matrix. Appendices $\mathrm{C}$ and $\mathrm{D}$ contain the anatomy and kinesiology tests respectively. 
Both the anatomy and kinesiology instruments were tested for content validity by asking two experts from university faculty to review the items. Both expert reviewers found the anatomy and kinesiology instruments to be valid measures of anatomy and kinesiology knowledge. The instruments were tested for test-retest reliability by administering the instrument to 25 PT students on two consecutive weeks. The scores for the tests were analyzed with a paired $t$ test. A statistically significant difference $(p<.05)$ was found for the kinesiology test from the first administration to the second. However, this calculation had low power $(1-\beta=.333)$, indicating that the sample size may have been too low to detect true differences from one administration to the next. A paired samples correlation found statistically significant $(p<.01)$ correlations for both the anatomy test $(r=.767)$ and the kinesiology test $(r=.796)$.

\section{Study journals.}

The students in both the control and treatment groups kept study journals that documented time spent and method for studying (e.g., re-writing notes, quizzing friends, flashcards, concept mapping). The students also responded in writing to questions regarding the success of the study session. The journals were maintained from the start of the study in the fall semester through the completion of the study in the spring semester and therefore covered approximately 24 weeks total (12 weeks per semester). See Appendix E for a copy of a typical study journal sheet. Appendix F shows a study journal that has been completed by one of the participants. 


\section{Concept maps.}

The researcher scored the concept maps based on the method described by Novak and Gowin (1984). Valid propositions and examples received one point each. Each level of hierarchy received five points. Each valid crosslink was awarded ten points (Novak \& Gowin, 1984). The students were not made aware of the scores on the concept maps. The concept map listed as Figure 1 in Chapter One would have a total score of 64 using this scoring method ( 9 valid propositions $* 1$ each +3 levels of hierarchy $* 5$ each +4 valid crosslinks * 10 each).

\section{Qualitative Procedures}

Qualitative data sources included a focus group, individual interviews, comments and responses on study journals and concept maps. All qualitative date were collected exclusively from members of the concept mapping group with the exception of study journals. Study journal data were collected from all study participants.

\section{Focus group.}

In the fall semester, the researcher conducted a focus group interview with a random sample of eight of the participants from the treatment group. The focus group interview was semi-structured with open-ended questions. Also, the researcher used probes to elicit complete responses questions. The focus group interview was audiotaped and the tapes were then transcribed verbatim. See Figure 3.2 for a sample script of the interview questions and probes. 


\section{Figure 3.2 Focus Group Interview Protocol}

1. What benefits do you see to concept mapping?

2. What are the drawbacks of concept mapping?

3. How is the technique of concept mapping useful to you?

4. How was the technique of concept mapping helpful to you for learning anatomy?

5. How does concept mapping compare to your previous study methods?

6. How do you plan to continue using concept maps beyond this study?

7. Comment on the feedback you received from me about your concept maps.

8. How have you used concept maps for other classes while you have been in this study? Tell me more about that.

9. Overall, what are your perceptions of the concept mapping technique?

\section{Interviews.}

Individual interviews were conducted with a total of six participants from the concept mapping group. Five students interviewed were participants of the focus group and one was not. The five focus group participants were chosen by the investigator to reflect the positive to negative range of responses to concept mapping. The researcher selected two students who expressed generally positive views about concept mapping and three students with generally negative views about concept mapping. One of the focus group participants chosen for individual interviews did not matriculate with the rest of the class in the spring semester as a result of a failing grade in another course. This student was interviewed only once, near the start of the spring semester. For the sixth participant, the researcher selected a student from the concept mapping group who had not participated in the focus group, but had expressed positive opinions about concept mapping. With the exception of the student who failed to matriculate into the spring semester, the researcher interviewed all the participants twice, once at the start of the spring semester and once shortly after mid-semester. 
The protocol for the individual interviews was tailored for each individual based on comments she or he made during the focus group interview, responses and comments made on study journals and informal interactions between the researcher and participant throughout the fall and spring semesters. The interviews were semi-structured with openended questions and are shown in Figure 3.3. Each of the interviews was audiotaped and transcribed verbatim. After the transcripts were completed, they were given to the participant for a check of the content. The participants read the transcripts and offered corrections or amendments as appropriate. The researcher incorporated amendments suggested by the participants into the transcripts prior to data analysis.

\section{Figure 3.3 First Individual Interview Protocol}

1. How would you describe your experience beginning last semester? How was last year different from previous years as far as your expectations and the realities?

2. Please describe your typical study habits.

3. Have you felt a need to change your habits with the classes offered this year?

4. Is there any reason to think that you may have to change your study habits to be successful in the curriculum?

5. How did concept mapping fit in with your previous study habits?

6. Describe how you used concept mapping in anatomy. What was your procedure for constructing the concept map? What role did concept mapping play in learning, or test preparation?

7. What limits the usefulness of concept mapping for you?

8. How do you plan to continue using concept maps?

9. Overall, what are your perceptions of concept mapping?

\section{Study journals.}

The study journal data were collected from members of both treatment and control groups. The study journals included questions about their study habits for the students to consider. The researcher generated questions for the study journals from 
responses that were made on previous journals and informal interactions between the researcher and the participants. See Appendix F for an example study journal completed by a participant.

\section{Concept maps.}

The concept maps served as a qualitative data source based on structure of the map (Kinchin, Hay, \& Adams, 2000). The analysis is described more fully in the data analysis section.

\section{Data Analysis}

\section{Quantitative Data}

The quantitative data were analyzed using an SPSS (Release 10.0.5) software package. Each analysis is described for the specific research question below. The data were analyzed for normal distribution and homogeneity. All of the data fit these conditions except for various tests of anatomy knowledge constructed by the course instructor to establish students' grades for the course. Therefore, non-parametric statistics were used to analyze research questions using data obtained from the anatomy course. Otherwise, parametric statistics were used. The demographic data (SAT scores and QPA) were analyzed with independent $t$ test to check for differences between the groups. The pre-treatment measures including initial LASSI scores, the researcher-constructed anatomy test, and the instructor-constructed first written and practical examinations were also analyzed with independent $t$ tests. Power analysis was also done for each of the parametric tests. Results of quantitative data analysis are presented in table form in Appendix G. 


\section{Research Question One.}

Research Question (RQ) One asked: Does the use of concept mapping significantly improve $(p<.05)$ academic performance on tests of anatomy knowledge? The null hypothesis for Research Question One $\left(\mathrm{Ho}_{1}\right)$ stated: Use of concept mapping does not significantly improve $(p<.05)$ academic performance on tests of anatomy knowledge. The researcher-constructed anatomy tests were analyzed with a comparison of means between the two groups for an immediate and delayed posttest with a KruskalWallis $H$ statistic. The anatomy course instructor-generated written and practical examination scores were analyzed with a comparison of means between control and concept mapping groups with the Kruskal-Wallis $H$ statistic. Finally, the anatomy course final grade averages were analyzed with means between the two groups with the MannWhitney $u$ test.

\section{$\underline{\text { Research Question Two. }}$}

Research Question Two asked: Does the use of concept mapping in anatomy significantly improve $(p<.05)$ academic performance on tests of kinesiology knowledge? The null hypothesis for Research Question Two $\left(\mathrm{H}_{02}\right)$ stated: Use of concept mapping in anatomy does not significantly improve $(p<.05)$ academic performance on tests of kinesiology knowledge. The data collected to answer this question were kinesiology course instructor-generated final grades and the researcher-constructed kinesiology test. An independent $t$ test was used to analyze the final grade means between groups. A $2 \times 2$ (group $\mathrm{x}$ time) analysis of variance (ANOVA) with repeated measures was used to compare group means for the researcher-constructed test. 


\section{Research Question Three.}

Research Question Three asked: Does the use of concept mapping significantly improve $(p<.05)$ scores on the Learning and Study Strategies Inventory (LASSI)? The null hypothesis for this research question $\left(\mathrm{H}_{03}\right)$ stated: Use of concept mapping does not significantly improve $(p<.05)$ scores on the LASSI. The analysis for nine of the LASSI subscales was done with a 2x3 (group x time) ANOVA with repeated measures. One of the subscales, Selecting Main Ideas (SMI), was analyzed with a 2x2 ANCOVA with repeated measures using the pretest scores for the SMI as a covariate.

\section{$\underline{\text { Research Question Four. }}$}

Research Question Four asked: Is there a statistically significant relationship ( $p<$ .05) between kinesiology course grade average and anatomy course grade average and concept mapping? The corresponding null hypothesis $\left(\mathrm{H}_{04}\right)$ stated: There is no statistically significant relationship $(p<.05)$ between kinesiology course grade average and anatomy course grade average and concept mapping. A Spearman's rho correlation was used to compare kinesiology course grade average with anatomy course grade average. Concept mapping became a dichotomous variable (i.e., either the students had concept mapped or had not) because there was inadequate recording of time spent concept mapping on the study journals. A point biserial correlation was used to compare course grades in anatomy and kinesiology to the concept mapping or control group condition. 


\section{Research Question Five.}

Research Question Five asked: Is there a statistically significant relationship $(p<$ $.01)$ between anatomy course grade average, kinesiology course grade average and SAT scores, QPA, initial LASSI scores, study time and concept mapping? The corresponding null hypothesis $\left(\mathrm{H}_{05}\right)$ stated: There is no statistically significant relationship $(p<.01)$ between anatomy course grade average, kinesiology course grade average and SAT scores, QPA, initial LASSI scores, study time and concept mapping. A Spearman's rho correlation was used to compare the variables. Again, concept mapping was a dichotomous variable. Therefore, the point biserial correlation done for Research Question Four between concept mapping and course grades also applies here.

\section{Post hoc analyses.}

Two sets of data were analyzed after data collection that do not directly answer research questions, but do shed some light on the results of this study. These include quantitative analyses of scores on concept maps, scores on high-level versus low-level items testing kinesiology knowledge, and power analysis.

The concept maps were scored using the method described by Novak and Gowin (1984). Each valid level of hierarchy was given five points. Each valid proposition was given one point. Each valid crosslink was given 10 points. Each valid example was given one point. The investigator scored each of the concept maps for every participant. However, because the concept maps were done over the course of the last eight weeks of the fall semester, the maps had different main ideas each time. So, the investigator did not anticipate a significant change in scores based on increased level of knowledge. 
However, one would expect to see changes in concept map scores related to developing familiarity with the concept mapping technique. A descriptive analysis was done to look for trends as the fall semester progressed. There were no concept map data for the spring semester since none of the participants submitted concept maps to the investigator for feedback.

A $2 \times 2 \times 2$ (group $\mathrm{x}$ time $\mathrm{x}$ item level) ANOVA with repeated measures was used to analyze means between groups for the researcher-constructed kinesiology test. The alpha level for significance was set at .05 . The test was constructed so that there were both high (application, analysis and synthesis) and low (knowledge and comprehension) level items. Group means were compared across time by item level to check for differences.

Finally, a power analysis was done on the data for Research Questions One Three using SPSS software. A power analysis gives an estimation of probability of Type II error in which one fails to reject the null hypothesis when the null hypothesis is false. Low power will increase the risk of concluding there is no effect from treatment when there actually is a treatment effect.

\section{Qualitative Data}

\section{Research Questions Six and Seven.}

The qualitative data analysis was formative and ongoing throughout data collection so that early findings informed subsequent data collection sessions. The analysis of qualitative data initially took the form of a cross case comparison using two cases. The first case consisted of the data collected from participants who were selectively chosen for expressing an overall positive view of concept mapping. The 
second case included similar data from participants chosen for expressing an overall negative view of concept mapping. Each of the cases was analyzed using the method described below and then compared and contrasted to search for convergent and divergent themes. As data analysis progressed, the researcher did not maintain these cases as new findings led to the establishment of different classifications.

The analysis of the qualitative data was based upon recommendations of Patton (1990) and Strauss and Corbin (1998). Both of these resources recommended careful review of the data to look for emergent themes. The analysis followed the pattern of inductive and logical analysis. The researcher carefully read each of the data sources (focus group interview transcripts, concept maps and study journal entries) several times to search for themes or patterns that emerged from the data (i.e., inductive analysis) (Patton, 1990). Initially, the researcher grouped the themes in categories constructed by the researcher to bring meaning to the findings. This procedure also followed the recommendations for open coding (Strauss \& Corbin, 1998). Appendix H shows an example of an interview transcript after it had been coded through inductive analysis. The Ethnograph ${ }^{\mathrm{TM}}$ v5.0 software (Qualis Research, Salt Lake City, UT) was used to organize the inductive analysis coding process. When all of the data had been categorized into themes, then a logical analysis was done. In this analysis, the themes from all the data were entered into a matrix and compared to look for patterns that may not have emerged in the inductive analysis (Patton, 1990). In this step, the investigator performed axial coding of the data by looking for categories and subcategories and determining how they relate (Strauss \& Corbin, 1998). Appendix I shows an example of the matrix created to perform the logical analysis. Finally, the investigator performed selective coding to refine 
the definition of two cases for cross case analysis (Strauss \& Corbin, 1998). In this step, the data were sorted into categories that were characterized by meaningful or rote learning attributes.

The concept maps were analyzed qualitatively using the method described by Kinchin, Hay and Adams (2000). The scheme developed by these researchers is designed to "differentiate maps in terms of their complexity; resilience in accommodating additions; the establishment of a context for the key concepts; degree of appreciation of a wider viewpoint and its relationship with the 'expert' view" (Kinchin et al., 2000, p. 46). The three classifications of maps are spoke, chain and net. In a spoke map, the related concepts are all directly connected to the main concept, but are not connected to each other. A chain map resembles a flow diagram in that one concept links directly to another. However, the concepts do not link back to earlier concepts nor is there a legitimate hierarchical structure. A net concept map shows a deep level of understanding of the topic through a well-defined hierarchical structure and well-integrated system of crosslinks. During analysis, a progression from a spoke or chain structure to a more netlike structure would indicate that the creator of the map was integrating information. The maps from the six participants in the qualitative data collection were studied individually to see if there was a pattern of concept map structure from a spoke or chain to a net-like design.

\section{Triangulation of Methods.}

Data analysis included triangulation of methods and triangulation of sources. Methods triangulation was achieved through comparative analysis of the qualitative and quantitative data. Triangulation of qualitative sources was accomplished by comparing 
and cross-checking the emergent themes of the various data sources: the focus group interview, individual interviews, concept maps and study journal entries. All of the data sources were analyzed to find both consistencies among them and reasonable explanations for differences among them (Patton, 1990). 
Chapter Four Results for Research Questions One through Five

This chapter will present the findings from the quantitative data collection and analysis and discussion that respond to Research Questions One through Five. Those tables for Research Questions One through Five not included within the text of this chapter are shown in Appendix G.

\section{$\underline{\text { Review of Quantitative Methods }}$}

This study was a quasi-experimental pretest, posttest design with two groups, a concept mapping group and a control group. Members of both groups were tested on anatomy knowledge in the fall semester and kinesiology knowledge in the spring semester. Other data were also collected including scores on the Learning and Study Strategies Inventory and grades on course instructor-generated tests of content knowledge for anatomy and kinesiology.

\section{Findings and Discussion}

\section{$\underline{\text { Demographics }}$}

Thirty-eight participants volunteered and signed consent forms to participate in this study. Using a random number table, the participants were randomly assigned to either the concept mapping group or the control group. The concept mapping group consisted of 10 OT students and 9 PT students. In the control group there were 9 OT students and 10 PT students. Because of academic difficulty, 8 students failed to matriculate into the spring semester. Therefore, in the spring semester the concept 
mapping group consisted of 13 participants (6 OT students and 7 PT students) and the control group consisted of 17 participants (9 OT students and 8 PT students).

Of the original 38 participants, there were 36 females and 2 males. Incoming SAT scores and current QPAs were collected from the dean's office at the school. There was no statistically significant difference $(p<.05)$ between groups for QPA, total SAT, math SAT or verbal SAT scores using an independent $t$ test. It should be noted that a requirement for both the physical therapy and occupational therapy programs is that students maintain a 3.0 QPA in order to matriculate. There was one person in the concept mapping group who did not meet that requirement. The 2.59 QPA for this individual was from an undergraduate experience that was completed prior to admission to the occupational therapy program. Table G1 in Appendix G shows the results of the descriptive statistical analysis and independent $t$ test analysis for the groups. Finally, the scores of the initial LASSI were compared between groups. Results presented on Table G2 in Appendix G show no statistically significant difference $(p<.05)$ between groups for any of the LASSI subscales except Selecting Main Ideas $(\mathrm{SMI}) t(36)=2.361, p=$ .024. On SMI pre-test, the concept mapping group $(\mathrm{n}=19)$ had a mean score of 19.42 . The control group $(n=19)$ mean was 17.21.

The demographics data were also calculated for differences between groups excluding the eight students who failed to matriculate into the spring semester. All eight students did not matriculate because of a failing grade in the concurrent physiology course in the fall semester. With independent $t$ test, there was no statistically significant difference $(p<.05)$ between the concept mapping group $(\mathrm{n}=13)$ and the control group $(\mathrm{n}$ 
= 17) for SAT scores, QPA, initial LASSI scores, anatomy course written or practical examination pretests.

\section{$\underline{\text { Study Journals }}$}

All of the participants submitted weekly study journals that chronicled the amount of time spent studying for anatomy during the fall semester or kinesiology in the spring semester for the length of the study. These data were recorded in fractions of an hour by the participant on a daily basis and totaled for the week. On each study journal the participant also listed weekly goals and answered questions related to progress toward those goals. There were no statistically significant differences between groups with independent $t$ test for time spent studying for anatomy, kinesiology or total time spent studying $(p<.05)$. (See Table G3 in Appendix G.)

\section{Concept Maps}

The participants in the concept mapping group were required to produce a total of 7 concept maps for anatomy topics in the fall. The concept maps were submitted for feedback on a regular schedule. In the spring semester, the concept mapping group was given the option to submit concept maps for feedback. As the qualitative results will show, few participants did continue to use concept maps for the second (spring) semester of anatomy, and some used them for kinesiology. However no concept maps were given to the researcher for feedback.

The concept maps from the fall semester were analyzed quantitatively as described by Novak and Gowin (Novak \& Gowin, 1984). However, as the concept maps were each done on separate topics, there was no expectation that the scores on the 
individual concept maps would improve as a result of learning course content. There was the expectation that students may have improved concept map scores over time through increased numbers of crosslinks and additional levels of hierarchy as a result of becoming more familiar with the concept mapping technique and software. However, as can be seen from Table G4 in Appendix G, no such trend was evident.

A complete data set was collected only for the fourth concept map. All the other concept map sets were incomplete because at least one participant failed to submit the concept map. The sixth and seventh concept map sets had the fewest number of concept maps. The due dates for these concept maps corresponded with the end of the fall semester when students are experiencing increased demands while preparing for final examinations. Also, the scores of the concept maps diminished as the semester progressed, perhaps indicating less willingness to spend the time necessary to make a high-scoring concept map.

\section{$\underline{\text { Research Question One }}$}

Research Question One asked: Does the use of concept mapping significantly improve $(p<.05)$ academic performance on tests of anatomy knowledge? The data sources for the first research question included a researcher-constructed test of anatomy knowledge that was administered as a pretest, immediate posttest and delayed posttest. Only 30 complete data sets were obtained for the researcher-generated test of anatomy knowledge accounting for the eight participants who did not matriculate and therefore did not complete the delayed posttest. On pretest there were no statistically significant differences $(p<.05)$ between groups using independent $t$ test. The means were analyzed with a $2 \times 3$ ANOVA with repeated measures and there were no statistically significant 
differences $(p<.05)$ between groups. Within subjects effects showed a significant $(p<$ $.05)$ main effect for time $\mathrm{F}(1,38)=54.76, p<.05$. The immediate posttest $(\mathrm{M}=20.23, \mathrm{SD}$ $=5.73)$ and delayed posttest $(\mathrm{M}=21.17, \mathrm{SD}=5.72)$ both scored significantly higher than the pretest scores $(\mathrm{M}=11.87, \mathrm{SD}=3.58)$ for both groups. Data from those students who did not matriculate into the spring semester were excluded from this calculation. Table G5 in Appendix G shows the results.

Other sources of anatomy knowledge data were generated by the instructor for the anatomy course. Some of the anatomy data sets from the course instructor-generated examinations did not have a normal distribution, therefore non-parametric tests were used for analysis with these data. These included written examinations of anatomy knowledge using short answer, multiple-choice and K-questions formats and practical examinations that took place in the anatomy laboratory. The laboratory examinations directed the students to identify tagged structures on the cadavers or skeletons. One of the written examinations and one of the practical examinations took place prior to the start of the study and served as pre-tests. In the fall semester, complete data sets were obtained for all the participants $(n=38)$ for all of the anatomy course measures. Results of the MannWhitney $u$ test showed no statistically significant differences $(p<.05)$ between groups for written examinations or laboratory practical examinations prior to intervention.

Table G6 in Appendix G shows the results of analysis of scores using a KruskalWallis calculation for written examinations and laboratory examinations that took place after the intervention. Final scores for the anatomy course grade average were compared between groups using a Mann-Whitney $u$ test. The results are shown on Table G7 in 
Appendix G. No statistically significant differences $(p<.05)$ were found between groups for any of the calculations.

There were no statistically significant differences $(p<.05)$ found between groups for any of the measures of anatomy knowledge, therefore the null hypothesis was accepted for Research Question One. The null hypothesis stated that use of concept mapping does not significantly improve $(p<.05)$ academic performance on tests of anatomy knowledge. There was a significant main effect for test time on the researcherconstructed measure, which is expected given that there was instruction about the topics for both groups during the class between pre and posttests.

\section{$\underline{\text { Research Question Two }}$}

Research Question Two asked: Does the use of concept mapping in anatomy significantly improve $(p<.05)$ academic performance on tests of kinesiology knowledge? The data collected to answer the second research question included a researcherconstructed test of kinesiology knowledge and the final grade for the kinesiology course that was based on instructor-generated tests of kinesiology knowledge.

Table G8 in Appendix G shows the results of a 2x2 ANOVA with repeated measures for the researcher-constructed test of kinesiology knowledge. There was a statistically significant $(p<.05)$ main effect for test time $\mathrm{F}(1,28)=15.98, p=.000$. A review of the means showed that students in both groups had an increase in test score from the first test $(M=22.13, S D=4.73)$ to the second test administration $(M=26.7, S D$ $=7.03)$. 
The kinesiology instructor-constructed objective tests of kinesiology knowledge consisted of multiple-choice and K-type questions. The topics for the first 2 tests in the kinesiology course coincided with the topics concept-mapped and tested in the fall semester anatomy course. Each of these two examinations also contained items to test knowledge on other topics in kinesiology. On careful consideration of the items on the tests, the researcher found that there were few items that directly tested content that related to the anatomy tests. All of the test scores were used to calculate final grades for the kinesiology course. Therefore, course grades were taken as a whole rather than sorting out items related to the anatomy content. Table G9 in Appendix G shows results of an independent $t$ test of kinesiology final grade averages by group. There was no statistically significant difference $(p<.05)$ between groups.

As there were no statistically significant differences between groups on any of the kinesiology measures, the null hypothesis was accepted for Research Question Two. The null hypothesis for Research Question Two read: Use of concept mapping in anatomy does not significantly improve $(p<.05)$ academic performance on tests of kinesiology knowledge. Research Question Two was originally posed as a way to assess the transfer of anatomy knowledge learned with the use of concept mapping to kinesiology topics. Since kinesiology takes anatomy knowledge one step further toward clinical application by integrating anatomical elements in terms of movement, meaningful learning in anatomy might facilitate that transfer. However, the conditions that were present in the fall semester did not necessarily allow for meaningful learning of anatomy to take place.

Findings for Research Questions One and Two can be compared somewhat to published reports in the literature (Beissner, 1992; Bolte, 1999; De Simone et al., 1999; 
Heinze-Fry \& Novak, 1990; Markow \& Lonning, 1998; Okebukola, 1990) that compared scores on tests of content knowledge between groups of college students who did and did not use concept mapping with varying results. However, only one of those studies had the intent to use the concept mapping expressly as a vehicle to promote learning transfer from one topic to another. In that study, mental networking that used metacognitive cues did promote learning transfer (De Simone et al., 1999). However, results of the present study found that the method of concept mapping that these participants used neither improved scores of anatomy nor improved transfer of anatomy knowledge over students who did not use concept mapping. A question remains about the effectiveness of this method for PT and OT students in the topics of anatomy and kinesiology.

\section{Research Question Three}

Research Question Three asked: Does the use of concept mapping significantly improve $(p<.05)$ scores on the Learning and Study Strategies Inventory? The LASSI was administered to all the participants $(\mathrm{n}=38)$ as a pretest at the beginning of the study. The LASSI was then also administered to the remaining participants $(\mathrm{n}=30)$ in the spring at the start of the semester and at mid-term. The LASSI subscales data were analyzed with ANOVA with repeated measures except for SMI which was analyzed with an ANCOVA with repeated measures using the pretest scores as a co-variate. Tables G10-G19 in Appendix G show the results.

Significant main effects $(p<.05)$ were found for test time in Anxiety $\mathrm{F}(2.56)=$ $6.19, p=.004$, Concentration $\mathrm{F}(2,44)=4.34, p=.016$, Motivation $\mathrm{F}(2,56)=5.35, p=$ .008 , and Test Strategies $\mathrm{F}(2,56), p=.037$. For Anxiety and Concentration there was a significant effect between the pretest and both posttests. Anxiety pretest scores $(\mathrm{M}=$ 
$23.4, \mathrm{SD}=5.75)$ were lower than scores on the first posttest $(\mathrm{M}=25.67, \mathrm{SD}=7.52)$ and the second posttest $(\mathrm{M}=25.63, \mathrm{SD}=7.59)$. This is interesting because it indicates that test anxiety increased over the course of the study. Concentration pretest scores $(\mathrm{M}=$ $27.1, \mathrm{SD}=5.42)$ were significantly less than posttest one $(\mathrm{M}=28.5, \mathrm{SD}=4.45)$ and posttest two scores ( $\mathrm{M}=28.7, \mathrm{SD}=4.56)$ For Test Strategies there was a significant difference between the pretest $(M=29.27, S D=.790)$ and the first posttest $(M=30.70$, $\mathrm{SD}=.630)$. For Motivation, there was a significant difference between the second posttest and both the pretest $(\mathrm{M}=33.2, \mathrm{SD} .620)$ and first posttest $(\mathrm{M}=33.54, \mathrm{SD}=$ $.579)$. The mean went down in the second posttest $(\mathrm{M}=32.3, \mathrm{SD}=.705)$. No significant differences $(p<.05)$ were found between groups in any of the administrations among any of the LASSI subscales. Table G20 in Appendix G shows the descriptive statistics for the LASSI subscale scores.

The null hypothesis, use of concept mapping does not significantly improve $(p<$ .05) scores on the LASSI, was accepted for Research Question Three. One of the reasons that there may not have been an effect on learning strategies is the relatively brief time for the intervention. Many researchers have reported that students will resort to familiar strategies to learn new information (Garner \& Alexander, 1989; Kember, 1996; Lonka et al., 1994). The concept maps were required in the fall semester for a total of seven weeks, but were not required at all in the spring semester. Therefore, participants did not concept map as frequently in the spring semester. There may simply not have been enough time to establish concept mapping as a study habit and subsequently have an effect on learning and study strategies. 


\section{$\underline{\text { Research Question Four }}$}

Research Question Four asked: Is there a statistically significant relationship $(p<$ .05) between kinesiology course grade average and anatomy course grade average and concept mapping? The original intent for this research question was to use the amount of time spent concept mapping as recorded on the study journals for one of the variables. However, the study journals proved to be a poor source for concept mapping time. Students recorded total time spent studying, but did not specifically break the time down by method of studying. Therefore, the concept mapping variable became a dichotomous one in which participants either constructed concept maps or did not.

Kinesiology course grade was correlated with anatomy course grade using a Spearman's rho correlation for those students who had completed the entire study $(\mathrm{n}=$ 30). Anatomy course grade average correlated significantly $(p<.01)$ with kinesiology course grade average $(r=.547)$ for the whole group. A statistically significant correlation $(p<.01)$ was found for the control group between anatomy total grade and kinesiology total grade $(r=.685)$. There were no statistically significant correlations $(p<.01)$ found with concept mapping group for either anatomy course grade or kinesiology course grade. A point biserial correlation was used to compare the course grades for anatomy and kinesiology to participation in either the concept mapping or control group. There were low, negative correlations between anatomy course grade average and concept mapping $\left(r_{p b}=-.173\right)$ and kinesiology course grade average and concept mapping $\left(r_{p b}=-\right.$ .009). The null hypothesis, there is no statistically significant relationship $(p<.05)$ between kinesiology course grade average and anatomy course grade average and 
concept mapping, was rejected because of the significant correlation between the grades for the two courses.

\section{$\underline{\text { Research Question Five }}$}

Research Question Five asked: Is there a statistically significant relationship $(p<$ .01) between anatomy course grade average, kinesiology course grade average and SAT scores, QPA, initial LASSI scores, study time and concept mapping? The null hypothesis for Research Question Five stated: There is no statistically significant relationship ( $p<$ .01) between anatomy course grade average, kinesiology course grade average and SAT scores, QPA, initial LASSI scores, study time and concept mapping.

A Spearman's rho correlation was used to see if SAT scores, QPA, initial LASSI scores or study time correlated with course grades in kinesiology or anatomy. Again, concept mapping was a dichotomous variable and was analyzed with a point biserial correlation. Therefore, correlations between course grade averages and the concept mapping intervention for Research Question Five are the same as those for Research Question Four. Statistically significant correlations $(p<.01)$ were found in the control group between total anatomy course grade average and QPA $(r=.700)$, SAT Math scores $(r=.592)$, and kinesiology course grade average $(r=.685)$. Statistically significant correlations $(p<.01)$ were found in the concept mapping group between total anatomy course grade average and total SAT $(r=.767)$, QPA $(r=.633)$, pre-test LASSI subscales Anxiety $(r=.609)$. Statistically significant correlations $(p<.01)$ were found in the control group between kinesiology course grade average and SAT Math scores $(r=.504)$ and QPA $(r=.508)$. There were no statistically significant correlations $(p<.05)$ with kinesiology course grade average in the concept mapping group. 
The investigator also analyzed the entire group of participants, both concept mappers and control, using the same parameters. Anatomy course grade average correlated significantly $(p<.01)$ with kinesiology course grade average $(r=.547)$, SAT Math scores $(r=.721)$, SAT Verbal scores $(r=.464)$, SAT Total scores $(r=.686)$, and QPA $(r=.668)$. Kinesiology course grade average, in addition to correlating significantly with anatomy course grade average, also had statistically significant correlations $(p<.01)$ with SAT Math scores $(r=.386)$ and QPA $(r=.483)$. The null hypothesis was rejected for Research Question Five.

In answer to Research Questions Four and Five, use of concept mapping did not correlate significantly with either final grade for anatomy when concept maps were required or for kinesiology when concept maps were not required. However, kinesiology course grade average and anatomy course grade average did significantly correlate. This supports the supposition that the content for both courses is indeed closely related and may explain the lack of correlation with concept mapping. Knowledge that is transferred through the low road, as is suspected with anatomy and kinesiology, may not require an investment of meaningful learning that justifies use of concept mapping (Salomon \& Perkins, 1989).

\section{$\underline{\text { Post Hoc Analyses }}$}

Based on published findings that suggest that use of concept mapping benefits students on items testing higher levels of cognition (Okebukola, 1990), a post hoc analysis was done. The researcher-constructed kinesiology test was designed with items from the first five levels of Bloom's taxonomy: knowledge, comprehension, application, analysis and synthesis (Shepard \& Jensen, 1997). The test items were divided into low 
level (knowledge and comprehension) and high level (application, analysis and synthesis) groups. The mean scores for low and high level items on both administrations of the researcher-generated kinesiology test were compared using a 2x2x2 ANOVA (group $\mathrm{x}$ time $\mathrm{x}$ item level). Table G21 in Appendix G shows the results of this analysis. Table G22 in Appendix G shows the descriptive analysis of these results.

Significant main effects $(p<.05)$ were found for item $\mathrm{F}(1,28)=72.126, p=.000$, and time $\mathrm{F}(1,28)=14.890, p=.001$. Descriptive statistics reveal that members of both groups increased percentage scores on the entire examination from the first administration to the second. Also, members of both groups scored lower on high level items than low level items on both the first and second administrations of the examination. There was also a significant interaction $(p<.05)$ between item and group $\mathrm{F}(1,28)=5.811, p=.023$. The descriptive statistics reveal that a difference between groups on scores for low level items on both test administrations accounts for most of this interaction effect. Rather than scoring higher on high level items, members of the concept mapping group scored higher than non-concept mappers on low level items. This result contradicts that of Okebukola (1990) who found that those who constructed concept maps scored higher on high level items than those who had not. However, in his study Okebukola defined high level items as those at the comprehension level and beyond. In the present research project comprehension was categorized as relatively low level.

It is interesting that members of the concept mapping group scored higher than non-concept mappers on low level items testing the application of anatomy knowledge to kinesiology concepts even though there was no statistically significant difference between groups on the delayed posttest of anatomy knowledge. This finding may suggest 
that construction of concept maps does not improve scores for tests of rote knowledge (e.g., anatomy) but does allow for transfer of that knowledge to topics that apply that information in ways that are novel to the learner (i.e., kinesiology).

Post hoc power analysis revealed low power $(1-\beta<.8)$ for many of the statistical analyses done for this study. This was particularly true for ANOVA analyses comparing means between groups. Since the participants in this study represented a sample of convenience, there were not enough volunteers to provide data that would have sufficient power to confidently accept the null hypothesis. Therefore, lack of differences in groups cannot be fully explained and may be the result of small sample size, or small effect size among other factors.

\section{$\underline{\text { Summary Research Questions One through Five }}$}

Research Questions One and Two, and the post hoc analysis of kinesiology high level and low level items, looked for differences in academic performance in anatomy and kinesiology with the use of concept mapping. Statistical analysis showed that those students who concept mapped did not score significantly higher on tests of content knowledge than those students who did not concept map. Research Question Three looked at the differences in learning and study strategies between the two groups. Again there was no significant difference between those students who concept mapped and those who did not. Results of Research Questions One through Three must be viewed with consideration of results of power analysis which revealed a low power.

Research Questions Four and Five looked for factors that correlated most highly with anatomy course grade average and kinesiology course grade average. It was found 
that there was no statistically significant correlation between anatomy and kinesiology course grade averages and whether the student had concept mapped or not. Anatomy course grade average and kinesiology course grade average correlated highly with each other, which was to be expected and supports the role of learning transfer between these two subjects. Other strong correlates to course grades were QPA and some SAT scores.

Results of the quantitative analysis may be explained somewhat by findings from the qualitative portion of this study. At the end of Chapter Five a comparison of results and findings from both methods will be discussed. 


\section{Chapter Five Qualitative Findings and Discussion}

This chapter reveals the findings of the qualitative data analysis pertaining to Research Questions Six, How do students describe their experience learning with a novel strategy? and Seven, What are students' perceptions regarding concept mapping as a study tool? The chapter is arranged as a cross case analysis of the six individual participants from whom qualitative data were collected in the fall and spring semesters. These six individuals were all members of the concept mapping group. For this chapter, the term "participants" refers only to these six individuals as a subset of the concept mapping group.

\section{$\underline{\text { Participant Selection }}$}

Five of the participants were also members of the focus group conducted by the researcher in the fall semester. Of these five, one participant did not matriculate into the spring semester because she did not make a passing grade in the fall semester physiology course. The sixth participant was chosen from the concept mapping group as a person who had expressed positive views about concept mapping through unsolicited remarks that were made during the fall semester. The six participants were initially chosen by the researcher for the individual interviews based on an overall positive or negative view of concept mapping. However, as the analysis progressed, it was difficult to maintain a view of the two groups as having either positive or negative opinions on concept mapping, since members of each group expressed opinions that reflected feelings on both sides. Therefore, another method of categorization seemed appropriate. From analysis of the data, trends emerged that allowed the researcher to characterize the participants on a 
continuum between rote learners and meaningful learners. Themes that developed through data analysis were compared and contrasted within and across the rote and meaningful learning groups. The first group consisted of participants who tended to employ meaningful learning practices primarily through drawing connections among the facts being learned. The second group was made up of those individuals who tended to embrace rote learning. The members of this group were characterized by a memorization approach to learning where the goal was reproduction of the information in its original form. Although some of the participants showed a progression (or regression) along that continuum throughout the data collection, for the most part each participant could be classified into one group or the other.

In categorizing these participants into two groups, the researcher initially assumed that those in the rote learning group would tend to have more negative views of concept mapping and those in the meaningful learning group would generally have more positive views on concept mapping. As will be seen from the findings to answer the two qualitative research questions, this premise did largely hold true. Meaningful learners appreciated the linking and crosslinking features of the concept maps, the same features that make the concept map a tool for meaningful learning. When the rote learning group expressed positive views about concept mapping, they tended to speak to the ancillary features of the software such as the variety of colors and symbols. This chapter will describe the individual cases and the characteristics that the researcher used to place them into either the rote learning or meaningful learning group. Several data sources in which the participant expressed opinions and answered questions were triangulated to initially classify the participants. This analysis was then further compared with characteristics 
revealed in qualitative analysis of the concept maps that the participant submitted throughout the fall semester.

The meaningful and rote learning groups were compared and contrasted to answer Research Questions Six and Seven to describe both the participants' experience with a new study strategy and their overall perceptions of concept mapping. Exceptions are noted as they arose. There were two themes that were shared among members of both groups. First was the increased feelings of stress in the fall semester. Second was the external motivation provided by participation in this research project. To a certain extent, participation provided external motivation to attend to the participants' typical study habits. As this attention could have an effect on the overall outcome of the study as well as on grades for the semester, it is important to note that the participants did describe a sense of obligation to study.

\section{Themes Pertaining to All Participants}

\section{$\underline{\text { Stressful Time }}$}

The first theme sets the stage for the environment in which the students were introduced to a new study strategy. With the exception of $\mathrm{GD}_{\mathrm{M}}$, the students who participated in this study were juniors in college who had maintained a 3.0 QPA for their first 2 years. In order to maintain this level of academic achievement, they had to have established a method for studying. However, as was shown by the qualitative data, the first semester of the third year represented a departure from the status quo. To some extent, this was a shared experience among all of the participants. However, the response 
to and expectations of the academic rigor of the third year varied somewhat among the participants.

The six participants on the whole had expectations for a very busy semester. Two of the participants $\left(\mathrm{CG}_{\mathrm{M}} \& \mathrm{DK}_{\mathrm{R}}\right)$ told of being forewarned by upper classmen of the overwhelming nature of the first semester of the third year. Words used to describe the fall semester included "hectic," "overwhelming," "shocking" and "a kick in the butt." Participants in both groups confessed to feeling "scared," "disadvantaged," or "unprepared" for the level of academic rigor that characterized the fall semester. It is important to note that these feelings were not carried over into the spring semester. Whether the shock had worn off, or the spring semester was actually less stressful, the participants did not react to the course load in the spring the same way as they did in the fall.

\section{$\underline{\text { External Motivation }}$}

A theme, External Motivation, emerged that related primarily to participation in the study as a consequence or condition of learning the new study technique. A sense of participant accountability was induced primarily by the study journal requirement. The participants responded strongly to the study journal as an external motivator and stated explicitly that recording details about time and method of study at least increased awareness of study habits and at most made them feel obligated to study. On the final study journal of the fall semester, four of the six participants mentioned this when asked to name a benefit of participating in the study. 
The concept mapping requirement in the fall semester for anatomy topics also served as an external motivator for at least two of the participants to keep up with studying.

I just used them [concept maps], well I think what helped about those was ... the actual making of them. Like making them was forcing me to look at my notes throughout the ... couple weeks before the test, because, usually I wouldn't look at it at all. And that forced me to at least become ... familiar with terms, and a general idea of function ... and so I think that helped me. $\left[\mathrm{GJ}_{\mathrm{R}}\right]$

$\mathrm{JA}_{\mathrm{M}}$ described the external motivation this way: "What I used it for the most was just keeping me up to speed. ... Having those due made me do something every week." For both the concept mapping group and the control group, the study journal served as an external motivator to maintain consistency with study habits throughout the fall and spring semesters. Also, to some extent, the concept mapping group had further motivation at least during the fall semester to keep up with anatomy coursework in order to submit the required concept maps. However, in the spring semester, the concept maps were removed as a motivator since there were none required as a condition of participation in the study.

\section{Description of Meaningful and Rote Learners}

The following section describes the characteristics of the meaningful learners and rote learners that were elicited from the qualitative data analysis, particularly the logical analysis through use of matrices. It is important to note that even though the participants were categorized based on a triangulation of data sources, members of both groups 
occasionally displayed characteristics that might be attributed to members of the opposite group. Examples of concept maps for each of the participants are shown in Appendix J.

\section{$\underline{\text { Meaningful Learning Group }}$}

The members of the meaningful learning group, consisting of four of the six participants, are characterized by three features. First, each member of the group expressed a realization that as the curriculum progressed they would have to make both logistical changes (i.e., related to setting, timing, etc.) and cognitive changes in their study habits. Second, the meaningful learners tended to avoid memorization or rote learning as the method of choice for learning anatomy and kinesiology content. Third, the concept maps created by members of this group were also the most net-like among the concept mappers showing a well-integrated view of the content. The members of the meaningful learning group are identified within the text with their initials and a subscript M.

$\mathrm{JA}_{\mathrm{M}}$ was a PT student. She was the member of the concept mapping group who did not participate in the focus group. The investigator selected $\mathrm{JA}_{\mathrm{M}}$ because she expressed positive views on concept mapping throughout the fall semester. $\mathrm{JA}_{\mathrm{M}}$ was attracted to the research study as a way to give her studying a boost for a semester that she anticipated to be difficult. JAM's concept maps were primarily spoke designs with few crosslinks. As the fall semester progressed the concept maps had an increasing number of links labeled. $\mathrm{JA}_{\mathrm{M}}$ submitted outlines with her concept maps with notes that revealed information not contained on the concept map. See Figure J1 in Appendix J for a modified example of a concept map submitted by $\mathrm{JA}_{\mathrm{M}}$. 
$\mathrm{GD}_{\mathrm{M}}$, an OT student, differed from the other participants in a few ways. First, he was the only male participant in the group of six and in the concept mapping group. Second, he was a non-traditional student who had returned to school after working several years in the fitness industry. Third, he was the only participant with a prior completed undergraduate degree and therefore was not under the same academic pressures as the other students. This participant was the most likely to try to relate current learning with previous life, work and/ or academic experience in a meaningful way. For this reason, he tended to focus on learning conceptual information and shunned learning details. However, as the spring semester progressed, he confessed that he began to realize that in order to be successful, he may have to rely on memorization learning methods. $\mathrm{GD}_{\mathrm{M}}$ 's concept maps also differed from other members of the meaningful learning group. If decisions on group membership were based on the qualitative analysis of the concept maps alone, $\mathrm{GD}_{\mathrm{M}}$ would be in the rote learner group. The concept maps were primarily chain or flow chart patterns with inappropriate levels of hierarchy. There was minimal use of labels on links and few or no crosslinks. GD 's concept maps progressed to spoke design through the fall semester but did not reach net-like structures. $\mathrm{GD}_{\mathrm{M}}$ made moderate use of colors and symbols. See Figure $\mathrm{J} 2$ in Appendix $\mathrm{J}$ for an example of a concept map created by $\mathrm{GD}_{\mathrm{M}}$.

$\mathrm{SJ}_{\mathrm{M}}$ was a PT student who felt that her studying would need to be geared toward permanent learning. Although reluctant to use concept maps in place of other methods, $\mathrm{SJ}_{\mathrm{M}}$ thought she would be more inclined to use them if her schedule allowed because she perceived that they could be helpful. $\mathrm{SJ}_{\mathrm{M}}$ had the most net-like concept maps from the start of the study with well-labeled links and crosslinks. Her concept maps also had a 
prolific use of color and moderate use of a variety of symbols. Figure J3 in Appendix J provides an modified version of a concept map submitted by $\mathrm{SJ}_{\mathrm{M}}$.

$\mathrm{CG}_{\mathrm{M}}$ was an OT student with previous experience concept mapping with paper

and pencil. $\mathrm{CG}_{\mathrm{M}}$ sought out concept mapping in her second year as a way to learn without memorizing. She did not enjoy electronic concept mapping because of the "physical strain" of sitting by the computer. The concept maps that $\mathrm{CG}_{\mathrm{M}}$ submitted for feedback progressed from spokes or chains with minimally labeled links to net-like maps with well-labeled links and crosslinks. $\mathrm{CG}_{\mathrm{M}}$ 's concept maps tended to have a specific main idea. Therefore she handed in several small concept maps clustered together rather than a single well-integrated concept map. $\mathrm{CG}_{\mathrm{M}}$ made minimal use of color and symbols. Figure $\mathrm{J} 4$ in Appendix $\mathrm{J}$ contains a modified version of a concept map created by $\mathrm{CG}_{\mathrm{M}}$.

\section{$\underline{\text { Rote Learning Group }}$}

The rote learner group consisted of two people. Both students relied heavily on memorization for learning. Neither student made mention of use of new knowledge beyond testing. Both students expressed generally negative views of concept mapping as a potentially useful study strategy. The rote learners are identified throughout the text with a subscript $\mathrm{R}$.

$\mathrm{GJ}_{\mathrm{R}}$ was a PT student who relied on memorization for learning new content. She admitted to procrastination as her biggest flaw with studying. She was also one of the few participants who continued to concept map for anatomy in the spring semester, although not for kinesiology. $\mathrm{GJ}_{\mathrm{R}}$ 's concept maps were either spoke design or top-down tree design. The concept maps progressed from no labels on links to well-labeled links. Her maps had few to no crosslinks. $\mathrm{GJ}_{\mathrm{R}}$ made use of a variety of colors and symbols. She also 
used several features of the software including the arrangement and rapid fire icons. A modification of a concept map submitted by $\mathrm{GJ}_{\mathrm{R}}$ is shown in Figure $\mathrm{J} 5$ in Appendix $\mathrm{J}$.

$\mathrm{DK}_{\mathrm{R}}$ was a PT student who did not matriculate into the spring semester. She passed anatomy in the fall semester with a $79 \%$ average, but received less than $70 \%$ in a concurrent physiology course. $\mathrm{DK}_{\mathrm{R}}$ relied heavily on flash cards and memorization for learning, although she did use "drawings" to help her make connections among ideas. $\mathrm{DK}_{\mathrm{R}}$ 's concept maps made no progression in structure throughout the fall semester. Each of her concept maps was a spoke design with the links labeled but few to no crosslinks. $\mathrm{DK}_{\mathrm{R}}$ made moderate use of colors and symbols in her concept maps. See Figure J6 in Appendix $\mathbf{J}$ for an example concept map.

\section{Findings and Discussion}

\section{$\underline{\text { Research Question Six }}$}

Research Question Six asked: How do students describe their experience learning with a new study technique? Students relayed a variety of themes associated with learning with a new study technique. Some of the experiences were shared among all the participants and others were not. Figure 5.1 shows a concept map representation of the themes that respond to Research Question Six. Some of the themes help to set the stage for the introduction of a new study technique. For example, the emotional state and cognitive load of the participants in the fall semester, for the most part, represents a departure from the status quo for the students starting their first or second academic years. Essentially, the first semester of the third year is drastically different with respect to academic demands and rigor. 
Apprehension regarding use of concept mapping emerged as a theme that was understandable when considering the stressful time of this study. Some of the students perceived a risk with attempting to learn in a way that may or may not suit their own style. On the other extreme, a few of the participants actually sought a new way to learn as a way to enhance their current, already-proven study methods. When taken in context, establishing a new study strategy at a time of high academic stress and load can be understood to cause apprehension among some students.

Another stage-setting theme that emerged was the description of the Study Habits on which the participants relied to prepare for examinations and learn anatomy, and to a lesser extent, kinesiology content. The participants described various methods, settings or strategies that they employed to study. One of the most prominent study methods was the use of Flash Cards or note cards and served as an element of the Study Habit theme. The flash card method is a rote method of study that focuses on memorization as opposed to concept mapping which intends to promote meaningful learning. Again, there was a wide range among the participants with respect to affinity for flash cards.

Finally, the qualitative data revealed, to varying degrees, the level of Metacognition among the participants. Metacognition has been thought to be an important element to successful transfer of learning (Lin et al., 1994; Shih et al., 1997). Clearly, in the transfer of anatomy knowledge to kinesiology learning, the low road is taken (Salomon \& Perkins, 1989). For example, the anatomical features of skeletal muscle are easily transferred to kinesiology without changing the structure of the knowledge. Those same facts about location of the muscle are used in kinesiology to learn more about how the muscles act in a variety of situations and under different 
conditions. Thoughts about the students' own thinking and learning process were revealing in discerning differences between the meaningful learning and rote learning groups.

\section{Figure 5.1 Themes for Research Question Six}

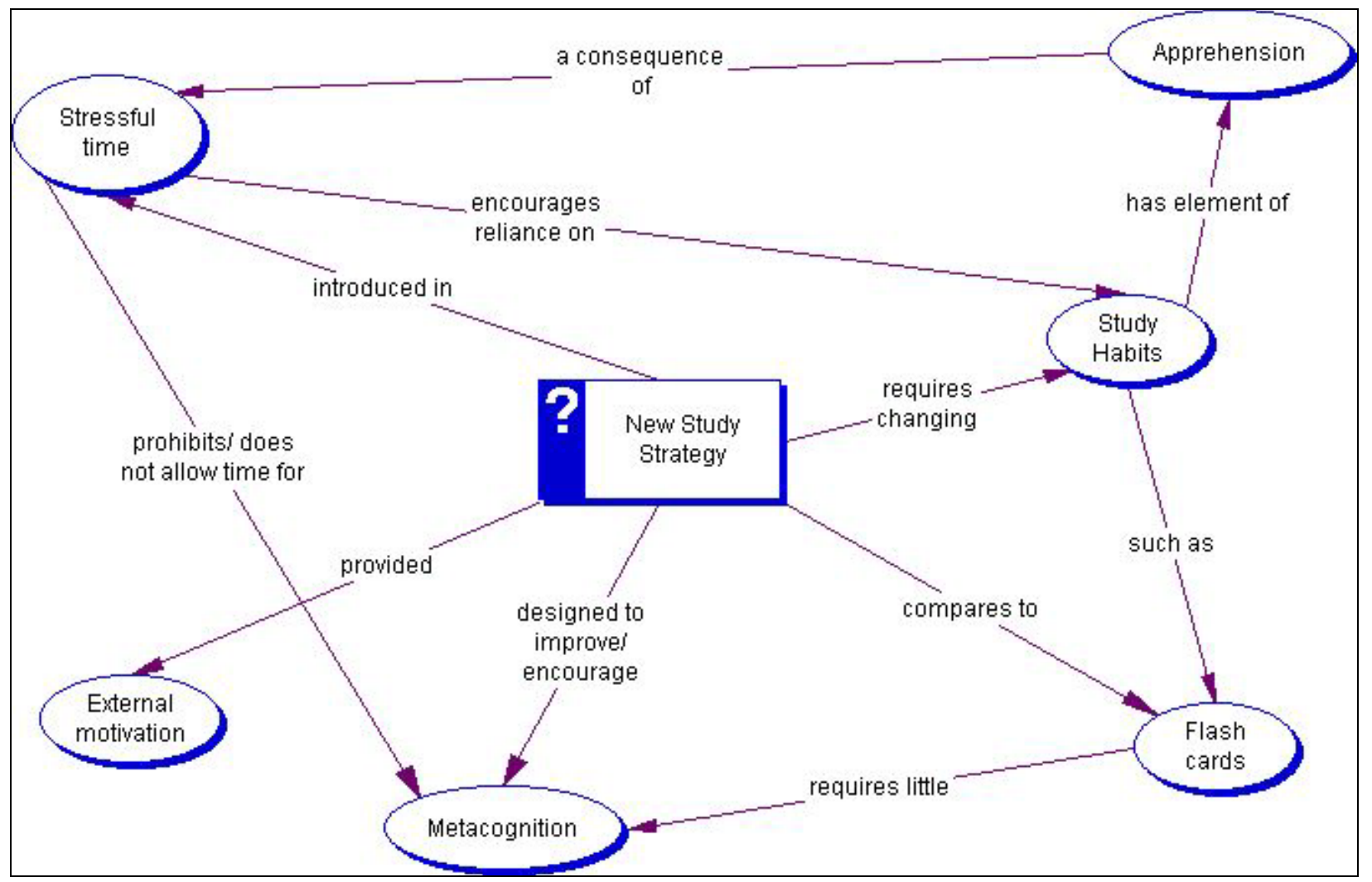

\section{Apprehension}

Considering the stressful setting in which this study took place, it is easy to understand why some students might have felt some apprehension for starting a new study technique. For some of the participants, this apprehension was explicitly directed at trying a new technique that might not allow them to be as successful as they could be. $\mathrm{CG}_{\mathrm{M}}$ and $\mathrm{JA}_{\mathrm{M}}$, both meaningful learners, expressed little or no apprehension about the use concept mapping. In fact, both of these participants sought a change in study habits as 
a way to be successful in what they viewed as a changing learning environment. $\mathrm{JA}_{\mathrm{M}}$ was looking for something in the way of a new study technique to give her "an edge" to alleviate her fears or nervousness about the rigor of the semester. $\mathrm{CG}_{\mathrm{M}}$ had previously taught herself the concept mapping technique.

Well, I tried memorizing and, I don't know, it wasn't working as well as it ought to, so I tried something else. I mean, you can't stick, like it it's not working for you, memorizing works for a lot of people, but if it's boring and you're not remembering it past the test, then something has to change, right? So. $\left[\mathrm{CG}_{\mathrm{M}}\right]$

Four students, including $\mathrm{SJ}_{\mathrm{M}}$ and $\mathrm{GD}_{\mathrm{M}}$ in the meaningful learner group, explicitly expressed fear of trying a new study technique. This fear was directed at being less successful with a new study technique, or taking up time using a new study technique that could have been used with a tried and true method. In this theme, $\mathrm{GD}_{\mathrm{M}}$ was aligned more with the rote learning group in being afraid to try a new study method at this stage in learning. In the focus group, $\mathrm{GD}_{\mathrm{M}}$ expressed similar concerns when asked about drawbacks related to concept mapping:

I really can't think of any other than takes a little ... more time than.. I guess it's a phobia thing that ... maybe I should be doing something else. (laughs) Using some other study technique then concept map. It's more specific.

During the focus group interview, $\mathrm{DK}_{\mathrm{R}}$ expressed this:

Overall it was good. I don't know if it's for me personally if it's going to be another way to study. Because I don't, it may have helped, it may not 
have, I just don't, I guess I'm so a creature of habit that I'm so used to doing everything else that I'm really afraid to start something new. So I don't, I think it's a good idea and I think it could help me study if I was open to that kind of thing.

The apprehension expressed by the rote learners tended to have them hold more closely to their previous study habits. However, the low apprehension by the meaningful learners was shown by their willingness to seek out other ways of studying as a supplement to their previous habits. Two members of the meaningful learner group $\left(\mathrm{GD}_{\mathrm{M}}\right.$ $\& \mathrm{SJ}_{\mathrm{M}}$ ) did express fear about using a new technique in lieu of an established habit. However, these two participants were also more aware of the cognitive investment required for adopting a new strategy. They each spoke about choosing among a variety of study strategies to find the one most appropriate to the task.

\section{$\underline{\text { Study Habits }}$}

As mentioned previously, one of the main reactions to learning a new study technique had to do with how well established earlier study habits might be. It is easy to see why a person would revert to the familiar in times of trouble or stress. Apparently, that is what happens to students even with the best intentions to make a full effort to use a new study technique (Garner \& Alexander, 1989; Kember, 1996). For both the meaningful learners and rote learners, changes in study habits in response to the increased demand of the third year resulted primarily in increasing the amount of time spent studying. For the meaningful learners, there was also a change in the nature of the study session. 
In the meaningful learner group, $\mathrm{CG}_{\mathrm{M}}$ and $\mathrm{JA}_{\mathrm{M}}$ both used a variety of methods to study new information and prepare for examinations. They both viewed concept mapping as a supplement to their other study techniques. $\mathrm{SJ}_{\mathrm{M}}$, like $\mathrm{DK}_{\mathrm{R}}$, also mentioned being a "creature of habit" such that concept mapping represented a step outside of the comfort zone for studying, but she did mention that she felt that would be true for any new method. She never considered replacing one of her old study habits with concept mapping. It is interesting to note that even with this reluctance to embrace concept mapping as a study habit, $\mathrm{SJ}_{\mathrm{M}}$ produced the best examples of assimilation in her concept maps. She also continued to use concept maps in the spring semester, although she did not submit those to the researcher for feedback. $\mathrm{GD}_{\mathrm{M}}$ tried many methods of studying. He tended to match the expectations of the test to the method of studying.

The rote learners, $\mathrm{DK}_{\mathrm{R}}$ and $\mathrm{GJ}_{\mathrm{R}}$, both described the major changes in their study habits in terms of beginning to study for exams earlier than they would have previously. The substance of their study habits did not change.

$\mathrm{DK}_{\mathrm{R}}:$...Probably before this I used to study a week in advance at top ... I'd do the readings, and I'd make flashcards but never as much studying. I'd slack off some things. Interviewer (I): So do you feel that it's just mainly a difference not so much in your approach or your method so much as the amount of time? $\mathrm{DK}_{\mathrm{R}}$ : Yeah, definitely. I mean I still take the same approach when I used to study before. I used to, flash cards, reading notes, but now it's more time, it's more energy so to speak. 
The reduction in concept mapping for the concept mapping group as a whole in the spring semester may be attributed in part to the failure of this study technique to become a habit. Another potential reason may be the nature of the content being learned. Even participants who saw value in the process of concept mapping may not have viewed concept maps to be the best study approach for learning the detailed information in the anatomy course. One study habit that was well-entrenched in the rote learners in particular and is also frequently used for learning anatomy is the flash card method.

\section{$\underline{\text { Flash Cards }}$}

Flash cards or note cards, a popular method of studying for anatomy, tend to be a rote approach to learning rather than a meaningful approach. Usually, each student creates a set of flash cards with the name of a muscle on one side of an index card, and the details of its anatomy on the other side. To study, one looks at the name of the muscle and tries to recite the details from memory. Then, one checks the accuracy of the response by turning the flash card over and comparing the answer with what is written there. All of the participants made mention of this study technique, but the range of response to this technique varied.

Anecdotally, the researcher can attest that flash cards are a time-honored way of learning certain aspects of anatomy, particularly muscle origin, insertion, innervation and action. This rote learning method provides the learner with the facts, but does not encourage the learner to draw connections between muscle anatomy (origin and insertion) and its function (action). Understanding this relationship is beneficial for designing exercise programs and plans for rehabilitation. Similarly, finding patterns among the nerve supply to various muscles will help the budding therapist to employ 
diagnostic skills when a patient or client presents with weakness that may or may not be related to dysfunction of some aspect of the nervous system.

The meaningful learners, with the exception of $\mathrm{GD}_{\mathrm{M}}$, found little value in studying from flash cards. $\mathrm{CG}_{\mathrm{M}}$ had a negative view of flash cards or note cards from two perspectives that represented the meaningful learners' view saying, "Note cards take so long and you find yourself writing detail after detail and then you're just memorizing." $\mathrm{JA}_{\mathrm{M}}$ also found flash cards to be ineffective although they were useful in the past. And I have to say, one thing I don't do this year, that I did in the past is make note cards. I just found that there's too much information that I get too caught up in putting words on cards and not studying what I already have.

$\mathrm{SJ}_{\mathrm{M}}$ used flash cards as a way to make sure that she reviewed her notes. Writing or creating the flash cards was a mechanism for her to keep up with her studying. "I make note cards for anatomy so I kind of, like I do read the notes when I do that because obviously you have to read them to make the note cards." However, $\mathrm{SJ}_{\mathrm{M}}$ acknowledged that actually employing the method of studying with the flashcards has its problems. “... when I do my note cards it's real easy to just say oh yeah, that's what I meant, and flip it over. (laughs)"

$\mathrm{GD}_{\mathrm{M}}$ chose note cards from among other study methods specifically for anatomy as a best method for that topic.

Yeah, I hate to make it sound like I use flash cards all the time, too, because I don't. It's just that it seemed like the best method for learning anatomy. For learning, not even for learning anatomy though, just 
specifically for a muscle, its origin, its insertion, its innervation. There are three, and action, there are four things that can go on one note card about one thing. So it seemed to be the best method.

For the rote learners, the method of studying with note cards, which promotes memorization, was well-suited to their view of learning. $\mathrm{DK}_{\mathrm{R}}$ expressed both a reliance on note cards and a comfort level with this method, saying "Flash cards I'll probably do the rest of my life." Because of the time investment in creating the note cards, $G_{R}$ switched to pre-made cards, eliminating the benefit gained by creation of the cards. $\mathrm{GJ}_{\mathrm{R}}$ : Yeah, I stopped making flash cards.

I: You stopped?

$\mathrm{GJ}_{\mathrm{R}}$ : Yeah. The only ones that I use still are the pre-made ones. I bought pre-made flash cards for the muscles and I use them still for origin insertion, action, function, innervation. But ... I stopped making those because that would take me days alone to do that and so I used that time instead to just read through the notes and I definitely think it worked a lot better this time.

For the meaningful learners, flash cards or note cards represent a level of learning that may have been sufficient in the past, but is no longer appropriate for this level of their education. Rote learners have not yet progressed beyond the notion that memorization and learning are one in the same. This concept is revealed further in the differences between groups in metacognition. Also, the reliance on particular study habits, such as flash cards, gives some insight into the difficulty a student might have taking on a new learning and study strategy at this stage in her or his education. 


\section{$\underline{\text { Metacognition }}$}

Metacognition is reported to be an important element in learning information that can later be transferred to new situations (Lin et al., 1994; Shih et al., 1997). Throughout data collection, metacognitive insights were offered by all of the participants. For the most part meaningful learners couched the learning in terms of future application whether it be in classes of the curriculum or application in clinical practice. The rote learners, $G J_{R}$ $\& \mathrm{DK}_{\mathrm{R}}$, did not make mention of future learning and were more oriented to improving test performance.

$\mathrm{CG}_{\mathrm{M}}$ expressed a willingness to actively seek out new ways to learn. For example, the fact that she was aware that "just memorizing" was insufficient for a learning experience led her to adopt concept mapping as a study strategy. $\mathrm{CG}_{\mathrm{M}}$ also realized that her progression through the curriculum and into her profession will require a change in thinking.

I: Do you have any reason to think that you might have to change your study habits in the future?

$\mathrm{CG}_{\mathrm{M}}$ : I know I will have to just because we're starting to get into clinical and I'm realizing that with kinesiology. That it's not enough on paper, I have to be able to just like apply it overall. And I've kind of done that by trying to put it into my own words, but now we're getting from the paper and we're going more towards the clinical stuff and I have to be able to make that change.

I: How do you think you'll be able to do that? 
$\mathrm{CG}_{\mathrm{M}}$ : I'm not sure actually. I'm not sure how, unless it's the practicing versus like index cards. Actually doing motions, or practicing that way. I haven't figured that out yet.

Specifically for anatomy, $\mathrm{CG}_{\mathrm{M}}$ acknowledged that she needs to pay more attention to the "connection" between action and location of skeletal muscles. This is an important point with anatomy. Students often memorize functions of the muscle, along with origin and insertion, but these items are listed as three separate facts on an index card. A muscle's location and orientation as determined by origin and insertion are integral to determining the function of that muscle (and vice versa). This represents a fundamental concept of anatomy, perhaps a subtle one, that if fully understood by the student would increase meaningful learning rather than rote learning for these topics. $\mathrm{JA}_{\mathrm{M}}$ expressly wanted to participate in this research study as a way to enhance her learning power with a new learning technique.

I thought this [participating in the study] was a really great idea for me to kind of boost my study in a way. Because I knew that it would add a different dimension other than just studying my notes and using my atlas and those kind of things. So, it was kind of exciting and right off the bat I thought I should do it.

$\mathrm{JA}_{\mathrm{M}}$ also demonstrated an ability to look forward to her professional career and realize that what she was learning serves as a foundation for future learning. In a followup question to her second interview, $\mathrm{JA}_{\mathrm{M}}$ was asked what the biggest change in her thinking was since she had started the professional phase of her education. Her response was, 
That getting As in subjects means everything, when in actuality it doesn't. I have tried to focus on how to be a good clinician. I try not to focus only on the material we have learned, but instead on how I can use it and be the best PT possible.

$\mathrm{SJ}_{\mathrm{M}}$ had a metacognitive insight about learning for her profession that represented a change from her previous approach to learning.

I: How about for clinical classes, do you think it'll be the same with that? $\mathrm{SJ}_{\mathrm{M}}: \ldots$ No, I think it will be a little different, like I think I'll have to study even more to remember than what I am doing this year. ... in the past ... it was kind of like memorize it for the test. And ... you would pick up some things but ... this year, when I study I know that I have to study and remember this stuff for the rest of my life really and I think it's going to be even more so with the clinical classes to really not just memorize things but actually learn it and remember it.

$\mathrm{SJ}_{\mathrm{M}}$ especially appreciated the linking and crosslinking aspects of the concept maps. This was reflected in the concept maps that she submitted for feedback. $\mathrm{SJ}_{\mathrm{M}}$ 's concept maps were by far the most well-integrated and net-like in structure of all the participants in the concept mapping group. $\mathrm{SJ}_{\mathrm{M}}$ mentioned that she saw benefit in constructing the concept maps for finding connections among topics in her notes.

I haven't really studied them [concept maps] much yet, but I think that when I do, it'll be really good because it, like I said earlier about connecting things. I think it'll help me a lot to do that because I don't always connect the things when I study my notes. 
This observation is in line with $\mathrm{SJ}_{\mathrm{M}}$ 's description of herself as an "active learner." She preferred to use activities to help her to learn and remember essential information. She admitted that some study methods, such as flash cards, make it easier to let yourself slide by without really learning. She also made reference to the worth of a study activity being enhanced if one "does it right" by engaging with the activity at a deeper cognitive level.

$\mathrm{GD}_{\mathrm{M}}$ made several metacognitive remarks throughout the focus group and individual interviews. It is interesting to note that he was a unique participant in that he was the only male in the concept mapping group from whom qualitative data were collected and he was also the oldest member of the group. In one of the individual interviews, he explained the difference between himself and his classmates in approach to learning.

I'm not used to, here's something. This is something that really blows my mind. I don't know if it will help you in your study, but when I sit in those classes, nobody will ask a question. They're like all scared to death to ask, those young kids. I mean, very seldom here. If you've ever taken a class, like a weekend program class with all adults. You learn so much! Especially like when I took that physiology, the A\&P, I took it at CCAC, there were a ton of nurses in there that were LPNs coming back to be RNs. And they knew everything about everything. They would tell you about drugs. It was so interesting, and you couldn't, it was all side stuff that helped you, that kept things concrete in your head, mind. And that's probably the hardest thing because, I mean, everyone in those classes are 
okay let's put our time in here, let's get the hell out of class. (laughs) You know, take the notes, let's get out of here. There are no questions and I don't see a lot of people really understanding. Especially physiology, what was going on there. I mean what they were supposed to get out of it, so. That was the hard adjustment for me. I don't know. There were a lot of really, really great students here, too, who do absorb it. I don't know how they do it at that age.

Another example of a difference between $\mathrm{GD}_{\mathrm{M}}$ and other participants was his reference to knowledge accumulated from work experience or previous academic experience specifically playing a role in his current learning. $\mathrm{GD}_{\mathrm{M}}$ also made an effort to selectively study content that specifically related to his perception of OT practice. $\mathrm{GD}_{\mathrm{M}}$ tried to avoid memorization in favor of learning the general concepts that would enable one to figure it out when needed.

I don't memorize. Now I don't memorize things, small points, little detailed stuff. I just try to look at the general concepts behind it and I try to relate the general concepts to other things. And if I get the general concept I'm fine.

$\mathrm{GD}_{\mathrm{M}}$ suspected that he may have to resort to memorization for certain content areas, like when learning muscle origins and insertions. However, for kinesiology the ability to move the body and observe the movement helped this participant. Other participants brought up this idea as well, but $\mathrm{GD}_{\mathrm{M}}$ seemed to have the most insight into how understanding motion has to do with observation. 
$\mathrm{GD}_{\mathrm{M}}$ : It's tough to move from learning science to using science, and I

think that's where they struggle.

I: So Kinesiology is using it?

$\mathrm{GD}_{\mathrm{M}}$ : Yeah, and a lot of sifting through the test questions, a lot of those people who are not doing well were memorizing notes, which I do, but a lot of those test questions could have been answered just by sitting there and doing the motion. Particularly on the last test, I bet $30-40 \%$ of the material that was on there I was able to just do the motions sitting there in my seat and know exactly what was going, needed to be done. It's kind of like that posterior tibial thing that screwed me up the other day. If you can do all of those motions, you know, the valgus stress, what ligaments stress, just do it. Instead of memorize it, just do it. You are sitting there, just do it. You can see what is being compressed and what's being stretched. I think it's really tough for a lot of those people who aren't doing well, to just get that across and forget. Read it in your notes, but don't memorize it. You are not going to remember. You're not going to be able to spit it out. If I asked you that three weeks from now, you're not going to able to spit it out, you're going to have to do it and see what's happening. I think that's where a lot of problems occur.

The rote learners, $\mathrm{GJ}_{\mathrm{R}} \& \mathrm{DK}_{\mathrm{R}}$, differed from the meaningful learners in their metacognitive insights. Both rote learners described themselves as "crammers" and procrastinators when it came to studying. They both also seemed to be firmly entrenched in the notion that memorization and learning are the same thing. 
For me ... studying is ... memorization ... I mean, I understand what I'm doing and once I've studied it, I'll remember it and I can apply it to things outside of class. ... when I go home and my dad's like Oh this hurts right here, what is this? ... I remember it and I know what he's' talking about, but the first time around and for a test, it's almost always strictly memorization. $\left[\mathrm{GJ}_{\mathrm{R}}\right]$

$\mathrm{GJ}_{\mathrm{R}}$ explained the reason that she did not feel completely comfortable taking up a new way of studying. In particular, for concept mapping she expressed a reluctance in this way.

Well number one, I'm ... a crammer. So, I know what's going to happen, I'm going to go to study this stuff and I'm going to look at these concept maps and they're not going to be specific enough so I'm going to end up doing the concept maps and then my normal method of studying which is just going through and memorizing ... stuff, just ... reading it. And so I'm probably going to take more time, this time studying with concept maps than I would just learning the information, because I'm going to... I couldn't possibly fit all the specifics in my concept map. Or else you'd have like this 8 page poster. ... (laughs)

$\mathrm{GJ}_{\mathrm{R}}$ expressly avoided using the features of concept mapping that seem to connect it most closely to Assimilation Theory, the links and crosslinks.

$\mathrm{GJ}_{\mathrm{R}}$ : Yeah, things that already have that ... flow to them, then it's easier for me to make the concept maps. But if they don't have the connections already laid out for me, forget it. 
I: So you have a hard time making the connections yourself or you just don't want to?

$\mathrm{GJ}_{\mathrm{R}}$ : Yeah ... both. I think both.

I: Why is it hard for you to make the connections, you think?

$\mathrm{GJ}_{\mathrm{R}}$ : I think it's because of how I learn things. Because I just ... memorize things. Not that I just memorize it and forget it. I memorize it and I'll remember it, but it seems like when I try to make connections, it's just even more added work to what I already have to do. Whereas if you memorize it, you memorize it, you know it, that's it. Like.

Similar to $\mathrm{GD}_{\mathrm{M}}, \mathrm{GJ}_{\mathrm{R}}$ found that kinesiology can be figured out by simply going through the motions. However, first one must memorize the particulars in order to learn it. To $\mathrm{GJ}_{\mathrm{R}}$, kinesiology did not represent a real challenge because the concepts were all “common sense."

I: Have you run into any topics in kines[iology] that you memorized it but it doesn't really stick?

$\mathrm{GJ}_{\mathrm{R}}$ : Not really because kines[iology] is more of an everyday thing. You just don't think about it. I think. I mean motions like to walk. ... it's stuff you use every single day. And then once you know it, you can apply it and remember it, but to learn it you just have to memorize it.

$\mathrm{DK}_{\mathrm{R}}$ describes her own learning style as "visual" requiring pictures or drawings to understand concepts. This would seem to imply that concept maps work well for this participant, however, she went on to explain further in the focus group interview, 
I didn't have any trouble with the software, but on the other hand I have never ... done any concept mapping before. So it was a new idea to learn. A new process. And I don't know if it, hopefully I'll benefit from it, but like said before, I think I'm better off whenever it comes to reading notes and not even necessarily memorizing but just understanding what I'm reading. That's it.

However, like $\mathrm{SJ}_{\mathrm{M}}, \mathrm{DK}_{\mathrm{R}}$ also acknowledged that a new study method takes an effort in order to be worthwhile, but one must also be "open" to trying a new way. By the end of the fall semester, $\mathrm{DK}_{\mathrm{R}}$ was considering her study habits as one of the vehicles that led to her failure to matriculate. $\mathrm{DK}_{\mathrm{R}}$ stated that she had enjoyed the anatomy class and felt that she had learned a lot, but what she learned was not reflected on the exams, because she would "freeze" when she got to the test. She mentioned that she did want to figure out where her faults were with studying.

\section{$\underline{\text { Summary Research Question Six }}$}

When describing their experience with a new study technique students spoke about the conditions under which that new strategy is introduced. For these students, the fall semester of the third year was a particularly stressful one in which the course content was voluminous and academic demands were more stringent than in previous semesters. In addition to the stress, the students also described the study habits that have helped them to be successful in the past and with which they have the most comfort. When describing the change from previous habits, members of both the meaningful learner and rote learner groups mentioned an increase in time and intensity of studying from previous years. However, meaningful learners also made mention of a change in the quality of 
their studying to include future applications of the knowledge in the curriculum or in the work place. Flash cards, an example of a tried-and-true study method, were viewed differently between groups. The meaningful learners tended to avoid flash cards because they promoted rote learning. (Although one of the meaningful learners thought that note cards might be the best way to memorize details of muscle anatomy.) One rote learner expected to use them for the rest of her learning career, even though the note cards as a primary study method did not lead to successful matriculation into the spring semester. The other rote learner discontinued making her own note cards because of the time investment, but did continue to rely on pre-made cards. Finally, metacognitive insights revealed that meaningful learners expressed more of an orientation to the role of current learning in the future curriculum and clinical practice. They sensed a change in how information was being presented as well as how information would be expected to be used in the future. Rote learners, who continued to rely on memorization for learning, did not convey a sense that they understood learning to involve anything more than committing facts to memory.

\section{$\underline{\text { Research Question Seven }}$}

Research Question Seven asked: What are students’ perceptions regarding concept mapping as a study tool? Concept maps, within the context of electronic concept mapping, were considered separately from being a novel study approach. In answering this question, aspects of concept mapping that had to do with it being a new study method or as a condition of participating in the study were eliminated. From the remaining aspects, related to the technique of concept mapping, several themes emerged. The first theme, Versatility, speaks to the various applications that the students used or anticipated 
for concept maps or for the Inspiration ${ }^{\circledR}$ software. Concept Map Construction emerged as a theme to represent the benefits that could be gleaned by the students through actually constructing the concept map. Some of the benefits were realized while others, although anticipated, were not. The use of concept maps to provide a General Reference for studying emerged as a theme when participants related the limitations of studying anatomy in particular with concept mapping. Participants also spoke of the Time Commitment required for concept mapping. Few students spoke about the value of concept mapping as a method for drawing Connections among various ideas with anatomy and kinesiology. However, this theme revealed the most difference between members of the meaningful and rote learner groups. Finally one theme, Appearance, related primarily to the computerized version of concept mapping and the options provided by the software to enhance the visual display. Figure 5.2 shows a concept map of the major themes involved with Research Question Seven.

The meaningful learners and rote learners had varying opinions on a few different themes that emerged to illustrate the value of using concept mapping to learn anatomy in particular. For example, one suggestion was raised that the concept map is well-suited for learning anatomy because the symbols and links can be placed on the page to resemble the actual anatomical arrangement of various structures. However, there was less of a distinction between the meaningful learner and rote learner groups with respect to the themes that emerged in response to this research question. This could be the difference between the theoretical and the practical. When discussing the students' experience with a new study strategy, one can draw conclusions based on the students' theoretical approach to learning and their feelings toward change. However, when asking 
specifically about a particular study technique, in this case concept mapping, the practical application of the strategy is revealed.

Figure 5.2 Themes for Research Question 7

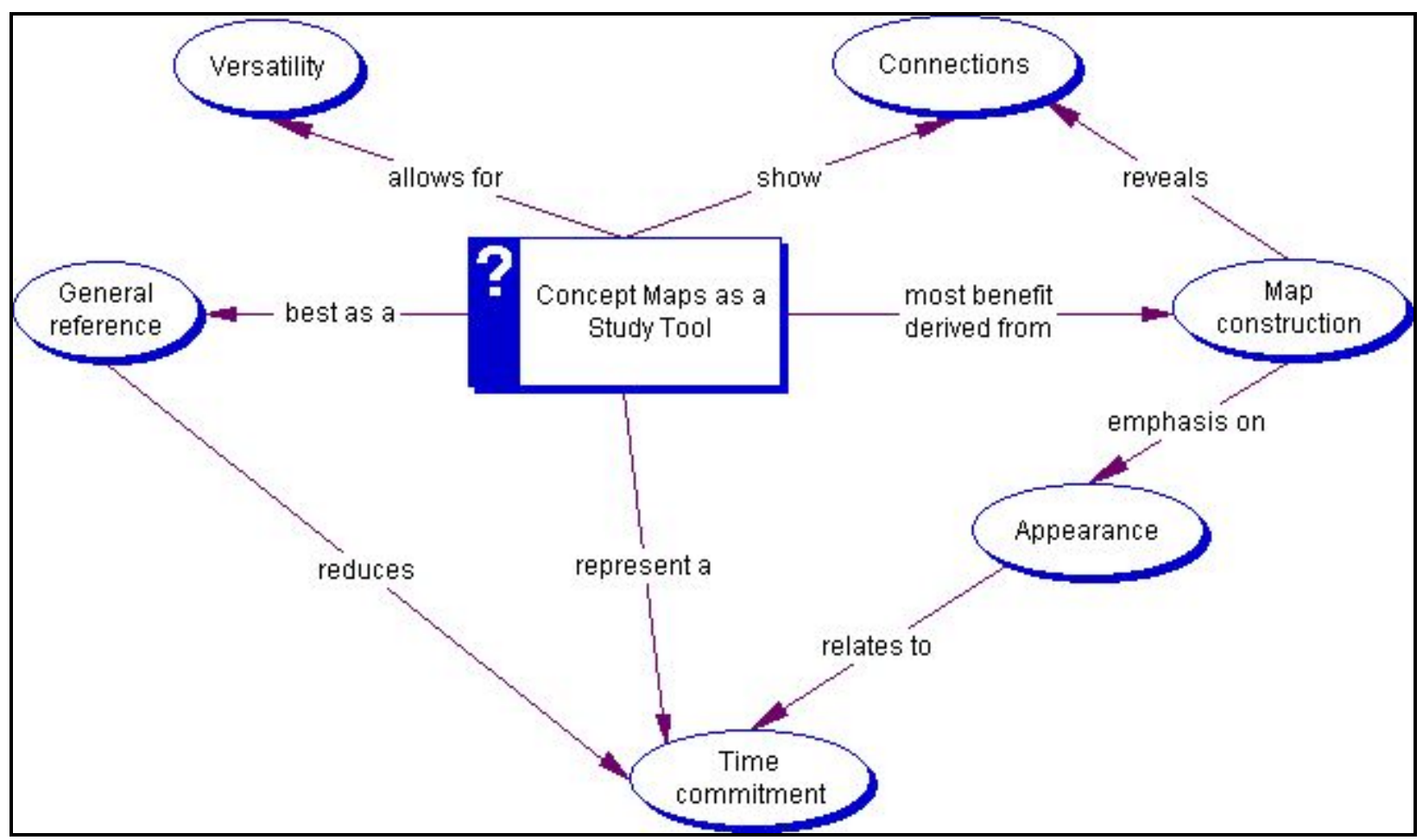

Versatility

Each of the participants was able to see potential uses for concept maps in their learning, even if concept mapping was not viewed as the most effective study method for anatomy or kinesiology.

I: Do you plan to continue to use concept maps at all?

$\mathrm{GJ}_{\mathrm{R}}: \ldots$ I think it would all depend on the type of class. ... I don't think I

would for anatomy any more, just because I found that other ways just

seem to work better for me for that class. But, and I don't know what 
kines[iology] is going to be like. I could see it working a little bit better for kinesiology just because you could ... focus on ... one joint at a time.

Students developed a variety of ways to use concept mapping and in particular electronic concept mapping. $\mathrm{CG}_{\mathrm{M}}$ asked the researcher for help in finding a way to manipulate the software to allow her to construct a concept map to make some of the symbols blank so that she could use that as a study exercise. She filled in the blanks as a self test of her knowledge for anatomy. $\mathrm{GD}_{\mathrm{M}}$ liked the software as a tool to make his own thinking more readable and neat. He liked to study with flow charts and this software allowed construction of flow charts to be easier than with word processing software. $\mathrm{JA}_{M}$ described several possible future uses for concept mapping primarily as a supplement to the activities she is already doing.

... I would definitely, when I'm done, let someone use it ... I think it was good. I'll actually offer it to somebody later or at least say, hey go get this, because when you're doing a presentation or want to do something other than just charts or writing things out.

Some of the participants felt that concept mapping was not the best method for learning anatomy, but suspected that it might be appropriate for other courses. However, only one student actually did concept map for other applications. It is interesting to note that the one student who failed to matriculate because of inadequate grades in a concurrent physiology course, offered that concept maps might be an appropriate study strategy for physiology. However, she did not use them for that course. 


\section{Concept Map Construction}

Several students alluded to the importance of actually using the construction of the concept maps as the learning exercise rather than studying the map after construction. This theme supports the findings of research that show there is more value in constructing concept maps than in studying concept maps constructed by experts (Jonassen, 2000; McCagg \& Dansereau, 1991). At the beginning of the study, the concept mapping group was instructed with the method for constructing concept maps as described by Novak and Gowin (1984). The students were asked to brainstorm and select key concepts from a topic that had been taught in anatomy and then to prioritize the concepts such that the most inclusive concept was listed first and the least inclusive listed last. Next, each student was to construct a concept map using the hierarchical list filling in appropriate linking words to illustrate the relationship between the concepts. Finally, the students were to complete the map by inserting appropriate crosslinks (i.e., links that connected or defined a relationship between concepts on different vertical threads of the map) on the concept map.

The method Novak and Gowin (1984) described is an activity that allows the concept map to serve as a vehicle to show what the mapper knows about a particular topic. However, the participants often did not follow the instructions for creating concept maps. Instead, the participants created the concept map directly from their notes. In some instances, that method amounted to no more than copying one's notes. The participants realized this and spoke to the value of concept mapping if it is done "right." $\mathrm{SJ}_{\mathrm{M}}$ described the pitfalls that can reduce the value of concept mapping as a study strategy. 
$\mathrm{SJ}_{\mathrm{M}}$ : I think that it could ... be really good if it's done right. ... if you take the time to make sure that everything is linked right and you don't do it just to turn it in and you don't worry about ... how pretty it is. ... if you really do it the right way. And not necessarily putting more time into it, just maybe some more thought. I think it could be very effective.

I: What keeps that from happening?

$\mathrm{SJ}_{\mathrm{M}}:$... I think just not waiting 'til the last minute, because I know I do that, too. And then, but I don't know if when I actually do it I learn that much from it because I just kind of like, all right, well I just have to get this over with and I think if you thought about it more, it was like yeah, this does link this. And then, I think that would be better. So I think it's just more thinking about what you're doing instead of just doing it.

$\mathrm{DK}_{\mathrm{R}}$ also referred to the value of concept maps as a study tool as being a function of the circumstances under which the concept map was made. In a way, this is the same as several participants views of flash cards. It is easy to move along and allow yourself to believe that you know the content when you really don't.

I: Did you tend to do those from your head, or did you kind of have your notes open and then go from there?

$\mathrm{DK}_{\mathrm{R}}$ : Usually, my notes were open. That might have been helpful too, if I kind of tested myself in the sense that if didn't know then I could go look at it instead of just looking at the answers all the time.

$\mathrm{GJ}_{\mathrm{R}}$ used the concept maps as a way to reinforce the notes that she took in class. By looking through her notes as she was constructing the concept map she could clarify 
points that might have been missed while taking notes in class. $\mathrm{GJ}_{\mathrm{R}}$ also used her notes as a way to structure the concept maps. She spoke directly about one of the features of the software.

$\mathrm{GJ}_{\mathrm{R}}:$... I just made them [concept maps] ... from my lecture notes. I would get out my binder and take a section ... just things that I needed the most work on. ... usually it was about 10-12 pages of notes, leaf through them first, like get a general idea of how I wanted to organize it. And then, ... I always used the ... lightning bolt.

I: Rapid fire.

$\mathrm{GJ}_{\mathrm{R}}$ : Rapid fire. I always used those and I would get my general headings ... out there and organized those first. And then I'd just go through one by one and ... using the rapid fire again, ... add specifics to each one of the general topics.

A few of the students mentioned that constructing the concept map helped them to better organize their thinking. $\mathrm{SJ}_{\mathrm{M}}$ also thought that constructing the concept maps actually could serve to clarify her thinking. "The concept maps seem like they will be helpful in organizing and connecting my thoughts and the info[rmation] that I need to learn."

Constructing the concept map is intended to be more of a metacognitive activity than copying notes or making flash cards. The difference, from a constructivist perspective, is that constructing the concept map allows the mapper to structure the knowledge in an individual way to allow for meaningful learning. This differs significantly from the rote learning method that occurs with copying one's notes or 
making flash cards which relies on verbatim repetition of information as a method to aid recall. However, the value of any study strategy is related to the amount of effort or mental engagement that is made in using it. In the case of concept mapping, the rote learners tended to construct the concept maps rotely and the meaningful learners tended to construct them in a meaningful way. The exception to this rule was $\mathrm{GD}_{\mathrm{M}}$, a meaningful learner who constructed concept maps in a rote style.

\section{General Reference}

Several of the students saw concept maps as an insufficient method for learning anatomy because success in the course depended on mastery of a high level of detail. On the other hand, some students saw this as an asset that would prohibit concentration on details at the expense of learning the overall concepts. $\mathrm{CG}_{\mathrm{M}}$ appreciated the fact that concept mapping is not conducive to inclusion of many details as a way to avoid falling into the trap of memorizing for a test rather than really learning information.

And, the fact that it's [the concept map] not all detailed, you have to kind of fill in the blanks, which is the point, but if ... you're geared toward memorizing, then it's not going to work because you have to fill in the blanks yourself. And there's not enough details there to do that. $\left[\mathrm{CG}_{\mathrm{M}}\right]$ $\mathrm{JA}_{\mathrm{M}}$ turned the limitation regarding details to her benefit by then only concept mapping those topics with which she was having the most difficulty.

I think I would try to isolate it to a certain region or to a certain topic, just because for example, if I did the whole brachial plexus, like I could have done all the trunks and terminal branches and everything like that and then could have done all the regions it went to, the muscles it went to, the 
functions of those muscles, it just would have gotten too big so maybe I wouldn't have picked something like that. Even with the heart I would, I limited it to the flow of blood coming into the heart where it goes from there going out, back into the system. So I didn't go into all the parts, like all the structure of the wall and stuff like that. I would try to limit it to something that I thought I really need to know. [JA $]$

Other participants, $\mathrm{DK}_{\mathrm{R}}, \mathrm{GD}_{\mathrm{M}}$ and $\mathrm{GJ}_{\mathrm{R}}$ found that creating a concept map that depicted the necessary level of detail was not "practical." $G J_{R}$ found the limitation of not being able to show sufficiently detailed information to be a real detriment when it comes to the testing.

I: It sounds like ... the concept maps didn't allow you to learn the specifics enough.

$\mathrm{GJ}_{\mathrm{R}}:$ Right

I: So ... what you wanted to focus on ... was more of the specifics.

$\mathrm{GJ}_{\mathrm{R}}$ : Yeah, because that's what always seems to be on the test ... there's some general concepts, but ... overall like if you don't know specific things that ... everything does then you're in trouble.

Overall, there were several references to the value of concept maps being in how well they condensed information into a more portable form. Several students spoke of the benefits of trimming a complex topic down to a single-paged concept map. However, particularly for anatomy, mastery of general concept maps was not sufficient for success on examinations that focused on accurate recall of specific details. This finding reinforces 
the notion that testing that focuses on verbatim recall of facts will encourage rote learning methods (Bolte, 1999; Markow \& Lonning, 1998).

\section{$\underline{\text { Time Commitment }}$}

An important recurring element was the time commitment required for concept mapping. This finding was also supported by research that found students' most frequent complaint regarding concept mapping to be the time it takes to create a quality concept map (Bolte, 1999). For the most part, the participants felt "hectic" and rushed, "bouncing" from one test to another in the fall semester. They did not want to risk wasting their study time. None of the participants replaced an established study habit with concept mapping, therefore concept mapping added to an already hectic studying schedule.

The estimates among the students varied from a low of 20 minutes to a high of 2-3 hours to construct each concept map. Some of the students constructed the concept map in one sitting. Others gradually built the concept map over the course of several days, adding and revising as they progressed with their studying. With respect to concept mapping, there was a range of perceptions that related to whether or not the time spent concept mapping was worth it.

\section{$\underline{\text { Connections }}$}

Concept maps are promoted as a method to encourage metacognition that accompanies meaningful learning (Jonassen, 2000). The primary benefit of concept mapping is to allow students to articulate or construct connections or links among the various concepts they are learning for any particular topic. Articulating these connections 
is designed to enhance the memory of the students by attaching the concepts to learning that has taken place in the past as well. Connection also serve establish a more intact structure for new learning.

As a benefit to participation in the study, the members of the concept mapping group received feedback from the researcher on concept maps that were submitted. See Appendix A for an example of a concept map with feedback. By far, the most frequent reminder by the researcher was for the concept mapper to look for places to insert crosslinks. This feedback was to encourage the concept mappers to pull together information and promote meaningful learning. Another frequent comment with the feedback was for students to make explicit the nature of a drawn link with words to describe the relationship between the two linked concepts. Labeling the link requires the concept mapper to articulate the relationship between two concepts. The articulation of the relationship of the link provides evidence that the concept mapper understands the relationship or has a misconception.

Drawing connections was a conspicuous area of difference between the rote and meaningful learners. On the whole, the concept maps of the meaningful learners had far more crosslinks than concept maps of the rote learners. The meaningful learners presented concept maps that had well-labeled links and crosslinks. $\mathrm{SJ}_{\mathrm{M}}$ particularly saw the value in connecting ideas.

I think most the learning I did ... with my usual studying, but I did look at them [concept maps] some for the final and I think it was ... a good ... supplement. It helped me to ... pull things together ... I did my studying 
the way I always do and then everything that I learned ... I was able to see where things related more with that. $\left[\mathrm{SJ}_{\mathrm{M}}\right]$

GD 's concept maps were the exception to the rule. Although $\mathrm{GD}_{\mathrm{M}}$ expressed thoughts that revealed him to be a meaningful learner, the concept maps he produced were more characteristic of a rote learner. However, $\mathrm{GD}_{\mathrm{M}}$ admitted that he did not spend a great deal of time constructing the concept maps (his was the estimate of 20 minutes) and he often forgot when a concept map was due. $\mathrm{GD}_{\mathrm{M}}$ reported that he did not use crosslinks although he recognized the crosslinks and thought about them. He said that since he knew them mentally, he did not need to write them out.

But I did look at them [the concept maps with feedback from the researcher] and it was kind of funny because when I was typing them up I knew you were going to put ... where's the links here? And I had them in my head. ... I know what the links are mentally. ... I don't need to write them out. $\left[\mathrm{GD}_{\mathrm{M}}\right]$

Tacit understanding of relationships among concepts is what is meant to be elicited with concept maps. By neglecting to make explicit the relationship, $\mathrm{GD}_{\mathrm{M}}$ did not take full advantage of the opportunity provided by concept mapping to ensure understanding of the topic. Although, this is not a completely rote use of concept mapping since the crosslinks and links are at least recognized, if not described by the mapper, it is not a completely meaningful activity either. One study reported improved recall of infectious disease information in postsecondary health sciences students with mental networking. However in this study, students were explicitly trained to network with metacognitive 
cues (De Simone et al., 1999). It is not clear that $\mathrm{GD}_{\mathrm{M}}$ used similar thought processing while constructing his concept maps.

The rote learners found that drawing crosslinks and labeling links was very difficult. $\mathrm{DK}_{\mathrm{R}}$ used her own study method of drawing pictures which she compared to concept maps in that the drawings were meant to connect ideas. However, while concept mapping she found that recognizing and describing links was difficult. $\mathrm{GJ}_{\mathrm{R}}$ admitted that she did not feel inclined to make crosslinks on her concept maps or draw connections among various concepts. She instead tended to rely on the links or crosslinks that were presented to her in the class. "Things that already have that ... flow to them, then its' easier for me to make the concept maps. But if they don't have the connections already laid out for me, forget it."

Fundamentally, crosslinks are the features that make concept maps unique as a study tool. Presumably, the effort a learner puts into accurately depicting links and crosslinks on a concept map pays off with a better integrated understanding of the content being mapped. For the most part, the meaningful learners found benefit in constructing crosslinks. The rote learners perceived the activity of creating and describing the links and crosslinks as extra work with little pay off.

\section{Appearance}

Finally, this study used electronic concept mapping as the intervention because of the constructivist idea that the computerized concept mapping could extend the thinking of the concept mapper beyond the abilities of paper and pencil versions (Jonassen, 2000). As a consequence, using the Inspiration ${ }^{\circledR}$ software added another element to the creation of the concept map by offering a multitude of features that could enhance the visual 
display of the concept map. These features related to use of color, a wide variety of symbols, capability to add symbols to the palette, different structural arrangements, and options for changing the size of the concept map to fit a particular number of pages. Participants had varying opinions on whether these features were beneficial or not.

$\mathrm{CG}_{\mathrm{M}}$ mentioned using concept maps as particularly helpful for anatomy because the mapper could use the anatomy to structure the map. This was a major benefit for using the appearance of the concept map to resemble the anatomy to some extent. It was useful for me for ... learning anatomy mostly because it's visual. Like the bubbles you can sometimes arrange them.... when I was doing the hand, I arranged them to move lateral to medial or medial to lateral so I can see it and then it flows that way. I can place them on the body and place them in my head.

An apparent disadvantage to using the software was the students' preoccupation with how to arrange the concept maps so that they looked nice. Often, discussions mentioned that a lot of time was spent arranging and rearranging the icons so that the concept map would be easy to read. On the other hand, students also mentioned that they used the software to their advantage for color-coding particular groups of ideas, or arranging the icons to resemble the anatomical structure or to represent the direction of flow.

$\mathrm{DK}_{\mathrm{R}}$ suspected that she spent so much time fiddling around with the appearance of the map, that she did not reap the full benefits of the learning that could have taken place. 
$\mathrm{DK}_{\mathrm{R}}$ : I honestly don't know if I'll continue using them [concept maps]. I agree with the fact that it did take me a lot of time. I was more particular about where everything was placed to make it look neat. And so I think that took up a lot of time. Maybe if I didn't worry about it so much it would be helpful.

I: ... Your concern to how it looks, was that related more to knowing that I'm going to look at it?

$\mathrm{DK}_{\mathrm{R}}:$ No, it's more me.

I: Okay

$\mathrm{DK}_{\mathrm{R}}: \ldots$ when I look at things, I like them to be neat. It's a terrible pet peeve of mine. If I can't read and see how something's arranged then it's not going to work for me.

$\mathrm{SJ}_{\mathrm{M}}$ also spent time to arrange the concept maps so that they looked nice with an array of colors, links, crosslinks and symbols. Her concept maps were by far the most elaborate and net-like among all the concept mapping group.

I think the drawback I found is there's so many pictures and colors that I spend more time ... making sure it looks good than actually learning the stuff. ... I'm always worried about links going over ... bubbles and ... so I actually tried not to use too many of the pictures 'cause that way I spent less time on that. But for me that's the biggest drawback. .

$\mathrm{GJ}_{\mathrm{R}}$ used colors as an organizational aide and a memory-enhancing strategy. At the end I always color-coded according to different groups, like if you had a group of glands ... those were all green, and then blood supply 
would be orange. I think color coding helped because ... For some reason, when I ... use different colors for things I remember them better.

Whether the concept mapper wanted to the concept map to look good, or resemble the anatomy being mapped, or be color-coded for visual cues, the arrangement of the symbols and links on the concept map mattered to the participants. While the software enhanced the ability to vary the appearance of the concept map, it also allowed the concept mapper to place perhaps too much of an emphasis on the appearance of the map at the expense of the concept map's substance.

\section{$\underline{\text { Summary of Research Question Seven }}$}

The practical application of concept maps as a study tool for anatomy was discussed in this section. Although students were encouraged to concept map for kinesiology, concept maps were not required in the spring semester. Consequently, few participants actually continued to concept map in the spring semester. For that reason, most of the comments related to concept maps a study tool were related to experiences the participants had while concept mapping for anatomy.

Participants from both the meaningful learner and rote learner groups mentioned both positive and negative aspects of using concept mapping to study anatomy. There was little difference between groups with respect to views on concept mapping as requiring a time commitment, or as a versatile tool with many potential applications and features for enhancing the appearance. There were differences between groups found in the theme of concept maps as a general reference. For the meaningful learners, the fact that concept maps do not readily allow for depiction of detailed information was seen as a 
positive feature since it would promote learning overall concepts. For the rote learners, this same feature was viewed negatively because the details were the items being tested in the course. Also, the groups differed with respect to the concept map's ability to help the mapper show or discover connections among various facts being learned. The rote learners, when including crosslinks, added them rotely based on links that were provided by the course instructor. The meaningful learners on the other hand, appreciated concept mapping as a strategy by which they could discover links and crosslinks for themselves. Finally, with respect to the value of constructing the concept map, the rote and meaningful learners both recognized the importance of intent. Members of the both groups realized that in order to gain benefit, one must pay attention to the activity and intend to learn in a meaningful way with it.

\section{$\underline{\text { Triangulation of Methods }}$}

Findings from the qualitative data analysis shed some light on the statistically insignificant findings from the quantitative data analysis for Research Questions One and Two related to improved performance for anatomy and kinesiology in participants who had used concept mapping versus those who had not. Most importantly, the fact that most of the participants revealed that they did not follow the correct procedure for creating the concept maps indicates that the concept maps were not used most effectively as a meaningful learning tool. The students, rather than engaging mentally with the activity, constructed concept maps from their notes in a way that had a very low cognitive investment. For that reason, concept maps could not be expected to have any greater effect on test performance or study strategies than a rote learning activity such as copying one's notes would. 
As was also shown by the qualitative data, flash cards were a popular method of studying for anatomy. This study method promotes rote learning by separating facts to be learned into small chunks of information rather than challenging the learner to search for overarching concepts and relationships among the facts. For example, students often have difficulty associating the anatomy of a skeletal muscle with its function. Flash cards do not promote this understanding. However concept maps, if done with this intent, may have promoted meaningful learning by drawing connections between the origin and insertion of a muscle, with its function.

Whether or not the concept maps help the student achieve the meaningful learning depends somewhat on how the student intends to learn with the method (Garner \& Alexander, 1989; Kember, 1996). Student intent is often driven by expected testing procedures (Thomas \& Bain, 1984). The rote learning required to pass an examination coupled with the students' lack of clinical experience for overt application of the learning, makes meaningful learning very difficult at this stage of the students' education. Given the demands of the semester, it is easy to see how a meaningful learning activity, such as concept mapping, can come to be perceived by the students as an additional burden with little immediate reward. The qualitative data analysis supports that conclusion.

The qualitative results also speak to the quantitative results of Research Question Three with respect to not finding significant difference between groups on the Learning and Study Strategies Inventory (LASSI) subscales. Participants were no longer required to turn in concept maps for kinesiology in the spring semester, although the participants were given the option to submit concept maps for feedback. From interviews, it was 
revealed that students did have difficulty with learning and understanding kinesiology content on occasion, yet there were no concept maps submitted to the investigator in the spring semester. Kinesiology is more abstract than anatomy, requiring ability to conceptualize in three dimensions in order to understand movement. Theoretically, electronic concept mapping with all of the extended capabilities to embed notes and connect to other maps would have worked well as a study method. However, as noted in the qualitative data analysis, the increased density of the concept map required to adequately incorporate the complexity of the topic was viewed as a drawback of the technique. Also, the fact that few participants continued to use concept mapping in the spring shortened the time of the intervention. This reduced period of time may not have been long enough to allow for the development of concept mapping as a study habit. 
Chapter Six Summary, Conclusions, Implications, and Recommendations

\section{$\underline{\text { Summary }}$}

This study examined the use of a meaningful learning tool, concept maps, for learning anatomy and transferring anatomy information to kinesiology in physical therapy (PT) and occupational therapy (OT) students. Meaningful learning is expected to facilitate metacognition to enable transfer of learning. Anatomy and kinesiology serve as foundations for future learning in the PT and OT curriculum. Using concept maps in these topics may promote transfer of anatomy and kinesiology knowledge to other topics in the curriculum. Also, employing a meaningful learning technique early in the professional curriculum may be helpful to students when learning more conceptually complicated topics involving patient care and decision-making.

\section{Purpose and Research Questions}

The primary purpose of this study was to explore the use of concept mapping as a method for promoting meaningful learning in a college anatomy course in order to facilitate learning transfer of anatomy knowledge in a subsequent course, kinesiology. This study links many areas that are involved with this overlying purpose including how PT and OT students study for their classes, what conditions must be in place in order for them to alter their typical studying strategies, and their perceptions of concept mapping. There were a total of seven research questions (RQ) that addressed all of these areas. The first five research questions were studied quantitatively. The sixth and seventh research questions were qualitative in nature. 
RQ 1: Does the use of concept mapping significantly improve $(p<.05)$ academic performance on tests of anatomy knowledge?

RQ 2: Does the use of concept mapping in anatomy significantly improve $(p<.05)$ academic performance on tests of kinesiology knowledge?

RQ 3: Does the use of concept mapping significantly improve $(p<.05)$ scores on the Learning and Study Strategies Inventory (LASSI)?

RQ 4: Is there a statistically significant relationship $(p<.05)$ between kinesiology course grade average and anatomy course grade average and concept mapping?

RQ 5: Is there a statistically significant relationship $(p<.01)$ between anatomy course grade average, kinesiology course grade average and ACT/SAT equivalent scores, GPA, initial LASSI scores, study time and concept mapping?

RQ 6: How do students describe their experience learning with a novel strategy?

RQ 7: What are students' perceptions regarding concept mapping as a study tool?

\section{$\underline{\text { Participants, Design and Data Collection }}$}

The design for this study was a mixed methods design. The quantitative portion was a quasi-experimental pretest posttest design. Quantitative methods were directed at answering Research Questions One through Five. Research Questions Six and Seven were addressed with qualitative methods that sought to elicit the experience of the students as they interacted with the new study strategy, concept mapping. The qualitative analysis also explained to some extent the results found in the quantitative data collection through triangulation of methods. 
The participants were 38 volunteers from the OT and PT students in their third year anatomy and kinesiology courses. The volunteers were randomly assigned to a concept mapping group or a control group. Each member of the concept mapping group was given a copy of Inspiration ${ }^{\circledR}$ software for installation on her or his own computer. Members of the concept mapping group were instructed with the use of Inspiration ${ }^{\circledR}$ software to construct concept maps as described by Novak and Gowin (1984). The concept maps were intended to be a meaningful learning activity with emphasis on drawing relationships among concepts using descriptive links and crosslinks. Members of the concept mapping group were required to submit seven concept maps in the fall semester on anatomy topics. The investigator supplied feedback to the students regarding the content and structure of the concept maps. There was no concept mapping requirement in the spring semester for the kinesiology course, although the concept mappers were encouraged to submit concept maps on kinesiology topics for feedback.

Initial data collection included quality point average (QPA), SAT scores and a Learning and Study Strategies Inventory (LASSI). A researcher-constructed test of anatomy knowledge of the upper extremity (UE) was given to all study participants prior to the concept mapping instruction as a pretest. Members of both the control and concept mapping groups also kept a study journal throughout the fall semester recording time spent and method of studying for anatomy. After instruction on the UE by the anatomy course instructor, all study participants were given the researcher-constructed anatomy test as an immediate posttest. Scores on anatomy course examinations, both written and practical, as well as final anatomy course grade average were collected for all study participants. 
In the spring semester, all participants who had successfully matriculated $(n=30)$ were given the third administration of the researcher-constructed anatomy test which served as a delayed posttest and the second administration of the LASSI. They also got a pre-instruction kinesiology test designed by the researcher to test students on kinesiological applications of UE anatomy knowledge at the first five levels of Bloom's taxonomy. The students continued to maintain study journals recording time spent and method of study for kinesiology in the spring. After instruction on UE topics in the kinesiology course the students underwent the last testing session consisting of the second administration of the researcher-constructed kinesiology examination and the final administration of the LASSI. Kinesiology course final grade averages were also collected for all participants in the spring semester.

The qualitative data collection began in the fall semester. The qualitative data were collected from a variety of sources including a focus group interview, individual interviews, concept maps and study journals. Near the end of the fall semester, a random sample of students $(n=8)$ from the concept mapping group participated in a focus group conducted by the researcher. This focus group sought to elicit student responses to the use of a new study strategy and overall perceptions of concept mapping. From this group the investigator purposefully selected five students, two students with generally positive views of concept mapping and three students with generally negative views of concept mapping. The investigator then selected another student with positive views of concept mapping from the concept mapping group who did not participate in the focus group. These six participants agreed to be interviewed individually by the investigator. 
All six participants were individually interviewed two times during the spring semester, except for one student who did not matriculate and was interviewed only once. Each interview was transcribed verbatim and then returned to the participant so that he or she could read and make corrections, deletions or additions as needed. The interview protocols were semi-structured with open-ended questions. The interviews were tailored to each individual participant with open-ended questions derived from responses provided by that participant in earlier qualitative data collection methods (i.e., focus group, study journal, concept map, first interview).

\section{$\underline{\text { Data Analysis }}$}

The demographic data were initially analyzed to look for differences between groups. Initial results of data analysis for Research Question One revealed a non-normal distribution of a variety of anatomy knowledge scores obtained from the course instructor. Therefore, any analysis involving anatomy course data was done with nonparametric statistics. Otherwise, parametric statistical analysis of data was performed. All of the procedures for Research Questions One through Three involved comparisons of means between groups with independent $t$ tests, ANOVA, ANOVA with repeated measures, or ANCOVA. The non-parametric statistics included Mann-Whitney and Kruskall-Wallis analyses. Since Research Questions Four and Five used anatomy course data, they were analyzed with Spearman's rho correlations. Point bisereal correlations were used to calculate correlations using concept mapping as a dichotomous variable.

Research Questions Six and Seven were analyzed with qualitative methods. Qualitative analysis followed inductive and logical analysis. First, the investigator read the source and looked for emergent themes. Then the investigator sorted the themes to 
look for patterns and dimensions. Finally, the investigator organized the themes on to matrices to look for emergent theoretical patterns. Based on findings from the matrices, the investigator then classified the individual cases in terms of rote or meaningful learning and did a cross case analysis comparing and contrasting the themes between these two groups.

\section{$\underline{\text { Findings }}$}

Initial analysis of demographic data revealed no statistically significant differences $(p<.05)$ between groups for QPA and SAT scores. There were no statistically significant differences $(p<.05)$ between groups for any measures of anatomy knowledge (i.e., researcher-constructed pretest, or instructor-constructed written and practical pretests). On the initial LASSI a statistically significant difference was found on only one subscale, Selecting Main Ideas (SMI). Therefore calculations with the SMI used the pretest score as a covariate.

The null hypotheses for Research Questions One and Two were accepted. Analysis of means revealed no statistically significant differences $(p<.05)$ between concept mapping and control groups for measures of anatomy knowledge or kinesiology knowledge. Post hoc analysis revealed a statistically significant interaction $(p<.05)$ between group and level of item on the researcher-constructed kinesiology test. The concept mapping group scored higher than the control group on low level items for both administrations of the researcher-constructed kinesiology test. The null hypothesis was also accepted for Research Question Three. Again, there were no statistically significant differences $(p<.05)$ between groups for any of the LASSI subscales on either of two posttests. Some of the analyses of variance for Research Questions One through Three 
found statistical significance in main effects, primarily time, indicating the participants increased scores on tests after instruction. However findings indicated no difference between groups on these measures.

Analyses for Research Questions Four and Five found that use of concept mapping did not correlate significantly $(p<.05)$ with final grade averages in either anatomy or kinesiology. A statistically significant correlation $(r=.547)(p<.01)$ was found between anatomy course grade average and kinesiology course grade average. The high correlation between anatomy and kinesiology supports the premise that these topics are closely related and therefore require only a low level of transfer between the two content areas. The null hypotheses were rejected for Research Questions Four and Five because of statistically significant correlations found between kinesiology course grade or anatomy course grade and the various other measures taken.

Power analysis found a high probability for Type II error, revealing insufficient power to confidently retain the null hypotheses for Research Questions One through Three. Therefore, the null hypotheses could not be accepted with a high degree of confidence. Insufficient power may be related to several factors including sample size and effect size (Huston, 1993). In this study both factors may have played a role in the finding of low power. First, the sample was one of convenience and there may not have been enough volunteers to have sufficient power. Also, only 30 participants completed the study, with a loss of six from the concept mapping group and two from the treatment group, bringing the sample size to below acceptable levels from the standpoint of power. Second, the effect size for the concept mapping intervention might have been too small to allow for sufficient power. The effect size estimates the degree to which the independent 
variable accounts for changes in the dependent variable (Huston, 1993). Considering the relatively homogenous group that made up the participants in the study, one would expect to see few differences in course grade outcomes..

Findings from qualitative analysis for Research Questions Six and Seven revealed several things. Students were classified into two groups that reflected dominant characteristics, meaningful and rote learners. They were then compared and contrasted as two case studies. When describing their experience with a new study strategy, participants in both the meaningful and rote learning groups first acknowledged that the fall semester represented a significant departure from previous academic semesters with respect to rigor and volume of material. Students were stressed and overwhelmed. The second theme that applied to members of both groups was the external motivation provided by participation in this study through the assigned concept maps and/or the assigned study journals. Several participants spoke to feeling obligated to keep up or study so that they had something to report on the study journal.

Research Question Six sought to elicit the participants' experience with a new studying and learning strategy. Participants revealed that a new study strategy introduced at this particularly stressful time had both benefits and drawbacks. Some of the participants expressed feelings along a continuum of apprehension. Two of the meaningful learners felt no apprehension about trying a new study technique and had in fact actively sought out a novel approach. The rote learners, and two of the meaningful learners, expressed fear for using a new method that might not work. Findings also revealed varied study habits for these participants. The meaningful learners tended to coordinate various study methods, both rote and meaningful, as an approach to test 
preparation. Rote learners tended to use primarily rote methods. Flash cards were one particular study method often mentioned with respect to anatomy. Meaningful learners tended to disdain the approach as it promotes memorizing. Rote learners held fast to the approach, although acknowledging that flash cards were time-intensive to make. Finally, differences were revealed in metacognition among members of the two groups. For the most part, meaningful learners viewed present learning as a pathway to future learning and clinical applications. The rote learners were more focused on learning to improve test performance. Their primary view of learning was that memorization was the goal.

Research Question Seven sought to describe the participants' overall perceptions of concept mapping as a study strategy. The main themes that emerged in response to Research Question Seven were: a) the Versatility of concept mapping and in particular Inspiration $^{\circledR}$ software, b) the value of concept maps as a General Reference, c) the Connections revealed as a result of concept map construction, d) the pros and cons of the software for changing the Appearance of the map, e) the Time Commitment necessary for developing concept maps, and e) Constructing the concept map the "right way." The differences between the rote and meaningful learners were more blurred in answer to this question than with RQ Six. However, the primary difference was seen in the feature that allows mappers to make connections among topics. Overall perceptions of concept mapping revealed that meaningful learners valued drawing connections among topics. The rote learning students did not see value in this, perhaps because of lack of direct benefit in improved scores on examinations that promote rote learning. The rote learners preferred to add only crosslinks that the instructor had explicitly defined. 
Findings from the qualitative portion of the study helped provide some explanation for the findings of the quantitative research questions through triangulation of methods. Primarily, it was shown that even though the participants were instructed in concept mapping as a meaningful activity as Novak and Gowin (1984) suggested, the participants often produced the concept maps in a rote manner. That is, rather than using the concept maps as a vehicle to show what they knew, they used them in much the same way as recopying their notes. Even the meaningful learners resorted to this method when time became tight and the pressure was high.

\section{Conclusions}

\section{$\underline{\text { Research Questions One and Two }}$}

The null hypotheses for Research Questions One and Two were retained. There were no statistically significant differences $(p<.05)$ between groups on tests of anatomy or kinesiology knowledge. Although anatomy and kinesiology represent steps along the way to problem-solving courses such as clinical courses, the primary method for learning in these classes continues to be rote. Testing methods may emphasize the acquisition of knowledge and not the application of that knowledge in novel ways. The benefits of a meaningful learning method may be too subtle for students to appreciate at this time as well as too inadequate to be revealed in improved scores on tests. Anatomy, a basic science, is a prerequisite course for kinesiology, an applied science. Kinesiology is a "another dimension" to anatomy, as one participant put it. Perhaps the low-road transfer that is necessary did not allow for the meaningful learning benefits to manifest themselves at this level. 


\section{$\underline{\text { Research Question Three }}$}

The null hypothesis for Research Question Three was also retained, as there were no statistically significant differences $(p<.05)$ between groups across time for any of the subscales on the Learning and Study Strategies Inventory. Even though this semester represented a substantially different work load than the students had previously experienced, the study strategies that they employed were not affected by the introduction of a new study strategy. This may reflect a lack of sensitivity in the LASSI instrument, but more likely a failure of the students to make a substantive change in approach to studying.

Although the concept mapping group was required to continue concept mapping for seven weeks of the fall semester, that may not have been enough time to establish concept mapping as a habit in such a way that a change might have been seen on the LASSI. Also, even though some students were concept mapping, they were not necessarily using the strategy in the way that it was intended, as a meaningful learning exercise. Students perceived no benefit nor felt encouraged to pursue meaningful learning by virtue of testing procedures within the anatomy and kinesiology courses. This may have disrupted the intent to pursue more meaningful learning.

\section{$\underline{\text { Conclusions from post hoc analyses }}$}

Post hoc analysis revealed a statistically significant interaction $(p<.05)$ between group and item level on the researcher-constructed kinesiology test. This interaction favored the concept mapping group on low level items for both administrations of the test. This result may be compared to one researcher who used concept mapping as a way 
to increase meaningful learning in genetics and ecology for college-level students. He found that on tests for meaningful learning in those topics (i.e., items to test comprehension, application, analysis, synthesis and evaluation) those students who concept mapped scored significantly higher in both ecology $(t(136)=16.01 ; p<.001)$ and genetics $(t(136)=12.27 ; p<.001)$ than the group who did not concept map (Okebukola, 1990). However, procedures for Okebukola's study differed from the present study in that concept mapping was integrated into the course work on those topics, was modeled by the instructor and also served as a method of grading for those students who used the technique. Therefore, one conclusion that may be drawn is that in order to affect meaningful learning as a strategy that will show results, students must have a seamless integration of that strategy into the classroom, at least initially. This may help to explain the lack of significant difference between groups on overall scores of the kinesology test in the present study.

In addition, Okebukola defined low level items as those in the knowledge category only. This investigator defined low level items as those in both the knowledge and comprehension levels. Members of the concept mapping group scored higher than members of the control group on low level items for both administrations of the researcher-constructed kinesiology test. This was an unexpected result but may be explained in part by the nature of transfer of anatomy knowledge to kinesiology concepts. Even low level kinesiology items (i.e., knowledge and comprehension) requires use of anatomy knowledge in a novel way to the learner. Concept mapping anatomy may have allowed the learner to make the transfer of that knowledge to kinesiology in a more effective way than the methods used by other learners. However, the failure to use 
concept mapping specifically for kinesiology topics would explain the lack of a statistically significant difference on high level items between groups. In other words, constructing concept maps in anatomy might have only allowed the learner to apply anatomical information at low levels to assist in learning kinesiology. In order to improve high level scores in kinesiology, the concept maps would have to be constructed to include kinesiological concepts.

Post hoc analysis also revealed that there was insufficient power to confidently accept the null hypothesis for Research Questions One through Three. This indicates that there may have been insufficient sample size and/or insufficient effect size to make a strong conclusion that concept mapping does not affect scores on tests of anatomy or kinesiology knowledge or learning and study strategies. Given that the nature of learning transfer from anatomy to kinesiology is at a relatively low level, meaningful learning in either of these two content areas might be better assessed in courses that use this information in clinically relevant ways. The acceptance of the null hypothesis (i.e., Use of concept mapping will not have a statistically significant $(p<.05)$ effect on scores on anatomy or kinesiology knowledge.) may not have been appropriate given the results of this study. However, in the event that the null hypotheses were correctly accepted, there were many other factors that may explain the lack of differences between groups. These factors were discussed with the specific research questions.

\section{$\underline{\text { Research Questions Four and Five }}$}

The use of concept mapping did not correlate significantly with any of a variety of factors that may have contributed to success in either the anatomy or kinesiology course. Concept mapping did not make enough of an impact to affect overall scores on course 
grades which is, unfortunately, the bottom line for many students. However, through qualitative analysis it was revealed that students did not adopt concept mapping as a study strategy in a meaningful way although they may have submitted the requisite number of concept maps to continue participation in the study. An analysis of the study strategies used by members of both groups may have been a better dependent variable to include in the correlation analysis. That is, seeing if students in either group used some rote strategies or meaningful learning strategies whether it be concept mapping or not, may have been a better distinguishing category than simply whether they were in the concept mapping group or not.

\section{$\underline{\text { Research Question Six }}$}

The successful introduction of a new study strategy is related to several factors as revealed by qualitative data analysis. First is the amount of stress that a student anticipates or experiences during the time in which the new strategy is to take place. Also, the level of satisfaction the student has with established study habits will affect the introduction of a new strategy. If certain learning strategies have proved beneficial in the past, then there may be apprehension about taking the risk of learning a new study strategy. Finally, the metacognitive insights of the student may reveal whether or not the student is open to the introduction of a new approach. For example, some students have not yet reached the understanding that learning is more than memorization. For these students, even if they do use concept mapping they will use it in a rote way. Students need to be shown benefits from new techniques. For rote learners, this benefit will come in terms of grades. For meaningful learners, the benefits come from better understanding 
and ability to apply information in other contexts, in this case future classes or clinical situations.

\section{$\underline{\text { Research Question Seven }}$}

Concept mapping was valued as a study strategy by the meaningful learners for the ability to connect ideas through the process of creating the map. It was valued by the rote learners for the ability to generalize or condense information. It could be that concept mapping was not introduced at an appropriate time for these students from two perspectives. First, there appears to be a disparity in metacognitive levels for the students. Some students were not ready to appreciate a meaningful learning exercise. Second, the curriculum at this stage is also not ready to promote a meaningful learning strategy, because the emphasis is clearly on acquiring a knowledge base rather than on application of that knowledge. This is not a criticism, since one must first have knowledge in order to manipulate it. However, the researcher surmised that it might benefit students to acquire this knowledge in a way that makes it easier to then apply. For anatomy, the benefits of meaningful learning might have been too subtle for students to notice, or the transfer of anatomy knowledge to kinesiology too overt.

\section{$\underline{\text { Triangulation of Methods }}$}

The qualitative data findings supported and explained to some extent the findings of the quantitative data analysis. For the most part, it was revealed that although students were given the opportunity to concept map, few of them actually used the technique in the way it was intended (i.e., as a meaningful learning exercise). This may serve as one explanation as to why there may have been no differences between groups in scores on 
tests of anatomy or kinesiology knowledge. Students who used concept mapping rotely

had no substantive difference with other students using other rote methods to prepare for the tests in the courses.

The qualitative analysis revealed the importance of quality of study over quantity of study, relating to the intention of the student. However, even when the student intends to learn for understanding or meaning, constraints of time and method of testing that emphasizes rote learning may interfere (Garner \& Alexander, 1989; Kember, 1996). The results of this study support the notion that students will choose study methods with which they are most familiar and have been most successful in the past, and that best match the expectations of the instructor as shown by the testing method. The acceptance of the null hypotheses for those research questions that sought to note differences between groups can also be explained, in part, by the student resistance to both using a novel learning strategy, and using a meaningful learning strategy appropriately.

\section{Implications for Educational Practice}

It is important to note that implications for educational practice were solely derived from the results of this study, since the investigator was not the course instructor for either the anatomy or the kinesiology course. Course instructors may make changes as a result of formative evaluation of the ongoing course. However, as an observer/ researcher with no role in the kinesiology course and minimal role in the anatomy course (as a laboratory instructor and occasional lecturer) implications for educational practice are directed more at the broad scope of teaching undergraduates these topics in a meaningful and transferable way. 
Even when students are shown how to concept map as a meaningful learning exercise, they will resort to the study strategy that is in line with their metacognitive approach to learning. The old adage, "You can lead a horse to water but you can't make it drink," applies. If meaningful learning is valuable to the development of physical and occupational therapists, introducing activities to promote meaningful learning must be carefully considered. The results of this study provide some suggestions for the introduction of meaningful learning activities for these students.

First at least initially, rather than have the students produce the maps independently the instructor should control for and eliminate the students' reliance on course notes to construct the concept maps. This would allow the instructor to challenge students to tell what they know and how they know it, rather than encouraging rote memorization. In addition, the students might benefit if the instructor modeled the concept mapping procedure using the relevant subject matter to relate to current content being learned as well as future applications in the curriculum or clinic. This could be done as a classroom activity that allows for students to observe the expert construction of a concept map, or to participate in construction of a concept map under the guidance of the content expert.

Students, especially highly stressed students, need enough time to develop a habit of meaningful learning. This means not only time building familiarity with a method, but also time to reflect on the process of the new strategy as well as the knowledge being revealed by the strategy. Often the curriculum is packed with information allowing little time for students to reflect on what is being learned. The instructor may promote this type of reflection by allowing students time in class to look for meaning when introducing 
new topics. This could be encouraged by asking students to relate new topics with previous topics or past experience.

Successful integration of a new study strategy requires that students see the benefit from the habit, preferably an immediate benefit. This requires an overhaul of the grading system to some extent. Courses that rely solely on examinations that test rote knowledge, will not have the means to show benefit of meaningful learning practices. Students are results-oriented and the results that matter are scores on examinations. Although many students realize that information will eventually be used in the OT or PT clinic, they still are operating under the constraints that are dictated to them by rules and regulations of the curriculum that rely on grades for matriculation. The method for testing meaningful learning may involve more time on the part of both the instructor as well as on the student. Oral examinations, practical examinations, essay examinations, concept maps or any method that will allow the student to reflect on what has been learned and how that new information can be useful will assess meaningful learning.

Finally, introducing meaningful learning strategies as a curriculum wide effort would take the focus off one particular course in the semester and promote meaningful learning strategies as methods that can be used in many different arenas. Especially early in the curriculum students have difficulty seeing the relevance of basic science information to the day-to-day practice of PT and OT clinicians. By promoting meaningful learning with changes in testing and studying strategies, students will have the opportunity to reflect on learning and how it will benefit them clinically. 


\section{$\underline{\text { Recommendations for Future Research }}$}

The results of this research open up several potential avenues for future research. One is the potential for replication of this study in a way that accounts for some of the variables that may have had an impact on the overall quantitative results. Other areas of inquiry that may be prompted by these results include further study of the roles of metacognition in the education of health professionals and the role of anatomy and kinesiology knowledge in both the professional curriculum and professional practice. Finally, more research may be done on electronic constructivist tools, such as concept mapping, as facilitators for meaningful learning in this population. What follows are descriptions of potential future lines of research to address some of these areas.

With respect to replication of this study there were two areas in particular that may have had the greatest impact on the results and therefore should be further examined. First is the relatively brief time devoted to the intervention. The timing of introduction of a new study strategy is important. In order to help students to develop the skills of concept mapping and metacognition, this study could be replicated with meaningful learning activities beginning earlier and continuing longer in the curriculum. This may allow for the habit to become better established and also span the curriculum from basic science (fact-based courses), to clinical science (concept-based courses). This would allow the students to more easily adapt the meaningful nature of concept mapping to practical situations that would require overt rather than subtle connections to be made. For example, concept mapping a topic that involved a patient with a rotator cuff repair and diabetes could pull together many aspects of care, from the pathophysiology of diabetes to its effects on the healing and tissue repair of the rotator cuff tendons. It would 
be interesting to see if the students who used concept maps glean benefit when it becomes necessary to apply anatomy knowledge to clinical skills such as manual muscle testing and designing therapeutic exercise programs.

Second, from qualitative findings it was shown that many of the students reduced the intention of concept mapping to a rote learning activity. Therefore, in order to see if meaningful learning strategies can promote metacognition, the study must be devised in such a way that rote learning is discouraged. The study could be designed so that there is supervision of the construction of concept maps ensuring that students could not construct the concept map directly from their notes. Rather, the instructor could allow the students to review their notes for a particular period of time then have them close their notebooks and begin construction of the concept map. The student could consult their notes after the concept mapping activity as a way to check accuracy of the information as well as perhaps add further understanding. This would increase the application of concept mapping as a meaningful rather than rote learning activity.

From qualitative findings, there was some indication that metacognitive level influenced the ease with which some students incorporated concept mapping into their typical study habits. Students who take a meaningful approach to learning seem to have more of an affinity for the process of concept mapping as a way to self assess and draw connections. Students who take a rote approach overall may benefit from an early assessment of their learning style and guidance in developing the metacognitive skills required to produce more meaningful learning. Further qualitative research should also examine the existing metacognitive and study strategies of the control group as a representation of how this population tends to study prior to an intervention. This could 
be done by interviewing members of the control group as well as the treatment group to see if there were differences in metacognition and study strategies within this group. The design could probe for what study strategies (other than concept mapping) were used by students with high levels of metacognition. Students with a relatively high level of metacognition may be inclined to devise their own strategies for meaningful learning that may serve the same purpose as concept mapping.

Results of this study also reflected on the underlying theoretical perspective that the computer may serve as a constructivist tool for learning. Since one of the main drawbacks of concept mapping for all of the participants in the qualitative portion of the study was the disadvantage to having greatly detailed concept maps, future research could examine the use of the embedded concept map feature of electronic concept mapping that allows concept maps to be concise but yet deep. The feature would allow the concept mapper to address particular issues initially from a broad perspective, and then to get more specific with a section on a separate concept map. So theoretically, as the learning gets deeper, the embedded maps would allow for the new depictions of knowledge to be mapped without adding clutter to the general outlines.

Finally, the role of anatomy and kinesiology in the further education and practice of the health professions is still in question. Research to determine how this information is used in these arenas would be helpful in understanding the best methods for teaching and learning. 


\section{References}

Agho, A. O., \& Williams, A. M. (1995). Actual and desired computer literacy among allied health students. Journal of Allied Health, 24(2), 117-126.

Alexander, P. A., \& Murphy, P. K. (1999). Nurturing the seeds of transfer: A domain-specific perspective. International Journal of Educational Research, 31, 561-576.

Anderson, J. C., \& Conley, L. K. (2000). Retention of anatomical detail. Journal of Physical Therapy Education, 14(1), 44-47.

Anderson-Inman, L., \& Ditson, L. (1999). Computer-based concept mapping: A tool for negotiating meaning. Learning and Leading with Technology, 26(8), 6-13.

Ausubel, D. P. (1968). Educational Psychology. New York: Holt, Rinehart and Winston, Inc.

Bacro, T. R. H., Murphy, J. C., \& Reeves, B. A. (1997). Integration of an Internet anatomy review of the knee joint in a rehabilitation sciences curriculum: "http://www.musc.edu/chp-rehab/anatomy/kneedemo.htm". Journal of Allied Health, $\underline{26}(2), 159-162$.

Baldwin, T. T., \& Ford, J. K. (1988). Transfer of training: A review and directions for future research. Personnel Psychology, 41, 63-105.

Balla, J. I., Biggs, J. B., Gibson, M., \& Chang, A. M. (1990). The application of basic science concepts to clinical problem-solving. Medical Education, 24, 137-147.

Beissner, K. L. (1992). Use of concept mapping to improve problem solving. Journal of Physical Therapy Education, 6(1), 22-27. 
Bernstein, P., Tipping, J., Bercovitz, K., \& Skinner, H. A. (1995). Shifting students and faculty to a PBL curriculum: Attitudes changed and lessons learned. Academic Medicine, 70(3), 245-247.

Berube, D., Murray, C., \& Schultze, K. (1999). Cadaver and computer use in the teaching of gross anatomy in physical therapy education. Journal of Physical Therapy Education, 13(2), 41-46.

Bolte, L. A. (1999). Using concept maps and interpretive essays for assessment in mathematics. School Science and Mathematics, 99(1), 19-30.

Boshuizen, H. P. A., van der Vleuten, C. P. M., Schmidt, H. G., \& MacielsBongaerts, M. (1997). Measuring knowledge and clinical reasoning skills in a problembased curriculum. Medical Education, 31, 115-121.

Boucher, B., Hunter, D., \& Henry, J. (1999). The effectiveness of computerassisted instruction in teaching biomechanics of the temporomandibular joint. Journal of Physical Therapy Education, 13(2), 47-51.

Buchanan, C. I. (1992). Use of visualization in teaching clinical gross anatomy. Journal of Physical Therapy Education, 6(2), 56-57.

Chi, M. T. H., Slotta, J. D., \& Leeuw, N. (1994). From things to processes: A theory of conceptual change for learning science concepts. Learning and Instruction, 4, 27-43.

Chin, C., \& Brown, D. E. (2000). Learning in science: A comparison of deep and surface approaches. Journal of Research in Science Teaching, 37(2), 109-138.

Chung, K. W. (1995). Gross Anatomy (3rd ed.). Baltimore: Williams and Wilkins. 
Cliburn, J. W. (1985). An Ausubelian approach to instruction: The use of concept maps as advance organizers in a junior college anatomy and physiology course. Unpublished doctoral dissertation, University of Southern Mississippi, Hattiesburg, MS.

Colliver, J. A. (2000). Effectiveness of problem-based learning curricula: Research and theory. Academic Medicine, 75(3), 259-266.

Croninger, W. R., Tumiel, J. P., \& Sowa, T. (1995). The effects of a Hypercard tutorial on student learning of biomechanics. The American Journal of Occupational Therapy, 49(5), 456-460.

De Grave, W. S., Boshuizen, H. P. A., \& Schmidt, H. G. (1996). Problem based learning: Cognitive and metacognitive processes during problem analysis. Instructional Science, 24, 321-341.

De Simone, C., Oka, E., \& Tischer, S. (1999). Making connections efficiently: A comparison of two approaches used by college students to construct networks. Contemporary Educational Psychology, 24, 55-69.

Fiebert, I. M., \& Waggoner, P. (1996). Retention of gross anatomy knowledge by physical therapy students. Journal of Physical Therapy Education, 10 (2), 82-84.

Fitzgerald, M. J. T. (1992). Undergraduate medical anatomy teaching. Journal of Anatomy, 180, 203-209.

Gall, M. D., Borg, W. R., \& Gall, J. P. (1996). Educational Research (6th ed.). White Plains, NY: Longman Publishers.

Garner, R., \& Alexander, P. A. (1989). Metacognition: Answered and unanswered questions. Educational Psychologist, 24(2), 143-158. 
Gest, T. R., Burkel, W. E., \& Waanders, N. A. (1993). Review Questions for Gross Anatomy and Embryology. Pearl River, NY: The Parthenon Publishing Group Inc.

Graham, C. L. (1994). Conceptual development in physical therapy students. Unpublished doctoral dissertation, Texas A\&M University, College Station, TX.

Graham, C. L. (1996). Conceptual learning processes in physical therapy students. Physical Therapy, 76(8), 856-865.

Gredler, M. E. (1999). Classroom Assessment and Learning. New York: Longman Publishing Group.

Guy, J. F., \& Frisby, A. J. (1992). Using interactive videodiscs to teach gross anatomy to undergraduates at The Ohio State University. Academic Medicine, 67(2), 132-133.

Hadwin, A. F., \& Winne, P. H. (1996). Study strategies have meager support. Journal of Higher Education, 67(6), 692-715.

Hammel, J. M., \& Smith, R. O. (1993). The development of technology competencies and training guidelines for occupational therapists. The American Journal of Occupational Therapy, 47(11), 970-979.

Haught, P. A., Hill, L. A., Walls, R. T., \& Nardi, A. H. (1998). Improved Learning and Study Strategies Inventory (LASSI) and academic performance: The impact of feedback on freshman. Journal of the First-Year Experience, 10(2), 25-40.

Heinze-Fry, J. A., \& Novak, J. D. (1990). Concept mapping brings long-term movement toward meaningful learning. Science Education, 74(4), 461-472.

Huston, H. L. (1993). Meaningfulness, statistical significance, effect size and power analysis: A general discussion with implications for MANOVA. Paper presented 
at the Annual Meeting of the Mid-South Educational Research Association, New Orleans, LA.

Johnson, M. A., \& Lawson, A. E. (1998). What are the relative effects of reasoning ability and prior knowledge on biology achievement in expository and inquiry classes? Journal of Research in Science Teaching, 35(1), 89-103.

Jonassen, D. H. (2000). Computers as Mindtools for Schools (2nd ed.). Upper Saddle River, NJ: Merrill, Prentice Hall.

Kanny, E. M., \& Anson, D. K. (1998). Current trends in assistive technology education in entry-level occupational therapy curricula. The American Journal of Occupational Therapy, 52(7), 586-591.

Kaufman, D. M., \& Mann, K. V. (1997). Basic sciences in problem-based learning and conventional curricula: Students' attitudes. Medical Education, 31, 177-180.

Kember, D. (1996). The intention of both memorise and understand: Another approach to learning? Higher Education, 31, 341-354.

Kinchin, I. M., Hay, D. B., \& Adams, A. (2000). How a qualitative approach to concept map analysis can be used to aid learning by illustrating patters of conceptual development. Educational Research, 42(1), 43-57.

Layman, J. W. (1996). Inquiry and Learning. New York: College Entrance Examination Board.

Lin, X., Newby, T., \& Glenn, N. (1994, February 16-20). Embedding $\underline{\text { metacognitive cues into hypermedia systems to promote far transfer problem solving. }}$ Paper presented at the National Convention of the Association for Educational Communications and Technology, Nashville, TN. 
Lonka, K., \& Lindblom-Ylanne, S. (1996). Epistemologies, conceptions of learning, and study practices in medicine and psychology. Higher Education, 31, 5-24.

Lonka, K., Lindblom-Ylanne, S., \& Maury, S. (1994). The effect of study strategies on learning from text. Learning and Instruction, 4, 253-271.

Luttgens, K., \& Hamilton, N. (1997). Kinesiology Scientific Basis of Human Motion (9th ed.). Madison, WI: Brown and Benchmark Publishers.

Markow, P. G., \& Lonning, R. A. (1998). Usefulness of concept maps in college chemistry laboratories: Students' perceptions and effects on achievement. Journal of Research in Science Teaching, 35(9), 1015-1029.

Marton, F., \& Saljo, R. (1976). On qualitative differences in learning: I- Outcome and process. British Journal of Educational Psychology, 46, 4-11.

Mattingly, G. E., \& Barnes, C. E. (1994). Teaching human anatomy in physical therapy education in the United States: A survey. Physical Therapy, 74(8), 720-727.

McCagg, E. C., \& Dansereau, D. F. (1991). A convergent paradigm for examining knowledge mapping as a learning strategy. Journal of Educational Research, 84(6), 317324.

McCracken, T. O., \& Spurgeon, T. L. (1991). The Vesalius Project: Interactive computers in antomical instruction. Journal of Biocommunication, 18(2), 40-44.

McNurlen, G., Gilkeson, G. E., \& Drake, C. S. (1996). Computer-assisted intruction in occupational therapy education. The American Journal of Occupational Therapy, 50(10), 890-893.

Mennin, S. P., Friedman, M., Skipper, B., Kalishman, S., \& Snyder, J. (1993). Performances on the NBME I, II, and III by Medical Students in the Problem-based 
Learning and Conventional Tracks at the University of New Mexico. Academic Medicine, 68(8), 616-624.

Mintzes, J. J., \& Wandersee, J. H. (1998). Reform and innovation in science teaching: A human constructivist view. In J. J. Mintzes \& J. H. Wandersee \& J. D. Novak (Eds.), Teaching Science for Understanding: A Human Constructivist View. San Diego: Academic Press.

National Research Council. (1996). National Science Education Standards. http://books.nap.edu/html/nses/html/index.html: National Academy Press.

National Research Council. (2000). Inquiry and the National Science Education Standards: A Guide for Teaching and Learning. Washington, D. C.: National Academy Press.

Nnodim, J. O. (1990). Learning human anatomy: By dissection or from prosections? Medical Education, 24, 389-395.

Norman, G. R., Patel, V. L., \& Schmidt, H. G. (1990). Clinical inquiry and scientific inquiry. Medical Education, 24, 396-399.

Norman, G. R., \& Schmidt, H. G. (1992). The psychological basis of Problembased Learning: A review of the evidence. Academic Medicine, 67(9), 557-565.

Norman, J. F., \& Boonyawiroj, E. B. (1997). Use of a test of logical thinking with first-year physical therapy students: Classroom performance prediction, at-risk student identification, and change in logical thinking ability. Journal of Physical Therapy Education, 11(1), 32-35.

Novak, J. D. (1990). Concept mapping: A useful tool for science education. Journal of Research in Science Teaching, 27(10), 937-949. 
Novak, J. D. (1992, April 24). A view on the current status of Ausubel's Assimilation Theory of Learning. Paper presented at the American Educational Research Association, San Francisco, California.

Novak, J. D., \& Gowin, D. B. (1984). Learning How to Learn. New York: Cambridge University Press.

Novak, J. D., \& Musonda, D. (1991). A twelve-year longitudinal study of science concept learning. American Educational Research Journal, 28(1), 117-153.

Okebukola, P. A. (1990). Attaining meaningful learning of concepts in genetics and ecology: An examination of the potency of the concept-mapping technique. Journal of Research in Science Teaching, 27(5), 493-504.

Painter, S. D. (1994). Microanatomy courses in U. S. and Canadian medical schools, 1991-92. Academic Medicine, 69(2), 143-147.

Patton, M. Q. (1990). Qualitative Evaluation and Research Methods (2nd ed.). Newbury Park: Sage Publications.

Rice, D. C., Ryan, J. M., \& Samson, S. (1998). Using concept maps to assess student learning in the science classroom: Must different methods compete? Journal of Research in Science Teaching, 35(10), 1103-1127.

Rosse, C. (1995). The potential of computerized representations of anatomy in the training of health care providers. Academic Medicine, 70(6), 499-505.

Ruiz-Primo, M. A., Schultz, S. E., Li, M., \& Shavelson, R. J. (2001). Comparison of reliability and validity of scores from two concept-mapping techniques. Journal of Research in Science Teaching, 38(2), 260-278. 
Salomon, G., \& Perkins, D. N. (1989). Rocky roads to transfer: Rethinking mechanisms of a neglected phenomenon. Educational Psychologist, 24(2), 113-142.

Santhanam, E., Leach, C., \& Dawson, C. (1998). Concept mapping: How should it be introduced, and is there evidence for long term benefit? Higher Education, 35, 317328.

Schrum, L. (1999). Technology in the classroom: Asking the right questions. ENC Focus for Classroom Innovators, 6(3), 16-19.

Shepard, K. F., \& Jensen, G. M. (1997). Preparation for teaching in academic settings. Handbook of Teaching for Physical Therapists. Boston: ButterworthHeinemann.

Shih, Y., Shyu, H., \& Chen, R. (1997, Feb 14-18). Effects of knowledge abstraction with anchored instruction on learning transfer. Paper presented at the National Convention of the Association for Educational Communications and Technology, Albuquerque, NM.

Simons, P. R. J. (1999). Transfer of learning: Paradoxes for learners. International Journal of Educational Research, 31, 577-589.

Strauss, A., \& Corbin, J. (1998). Basics of Qualitative Research (2nd ed.). Thousand Oaks: SAGE Publications.

Sundsten, J. W., Kastella, K. G., \& Conley, D. M. (1991). Videodisc animation of 3D computer reconstructions of the human brain. Journal of Biocommunication, 18(2), 45-49.

Swanson, H. L. (1990). Influence of metacognitive knowledge and aptitude in problem solving. Journal of Educational Psychology, 82(2), 306-314. 
Tait, H., \& Entwistle, N. (1996). Identifying students at risk through ineffective study strategies. Higher Education, 31, 97-116.

Talbot, G. L. (1994). The assessment of student study skills and learning

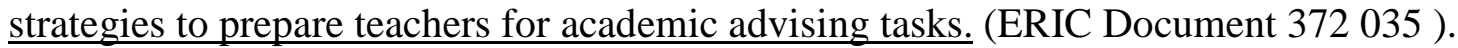

Thomas, P. R., \& Bain, J. D. (1984). Contextual dependence of learning approaches: The effects of assessments. Human Learning, 3, 227-240.

Toth-Cohen, S. (1995). Computer-assisted instruction as a learning resource for applied anatomy and kinesiology in the occupational therapy curriculum. The American Journal of Occupational Therapy, 49(8), 821-827.

Trowbridge, J. E., \& Wandersee, J. H. (1994). Identifying critical junctures in learning in a college course on evolution. Journal of Research in Science Teaching, 31(5), 459-473.

Trowbridge, J. E., \& Wandersee, J. H. (1998). Theory-driven graphic organizers. In J. J. Mintzes \& J. H. Wandersee \& J. D. Novak (Eds.), Teaching Science for Understanding: A Human Constructivist View. San Diego: Academic Press.

Vermunt, J. D. (1996). Metacognitive, cognitive and affective aspects of learning styles and strategies: A phenomenograghic analysis. Higher Education, 31, 25-50.

Vernon, D. T. A. (1995). Attitudes and opinions of faculty tutors about Problembased Learning. Academic Medicine, 70(3), 216-223.

Vernon, D. T. A., \& Hosokawa, M. C. (1996). Faculty attitudes and opinions about Problem-based Learning. Academic Medicine, 71(11), 1233-1238. 
Wallace, J. D., \& Mintzes, J. J. (1990). The concept map as a research tool: Exploring conceptual change in biology. Journal of Research in Science Teaching, 27(10), 1033-1052.

Walsh, R. J., \& Bohn, R. C. (1990). Computer-assisted instructions: A role in teaching human gross anatomy. Medical Education, 24, 499-506.

Weinstein, C. E. (1987). LASSI User's Manual. Clearwater, FL: H\&H Publishing Company, Inc.

Williams, A. M., Agho, A. O., \& Holm, M. B. (1996). Perceptions of computer literacy among occupational therapy students. The American Journal of Occupational Therapy, 50(3), 217-222.

Williams, A. M., Agho, A. O., \& McCloy, C. (1996). Attitudes and perceptions of computer applications among baccalaureate physical therapy students. Journal of Physical Therapy Education, 10(1), 14-17.

Wilson, J. L. (1991). Anatomy (9th ed.). New York: Medical Examination Publishing Company. 
Appendix A: Example of Concept Map with Feedback

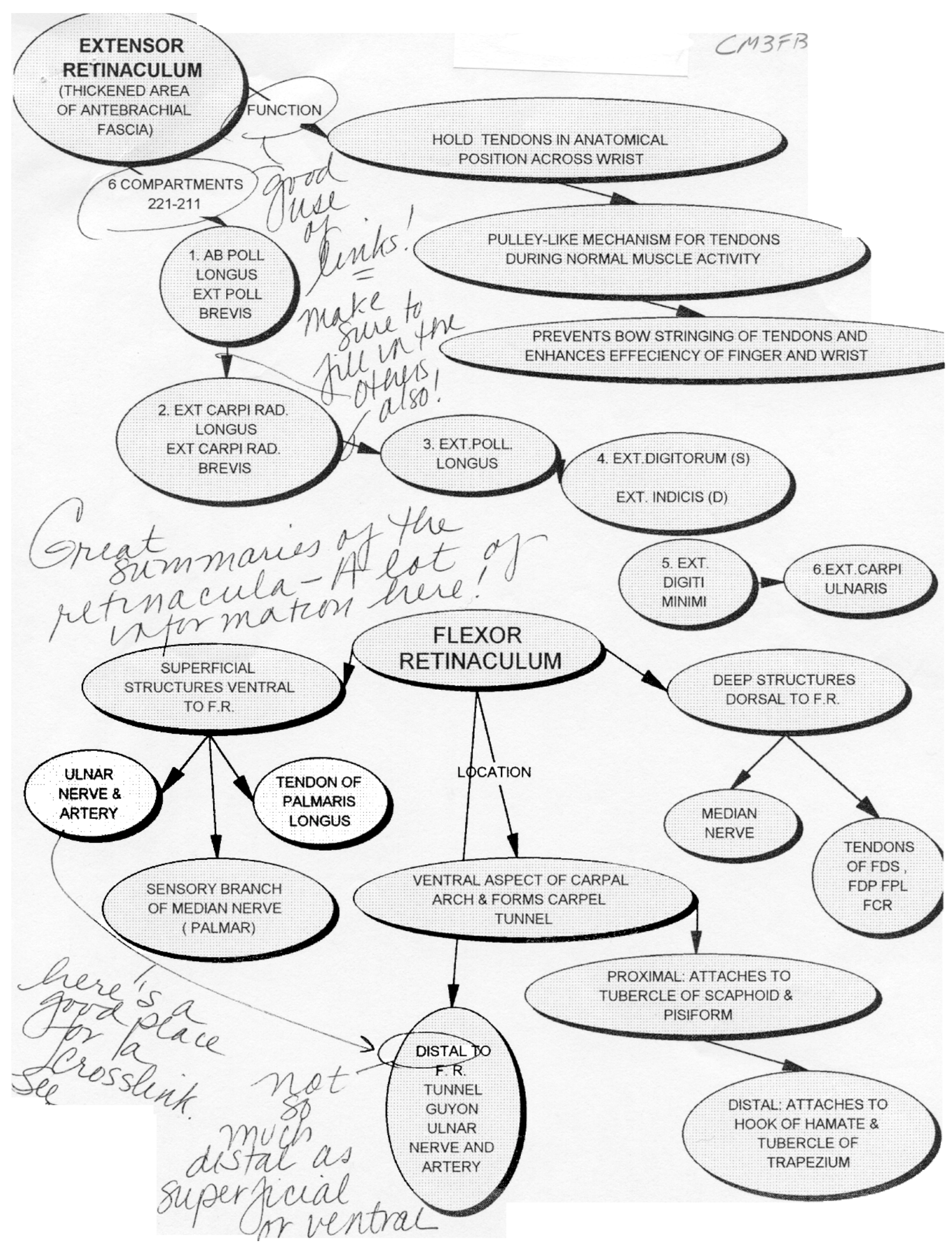


Appendix B: Test Matrix and Objectives for Researcher-constructed Kinesiology Test

\section{Kinesiology Test Objectives}

Goal: Apply the knowledge of gross anatomy of muscle to the analysis of normal motion (kinesiology concepts) of the shoulder, elbow, radio-ulnar and wrist joints.

Upon completion of this unit, via a multiple choice test on upper extremity musculature, the student will be able to ...

1. (Knowledge)

a. Identify the bony attachments of a particular muscle.

b. Identify the function of a particular muscle.

2. (Comprehension)

a. Explain the role of a muscle in a single plane action.

b. Illustrate the force vectors created by a muscle.

3. (Application)

a. Interpret the contribution made by each muscle involved in a given multi-joint activity.

b. Apply concepts of length-tension to determine which position of a joint will enable a particular muscle to produce the greatest torque.

4. (Analysis) Contrast among several muscles the specific role each muscle plays in a given movement pattern.

5. (Synthesis) Design an activity that will incorporate a specific type of contraction for a particular muscle. 
Table of Specifications

\begin{tabular}{|l|l|l|}
\hline Level & Obj. \# & $\begin{array}{l}\text { \# of } \\
\text { items }\end{array}$ \\
\hline Knowledge & $1 \mathrm{a}$ & 5 \\
\hline & $1 \mathrm{~b}$ & 5 \\
\hline Comprehension & $2 \mathrm{a}$ & 5 \\
\hline & $2 \mathrm{~b}$ & 5 \\
\hline Application & $3 \mathrm{a}$ & 5 \\
\hline & $3 \mathrm{~b}$ & 5 \\
\hline Analysis & 4 & 10 \\
\hline Synthesis & 5 & 10 \\
\hline & Total & 50 \\
\hline
\end{tabular}




\section{Appendix C: Anatomy Test}

Instructions: Each of the following questions or incomplete statements is followed by a number of suggested answers or completions. Select the BEST answer or completion in each case.

1. The nerve most likely to be injured in a fracture of the humeral shaft is the
a) median.
b) ulnar.
c) radial.
d) musculocutaneous.
e) axillary.

2. An injury to the thoracodorsal nerve might affect which of the following movements?
a) Lateral rotation of the arm
b) Flexion of the arm
c) Rotation of the scapula
d) Extension of the arm
e) Elevation of the scapula

3. If the entire greater tubercle of the humerus was torn away as a result of an injury, which of the following movements of the humerus would be affected?
a) Flexion and abduction
b) Flexion and medial rotation
c) Extension and medial rotation
d) Flexion, abduction, and adduction
e) Abduction and lateral rotation

4. Lateral rotation of the humerus is a function of muscles innervated by which of the following nerves?
a) Radial
b) Suprascapular and axillary
c) Axillary and dorsal scapular
d) Accessory and thoracodorsal
e) Thoracodorsal and dorsal scapular

5. A muscle that crosses both the shoulder and elbow joints is the
a) coracobrachialis.
b) brachialis.
c) biceps brachii.
d) medial head of the triceps brachii.
e) brachioradialis.

6. Which of the following muscles inserts on the crest of the lesser tubercle of the humerus?
a) Pectoralis major
b) Teres major
c) Subscapularis
d) Supraspinatus
e) Coracobrachialis 
7. If a stab wound lacerates the posterior humeral circumflex artery passing through the quadrangular space on the shoulder region, which of the following nerves might be injured?
a) Radial nerve
b) Thoracodorsal nerve
c) Suprascapular nerve
d) Accessory nerve
e) Axillary nerve

8. Which of the following muscles acts to flex the elbow but is not innervated by the musculocutaneous, median, or ulnar nerves?
a) Flexor digitorum longus
b) Brachioradialis
c) Brachialis
d) Extensor digitorum longus
e) Biceps brachii

9. The infraspinatus muscle is innervated by the
a) dorsal scapular nerve.
b) lower subscapular nerve.
c) suprascapular nerve.
d) axillary nerve.
e) upper subscapular nerve.

10. The subacromial bursa separates the acromion process from the tendon of the
a) supraspinatus muscle.
b) teres major muscle.
c) teres minor muscle.
d) subscapularis muscle.
e) pectoralis minor muscle.

11. Which of the following passes behind the medial epicondyle of the humerus?
a) Musculocutaneous nerve
b) Deep brachial artery
c) Middle collateral artery
d) Radial nerve
e) Ulnar nerve

12. The musculocutaneous nerve after innervating the biceps brachii and brachialis muscles becomes what?
a) Lateral antebrachial cutaneous nerve
b) Posterior antebrachial cutaneous nerve
c) Medial antebrachial cutaneous nerve
d) Anterior antebrachial cutaneous nerve
e) Nothing, it ends in the biceps brachii 
13. The artery accompanying the ulnar nerve in the posterior compartment of the brachium is called
a) inferior ulnar collateral branch of the brachial artery.
b) brachial artery.
c) ulnar artery.
d) medial collateral artery.
e) superior ulnar collateral branch of the brachial artery.

14. The nerve passing between the medial and lateral heads of the triceps brachii muscle is called the
a) radial nerve.
b) axillary nerve.
c) median nerve.
d) musculocutaneous nerve.
e) ulnar nerve.

15. A car accident victim has lost the function of all abductors of the arm. This indicates damage to which of the following parts of the brachial plexus?
a) Middle trunk and posterior cord
b) Middle trunk and lateral cord
c) Lower trunk and lateral cord
d) Upper trunk and posterior cord
e) Lower trunk and medial cord.

16. A lesion of the radial nerve in the spiral groove of the humerus would cause which of the following conditions?
a) Numbness over the medial side of the forearm
b) Inability to oppose the thumb
c) Weakness in pronating the forearm
d) Inability to extend the hand
e) Weakness in abducting the arm

17. The biceps brachii muscle arises from the
a) scapula and humerus.
b) scapula and clavicle.
c) scapula only.
d) humerus only.
e) clavicle, scapula and humerus.

18. Name one muscle innervated by the radial nerve or its branches that is a flexor.
a) Pronator teres
b) Brachioradialis
c) Flexor carpi radialis
d) Flexor pollicis longus
e) Anconeus 
19. The deepest muscle group of the anterior forearm includes
a) pronator teres.
b) flexor pollicis longus.
c) flexor digitorum superficialis.
d) abductor pollicis longus.
e) palmaris longus.

20. Following a complete severance of the median nerve in the upper arm near the axilla, the most affected movement will be
a) flexion of the elbow joint.
b) flexion of the interphalangeal joint of the thumb.
c) abduction of the digits.
d) adduction of the thumb.
e) supination of the hand.

21. Which of the following muscles has attachment on the ulna?
a) Brachioradialis
b) Biceps brachii
c) Flexor carpi radialis
d) Brachialis
e) Coracobrachialis

22. If a patient has difficulty in abducting the arm AND in extending the elbow and wrist joints, the most likely damage is to the
a) suprascapular nerve.
b) radial nerve.
c) axillary nerve.
d) posterior cord of the brachial plexus.
e) lower subscapular nerve.

23. Your patient experiences elbow pain with turning doorknobs, but not with lifting heavy objects. From the choices listed below, what is the most likely cause of the pain?
a) A biceps brachii tendinitis
b) An injury to the radial nerve
c) Dislocation of the radial head
d) A supinator muscle strain
e) Injury to the ulnar collateral artery

24. The pectoralis minor muscle is the basis for identifying the three parts of the
a) subclavian artery.
b) brachial artery.
c) axillary artery.
d) lateral thoracic artery.
e) cephalic vein. 
25. Total absence of abduction of the arm is probably due to
a) the severing of the suprascapular and axillary nerves.
b) atrophy of the deltoid muscle.
c) paralysis of the supraspinatus muscle.
d) rupture of the tendon of the long head of the biceps brachii muscle.
e) radial nerve damage.

26. The teres major muscle would be paralyzed by severing the
a) axillary nerve.
b) dorsal scapular nerve.
c) suprascapular nerve.
d) lower subscapular nerve.
e) upper subscapular nerve.

27. Inability to initiate abduction of the arm could result from severing the
a) thoracodorsal nerve.
b) long thoracic nerve.
c) suprascapular nerve.
d) lower subscapular nerve.
e) upper subscapular nerve.

28. Which muscle inserts on the greater tubercle of the humerus?
a) Teres major
b) Supraspinatus
c) Subscapularis
d) Deltoid
e) Pectoralis major

29. The axillary artery begins at the , and is a continuation of the artery.
a) first rib, brachiocephalic
b) acromion process, brachiocephalic
c) scapula, brachial
d) clavicle, subclavian
e) first rib, subclavian

30. The medial wall of the axilla is formed by the
a) lateral border of the pectoralis major muscle.
b) chest wall and serratus anterior muscle.
c) suspensory ligaments of the axilla.
d) chest wall and serratus posterior.
e) humerus.

31. The lateral and medial boundaries of the cubital fossa are formed by
a) brachioradialis and flexor carpi radialis.
b) brachialis and pronator teres.
c) brachioradialis and pronator teres.
d) extensor carpi radialis longus and brachialis.
e) biceps brachii and supinator. 
32. An injury to the median nerve in the middle third of the arm would affect which of the following muscles?
a) Flexor carpi ulnaris
b) Adductor pollicis
c) Abductor digiti minimi
d) Abductor pollicis brevis
e) Extensor carpi radialis longus

33. Which of the following nerves passes between the two heads of the flexor carpi ulnaris?
a) Radial nerve
b) Deep radial nerve
c) Median nerve
d) Ulnar nerve
e) Superficial radial nerve

34. At the wrist, the radial artery is just lateral to what tendon?
a) Abductor pollicis longus
b) Palmaris longus
c) Flexor carpi radialis
d) Brachioradialis
e) Flexor carpi ulnaris

35. Which of the following statements concerning the pectoralis major is correct?
a) It inserts on the distal $1 / 3$ of the humerus.
b) It acts to flex, abduct and medially rotate the shoulder joint.
c) It originates from the distal $1 / 3$ of the clavicle and the costal cartilages of the lower 6 ribs.
d) It is innervated by the medial and lateral pectoral nerves.
e) It divides the axillary artery into three parts.

36. The tendon of the long head of the biceps
a) originates from the coracoid process.
b) originates from the infraglenoid tubercle.
c) is an intracapsular tendon.
d) assists with shoulder extension.
e) stabilizes the shoulder joint medially.

37. Which of the following muscles originate from the lateral epicondyle of the humerus?
a) Brachioradialis
b) Extensor digitorum
c) Extensor pollicis longus
d) Pronator quadratus
e) Supinator

38. Identify the flexors of the digits in the forearm that do NOT attach to the humerus.
a) Flexor carpi ulnaris
b) Flexor digitorum superficialis
c) Brachioradialis
d) Flexor digitorum profundus
e) Palmaris longus 
39. You are seeing a patient that has been diagnosed with a muscle strain. She has pain at the lateral epicondyle of the humerus. Which of the following muscles might be involved?
a) Flexor carpi ulnaris
b) Brachialis
c) Extensor carpi radialis brevis
d) Supinator
e) Flexor pollicis longus

40. Which muscle, if injured, would present with tenderness over the coronoid process of the ulna and the medial epicondyle of the humerus and the anterior proximal radius?
a) Flexor digitorum superficialis
b) Pronator teres
c) Extensor carpi ulnaris
d) Flexor pollicis longus
e) Supinator 


\section{Appendix D: Kinesiology Test}

Instructions: Please select the one BEST answer for the for the following questions. Unless otherwise stated, the reference position is anatomical position.

1. Where does the supraspinatus muscle insert?
a. Lesser tubercle of the humerus
b. Inferior facet on greater tubercle of humerus
c. Superior facet on greater tubercle of humerus
d. Supraspinous fossa

2. What is the role of the triceps muscle during the downward phase of the push up?
a. The triceps acts concentrically to bring the body toward the floor.
b. The triceps has a synergistic action with the rotator cuff muscles.
c. The triceps acts eccentrically to control the body against the pull of gravity.
d. The triceps is inactive during this phase.

3. Which muscle is described as having proximal attachment to the anterior surface of the ulna and interosseous membrane and distal attachment to the base of the distal phalanx of the fingers?
a. Extensor digitorum
b. Flexor digitorum profundus
c. Flexor digitorum superficialis
d. Palmaris longus

4. Which of the following describes the function(s) of the triceps brachii muscle when acting alone?
a. Shoulder flexion and elbow extension
b. Shoulder extension and elbow extension
c. Elbow extension
d. Medial rotation and abduction of the shoulder and elbow extension

5. Which of the following best describes the roles of the serratus anterior and trapezius muscles during shoulder abduction?

a. The serratus anterior and upper and lower portions of the trapezius muscle work together in a force couple to upwardly rotate the scapula during shoulder abduction.

b. The serratus anterior and trapezius muscles both have resultant force vectors that produce scapular protraction for shoulder abduction.

c. The serratus anterior and trapezius act in opposition to prohibit movement. The scapula remains immobile for shoulder abduction.

d. The serratus anterior and trapezius muscles are inactive during shoulder abduction.

6. Which activity would require the strongest concentric contraction of the infraspinatus muscle?
a. Slamming shut the passenger side door on the car
b. Pushing your glasses up on your nose
c. Hanging up a heavy coat
d. Pulling your belt out of the loops 
7. What motion would result if the infrapinatus muscle and the subscapularis muscle contracted simultaneously with equal force?

a. There would be no movement. The vectors cancel each other out.

b. The shoulder would medially rotate.

c. The shoulder would adduct.

d. The shoulder would abduct and flex.

8. Which of the following muscles would be most effective as an elbow flexor under the condition described?

a. Palmaris longus with wrist flexed

b. Flexor carpi ulnaris with wrist ulnar deviation

c. Pronator teres with forearm pronated

d. Flexor carpi radialis with wrist neutral

9. The greatest force production of the flexor digitorum superficialis muscle for grip strength occurs with $\ldots$
a. neutral wrist extension.
b. full wrist flexion.
c. neutral forearm supination.
d. full forearm pronation.

10. The force vectors of the infraspinatus, teres minor, and subscapularis muscles combine to form a vector in which direction?
a. An inferiorly-directed force vector
b. An inferior and medially-directed force vector
c. A superior and laterally-directed force vector
d. A superiorly-directed force vector

11. What would the resultant vector force be for the rotator cuff muscles if the teres minor muscle was absent?

a. The force vector would be directed more superiorly than before creating a relative increase in compression and a decrease in inferior glide.

b. The force vector would be more inferiorly directed. The compression force vector would remain the same.

c. The resultant force vector would be directed more posteriorly.

d. The resultant force vector would be directed in a lateral direction.

12. Which muscle has its origin at the lateral margin of the scapula and its insertion at the bicipital groove and crest of the lesser tubercle of the humerus?
a. Pectoralis major
b. Triceps brachii
c. Teres major
d. Coracobrachialis 
Questions 13-17: Answer the following questions for this activity: Taking a full gallon carton of milk out of a refrigerator. (Begin from the point where you have already grabbed the handle of the carton and lifted it from the shelf and are now bringing it toward your body.)

13. During this activity, the latissimus dorsi muscle ...
a. is mostly inactive.
b. contracts isometrically to stabilize the scapula.
c. acts eccentrically to control shoulder flexion.
d. contracts concentrically to extend the shoulder.

14. During this activity, the deltoid muscle ...
a. is active concentrically in the posterior portion producing extension.
b. is active isometrically throughout the extent of the muscle to maintain shoulder position.
c. contracts eccentrically in the anterior portion to control extension.
d. acts concentrically to control the flexion movement of the shoulder.

15. During this activity, the triceps muscle may have a role ...
a. concentrically at the shoulder as an extensor.
b. concentrically at the elbow as an extensor.
c. isometrically at the elbow as a stabilizer.
d. eccentrically at the shoulder as an extensor.

16. During this activity, the brachialis muscle ...
a. contracts concentrically to flex the elbow.
b. acts isometrically to stabilize the elbow.
c. is probably inactive during this contraction since the work may be done by other muscles.
d. contracts eccentrically to control elbow flexion.

17. During this activity, the extensor carpi radialis brevis muscle ...
a. contracts eccentrically to stabilize the wrist in flexion.
b. contracts concentrically to extend the wrist
c. assists the extensor carpi ulnaris in stabilizing the wrist.
d. contracts isometrically to stabilize the wrist against ulnar deviation.

18. Which of the following describes the component vectors of the biceps brachii muscle?
a. The rotary component causes a compression force when flexed beyond 90 degrees.
b. The translatory component produces the flexion moment.
c. The translatory component changes from a compression to a distraction force during flexion.
d. The rotary component remains constant throughout the range of motion.

19. How is the subscapularis muscle active during shoulder abduction?

a. The subscapularis is active to depress the humeral head to allow for full upward spin.

b. The subscapularis initiates abduction.

c. The subscapularis produces the medial rotation required to complete the range of motion.

d. The subscapularis is not active during shoulder abduction. 
20. Which of the following muscles may flex the wrist and assist with elbow flexion?
a. Pronator teres
b. Biceps brachii
c. Flexor carpi radialis
d. Flexor digitorum superficialis

21. How would the function of the deltoid muscle change if the posterior portion of the deltoid muscle were inactive?

a. The deltoid would have more of a role in shoulder joint extension and abduction.

b. The deltoid would have an increased abduction role.

c. The deltoid would have increased flexion and medial rotation activity.

d. The deltoid would lose its function as a medial rotator.

22. In which position would the triceps muscle have the largest contribution as a shoulder extensor?
a. With the shoulder fully medially rotated
b. With the elbow fully flexed
c. With the forearm fully pronated
d. With elbow fully extended

23. Which of the following activities would best isolate the flexor digitorum profundus muscle in an isometric contraction?
a. Curling your hand into a fist
b. Pointing with your index finger
c. Hanging on to the edge of a cliff with your fingertips
d. Picking up the strap of a bag

24. Which of the following describes the functions of the extensor digitorum muscle when acting alone?
a. Elbow extension, wrist extension and digit abduction
b. Forearm supination, wrist flexion and digit extension
c. Wrist radial deviation and extension of all five digits
d. Extension of wrist, MCP joints, and interphalangeal joints of fingers

25. The biceps brachii muscle will produce the most elbow flexion torque in which of the following positions?

a. With the forearm fully supinated and shoulder flexed

b. With the forearm in neutral and elbow at mid range flexion

c. With the shoulder fully flexed

d. With the shoulder fully abducted 
26. Which of the following best describes the force couple activity of the deltoid and rotator cuff muscles during shoulder abduction?

a. The torque generated by the rotator cuff produces the lateral rotation required to complete the abduction created by the deltoid muscle.

b. The rotator cuff creates an inferior glide and compression force that counteracts and directs the deltoid's superior translatory force and lateral rotary force.

c. The deltoid distracts the joint while the rotator cuff compresses the joint. The supraspinatus produces the abduction.

d. The rotator cuff and deltoid have similar vectors which increase the force generated by abduction movement.

27. Which of the following describes the component force vectors of the brachioradialis muscle during elbow flexion?

a. The translatory component remains constant throughout the range of motion.

b. The translatory component maintains a compression force throughout the range of motion.

c. The rotary component moves closer to the joint axis as the forearm is flexed.

d. The rotary component has a larger magnitude than the translatory component.

28. The extensor indicis muscle is most active as a digit extensor under which of the following conditions?
a. With full forearm supination
b. In any wrist position
c. With slight wrist flexion
d. With full elbow flexion

29. What is the action of the flexor carpi radialis muscle during radial deviation of the wrist?
a. Antagonist to the extensor digitorum
b. Synergist to the extensor carpi radialis longus and brevis
c. Independent agonist
d. It is not active

30. In which of the following positions would the biceps brachii muscle be able to produce the most shoulder flexion torque?

a. With the elbow fully flexed and forearm in neutral

b. With the elbow and forearm in anatomical position

c. With the forearm fully supinated and elbow fully flexed

d. With the shoulder fully laterally rotated

31. If the proximal and distal radioulnar joints remain in the mid range between supination and pronation when the elbow is flexed against resistance, then the most active muscle(s) is/are the ...
a. biceps.
b. brachialis.
c. coracobrachialis.
d. wrist flexor group. 
32. Which of the following muscles serves to adduct, extend and medially rotate the humerus at the shoulder?
a. Pectoralis major
b. Short head of biceps brachii
c. Teres minor
d. Latissimus dorsi

33. Which of the following describes the rotary and translatory components of the deltoid muscle at the shoulder?

a. The rotary component is much greater than the translatory component.

b. The result of the rotary and translatory component vectors is a distraction force.

c. The translatory component produces the abduction movement.

d. The translatory component is greater than the rotary component.

34. How does the brachioradialis muscle action contrast with biceps brachii muscle action during resisted elbow flexion?

a. The biceps and brachioradialis have the same action, elbow flexion, and therefore the resultant force vectors must be the same.

b. The biceps brachii and brachioradialis both have translatory force vector components that distract the joint throughout the range of motion.

c. The biceps brachii may be both a joint compressor as well as a distractor depending on the point in the range of motion. The brachioradialis is a joint compressor only.

d. During resisted elbow flexion, the biceps brachii provides joint stability while the brachioradialis produces the elbow flexion torque.

35. Choose the proximal attachment site of the extensor carpi radialis brevis muscle.
a. Lateral epicondyle of the humerus
b. Base of the third metacarpal
c. Medial epicondyle of the humerus
d. Base of the second metacarpal

36. What type of activity would require an eccentric contraction of the serratus anterior muscle?
a. Shoulder flexion resisted by a hand held weight and gravity
b. Shoulder abduction with an elastic band attached to the ipsilateral foot against gravity
c. Slow lowering of a hand held weight from flexion into extension against gravity
d. Holding a weight at arms length for 10 seconds at 90 degrees shoulder flexion against gravity

37. Which of the following activities would best isolate a concentric contraction of the brachialis muscle?
a. Concentrating on slowly lowering the body to the floor on the downward phase of a pushup
b. Lifting a bucket with the forearm pronated
c. A handstand
d. The downward phase of a chin up 
38. Which of the following describes the function of the serratus anterior muscle when acting independently?
a. Scapular protraction
b. Scapular upward rotation
c. Scapular retraction
d. Glenohumeral joint flexion

39. Which of the following have resultant force vectors that offset each other?
a. Flexor digitorum superficialis and extensor digitorum
b. Pronator quadratus and pronator teres
c. Flexor carpi radialis and extensor carpi radialis longus
d. Flexor digitorum profundus and flexor digitorum superficialis

40. How would a coordinated contraction of the extensor carpi radialis longus and extensor carpi ulnaris muscles differ from an isolated extensor carpi ulnaris muscle contraction?

a. The isolated extensor carpi ulnaris contraction would produce multiplanar movement.

b. The isolated extensor carpi ulnaris contraction would produce sagittal plane movement alone.

c. The isolated extensor carpi ulnaris contraction would generate more radial deviation torque.

d. The isolated extensor carpi ulnaris contraction would increase the distraction forces across the elbow joint.

41. Which activity requires a concentric contraction of the pronator teres muscle?
a. Turning up the volume with a knob
b. Typing at a keyboard
c. Picking up a face-down card to see the face
d. Flipping a burger with a spatula

42. Which of the following activities would most likely require an isometric contraction of the triceps muscle?
a. The downward phase of a push up
b. Striking a nail with a hammer
c. Holding a microphone to your mouth
d. Pushing a lawn mower

43. Which of the following is a site of attachment for the biceps brachii muscle?
a. Anterior aspect of the humeral shaft
b. Coronoid process of the ulna
c. Coracoid process of the scapula
d. Head of the radius

44. Which of the following would be an eccentric contraction of the subscapularis muscle?
a. The follow through phase of a tennis serve
b. Reaching around your back to take something out of your back pocket
c. The end of the cock up phase of a foot ball pass
d. Resisted abduction of the shoulder 
45. When lifting a bucket from the ground by flexing the elbow, the elbow flexors are acting ...

a. concentrically to lift the weight against the pull of gravity.

b. eccentrically to control the pull of the weight against gravity.

c. isometrically to stabilize the elbow.

d. isokinetically to maintain the rate of lifting with a changing resistance.

46. Which activity would require an isometric contraction of the serratus anterior muscle?
a. Putting in a light bulb overhead
b. Putting a robe on a hook
c. Carefully lowering a heavy glass bowl to a table
d. Throwing darts

47. The flexor carpi ulnaris and extensor carpi ulnaris muscles have resultant force vectors that ...
a. act together to ulnarly deviate the wrist.
b. act in opposition to radially deviate the wrist.
c. are combined in sagittal plane actions.
d. produce increased transverse plane motion at the wrist.

48. Which activity requires an eccentric triceps muscle contraction?
a. Catching yourself on the palms of your hands when falling forward
b. Pushing yourself up to sit on a countertop
c. Stepping through when walking on crutches with non-weight bearing gait
d. Hammering a nail

49. Which activity requires a concentric contraction of the extensor digitorum?
a. Holding a phone to your ear
b. Putting a peg in a hole
c. Lifting your hand off a hot stove
d. Pointing to a spot on a map

50. Which of the following describes the component vectors of the biceps brachii muscle?
a. The rotary component causes a compression force when flexed beyond 90 degrees.
b. The translatory component produces the flexion moment.
c. The translatory component changes from a compression to a distraction force during flexion.
d. The rotary component remains constant throughout the range of motion. 


\section{Appendix E: Study Journal Example}

\section{Anatomy Study Journal}

Please make entries in your journal everyday, even if it is just to say that you did not study anatomy that day. Feel free to use extra sheets of paper if needed.

\begin{tabular}{|c|c|c|}
\hline \multicolumn{3}{|c|}{ What do you plan to accomplish with your studying experiences for anatomy this week? } \\
\hline Day & Time & Activity * \\
\hline \multicolumn{3}{|l|}{ Mon } \\
\hline \multicolumn{3}{|l|}{ Tue } \\
\hline \multicolumn{3}{|l|}{ Wed } \\
\hline \multicolumn{3}{|l|}{ Thu } \\
\hline \multicolumn{3}{|l|}{ Fri } \\
\hline \multicolumn{3}{|l|}{ Sat } \\
\hline \multicolumn{3}{|l|}{ Sun } \\
\hline $\begin{array}{l}\text { Total } \\
\text { Hours }\end{array}$ & & $\begin{array}{l}\text { * In the Activity space, describe the study session (i.e., what you } \\
\text { did, alone or with others, where, etc.). }\end{array}$ \\
\hline
\end{tabular}


To complete at the end of the week: Did you accomplish your objectives for studying? Why or why not?

Compare this week to previous weeks. (For treatment group: Aside from concept mapping how was your study time spent differently?) (For control group: How was your study time spent differently?)

\section{Other comments:}

Thank you for participating!! 
Appendix F: Example of Study Journal Completed by Participant

Name:

Kinesiology Study Journal

Please make entries in your journal everyday, even if it is just to say that you did not study kinesiology that day. Feel free to use extra sheets of paper if needed. Don't forget the questions on the back! (9) Thanks!

What do you plan to accomplisb with your studying experiences for kinesiology this week?

Review topics I and trouble with on the test organize elbow oomplex notes

\begin{tabular}{|c|c|c|}
\hline Day & Time & Activity \\
\hline $2 / 19$ & $10: 00-11130$ & Skimmed chapter on elbow complex. \\
\hline $\begin{array}{l}\text { Tue } \\
2 / 20\end{array}$ & $7: 00-8: 00$ & $\begin{array}{l}\text { Revicied Chapters that Iskimaded over } \\
\text { Monday }\end{array}$ \\
\hline $\begin{array}{l}\text { Wed } \\
2 / 21\end{array}$ & $3: 00-6: 00$ & $\begin{array}{l}\text { Rewribe notes fromketure } \\
\text { Use Angelas notemat to fell any blants }\end{array}$ \\
\hline $\begin{array}{l}\text { Thu } \\
2 / 22\end{array}$ & $8: 30-9: 30$ & $\begin{array}{c}\text { Draw roteoands for Kines lab Mandal } \\
\text { Maecle } \\
\text { Teat }\end{array}$ \\
\hline $\begin{array}{l}\text { Fri } \\
2 / 23\end{array}$ & & 7lo Kines \\
\hline $\begin{array}{l}\text { Sat } \\
2 / 24\end{array}$ & 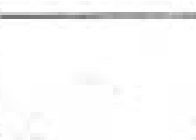 & $n_{0}$ Kines \\
\hline $\begin{array}{l}\text { Sun } \\
2 / 25\end{array}$ & $9: 00-10 ; 50$ & $\begin{array}{l}\text { Read ovee wrist hand complex notes } \\
\text { and chapter for Wed becture }\end{array}$ \\
\hline $\begin{array}{l}\text { Total } \\
\text { Hours }\end{array}$ & 7 & $\begin{array}{l}\text { - In the Activity space, describe the study session (i. e, what you } \\
\text { did, alone or with others, where, etc.). }\end{array}$ \\
\hline
\end{tabular}


To complete at the end of the week: Did you accomplish your objectives for studying? Why or why not?

\section{I didn't take time to revieal the topics I had trouble} with onthe test.

Compare this week to previous weeks. (For treatment group: Aside from concept mapping how was your study time spent differently?) (For control group: How was your study time spent differently?)

$$
\text { Time vasn't really differeat sapet }
$$

I did not make any maps

How well prepared did you feel for the kinesiology exam? Do you plan to study any differently for the next one? If so, how?

$$
\text { I felt }
$$

pretly repaed it think

I will definitely beve to stady deffeently fer the next one. I will have to work out some kayto know details in every way. The question an the test other comments, observations, questiotls of remark: May be I'll try meking apong

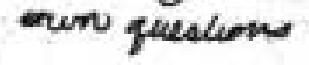

\section{Happy Presidents' Dayll}

Thank you for participating .

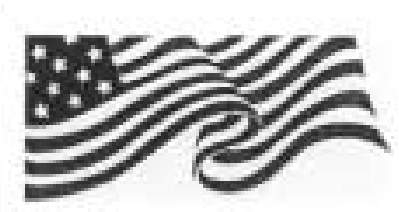


Appendix G: Tables of Results for Quantitative Analyses

Table G1 Descriptive Statistics and Independent $t$ test Results for Demographic Data

\begin{tabular}{|c|c|c|c|c|c|c|c|c|}
\hline & \multicolumn{3}{|c|}{ Control group } & \multicolumn{3}{|c|}{ Concept mapping group } & \multirow[b]{2}{*}{$t$} & \multirow[b]{2}{*}{$\mathrm{df}$} \\
\hline & $\mathrm{N}$ & Mean & SD & $\mathrm{N}$ & Mean & SD & & \\
\hline SAT Math & 19 & 606.8 & 73.9 & 18 & 562.8 & 80.6 & 1.734 & 35 \\
\hline SAT Verbal & 19 & 588.9 & 72.1 & 18 & 567.2 & 64.7 & .963 & 35 \\
\hline SAT Total & 19 & 1195.8 & 125.5 & 18 & 1130.0 & 116.9 & 1.648 & 35 \\
\hline QPA & 19 & 3.49 & .281 & 19 & 3.47 & .338 & .110 & 36 \\
\hline
\end{tabular}


Table G2 Descriptive Statistics and Independent $t$ test Results for LASSI Pretest Subscales

\begin{tabular}{|c|c|c|c|c|c|c|c|c|}
\hline & \multicolumn{3}{|c|}{ Control Group } & \multirow{2}{*}{\multicolumn{3}{|c|}{$\begin{array}{c}\text { Concept Mapping } \\
\text { Group }\end{array}$}} & \multirow[b]{3}{*}{$t$} & \multirow[b]{3}{*}{$\mathrm{df}$} \\
\hline & & & & & & & & \\
\hline & $\mathrm{N}$ & Mean & SD & $\mathrm{N}$ & Mean & SD & & \\
\hline ATT & 19 & 34.47 & 3.32 & 19 & 33 & 4 & 1.235 & 36 \\
\hline MOT & 19 & 32.21 & 3.55 & 19 & 31.68 & 5.07 & .371 & 36 \\
\hline TMT & 19 & 26.58 & 6.06 & 19 & 25.58 & 6.91 & .474 & 36 \\
\hline ANX & 19 & 24 & 6.02 & 19 & 20.63 & 5.76 & 1.763 & 36 \\
\hline $\mathrm{CON}$ & 19 & 26 & 5.86 & 19 & 26.26 & 6.49 & -.131 & 36 \\
\hline INP & 19 & 29.05 & 4.94 & 19 & 30.16 & 5.13 & -.676 & 36 \\
\hline SMI & 19 & 19.42 & 2.55 & 19 & 17.21 & 3.19 & $2.361 *$ & 36 \\
\hline STA & 19 & 27.79 & 4.35 & 19 & 27.74 & 4.08 & .038 & 36 \\
\hline SFT & 19 & 26.68 & 3.64 & 19 & 26.05 & 3.57 & .540 & 36 \\
\hline TEST & 19 & 29 & 6.19 & 19 & 26.84 & 4.69 & 1.211 & 36 \\
\hline
\end{tabular}

Note. ATT $=$ Attitude. MOT $=$ Motivation. TMT $=$ Time Management. ANX $=$ Anxiety. CON $=$ Confidence. INP $=$ Information Processing. SMI $=$ Selecting Main Ideas. STA $=$ Study Aids .

$\mathrm{SFT}=$ Self Testing. TEST $=$ Test Strategies. $p<.05$. 
Table G3 Total Study Time (in hours) for Anatomy and Kinesiology

Control Group $\quad$ Concept Mapping

Group

\begin{tabular}{llllllll}
\hline $\mathrm{N}$ & Mean & $\mathrm{SD}$ & $\mathrm{N}$ & Mean & $\mathrm{SD}$ & $t$ & $\mathrm{df}$
\end{tabular}

\begin{tabular}{lcccccccc}
\hline Anatomy & 18 & 113.7 & 31.5 & 15 & 100.7 & 36.3 & 1.103 & 31 \\
& & & & & & & & \\
Kinesiology & 16 & 36.2 & 13.4 & 12 & 29.2 & 13.5 & 1.37 & 26 \\
\hline
\end{tabular}

Table G4 Descriptive Statistics for Anatomy Concept Map Scores

\begin{tabular}{lcccccc}
\hline & N & Mean & SD & Range & Minimum & Maximum \\
\hline CM 1 & 18 & 49.4 & 33.1 & 117 & 8 & 125 \\
CM 2 & 18 & 67.3 & 41.0 & 160 & 11 & 171 \\
CM 3 & 18 & 74.6 & 66.1 & 209 & 10 & 219 \\
CM 4 & 19 & 64.1 & 60.2 & 211 & 6 & 217 \\
CM 5 & 18 & 45.7 & 29.5 & 91 & 16 & 107 \\
CM 6 & 16 & 47.7 & 22.0 & 76 & 13 & 89 \\
CM 7 & 11 & 50.9 & 22.1 & 66 & 20 & 86 \\
Valid N (listwise) & 10 & & & & & \\
\hline
\end{tabular}

Note. CM 1-7 are the seven required concept maps for the fall semester. 
Table G5 2x3 ANOVA with Repeated Measures for Researcher-constructed Anatomy Test

\begin{tabular}{|c|c|c|c|c|}
\hline Source & SS & $\mathrm{df}$ & MS & $F$ \\
\hline \multicolumn{5}{|l|}{ Between subjects } \\
\hline Group & 10.92 & 1 & 10.92 & .216 \\
\hline Error & 1413.70 & 28 & 50.5 & \\
\hline \multicolumn{5}{|l|}{ Within subjects } \\
\hline Time & 1598.09 & 1.37 & 1166.4 & $54.76^{*}$ \\
\hline Time * Group & 31.16 & 1.37 & 22.74 & 1.07 \\
\hline Error & 817.22 & 38.36 & 21.30 & \\
\hline
\end{tabular}

Note. $* p<.05$. Greenhouse-Geisser calculation used because sphericity requirement was not satisfied.

Table G6 Kruskal-Wallis Analysis of Instructor-constructed Anatomy Tests

Control Group $\quad$ Concept Mapping Group

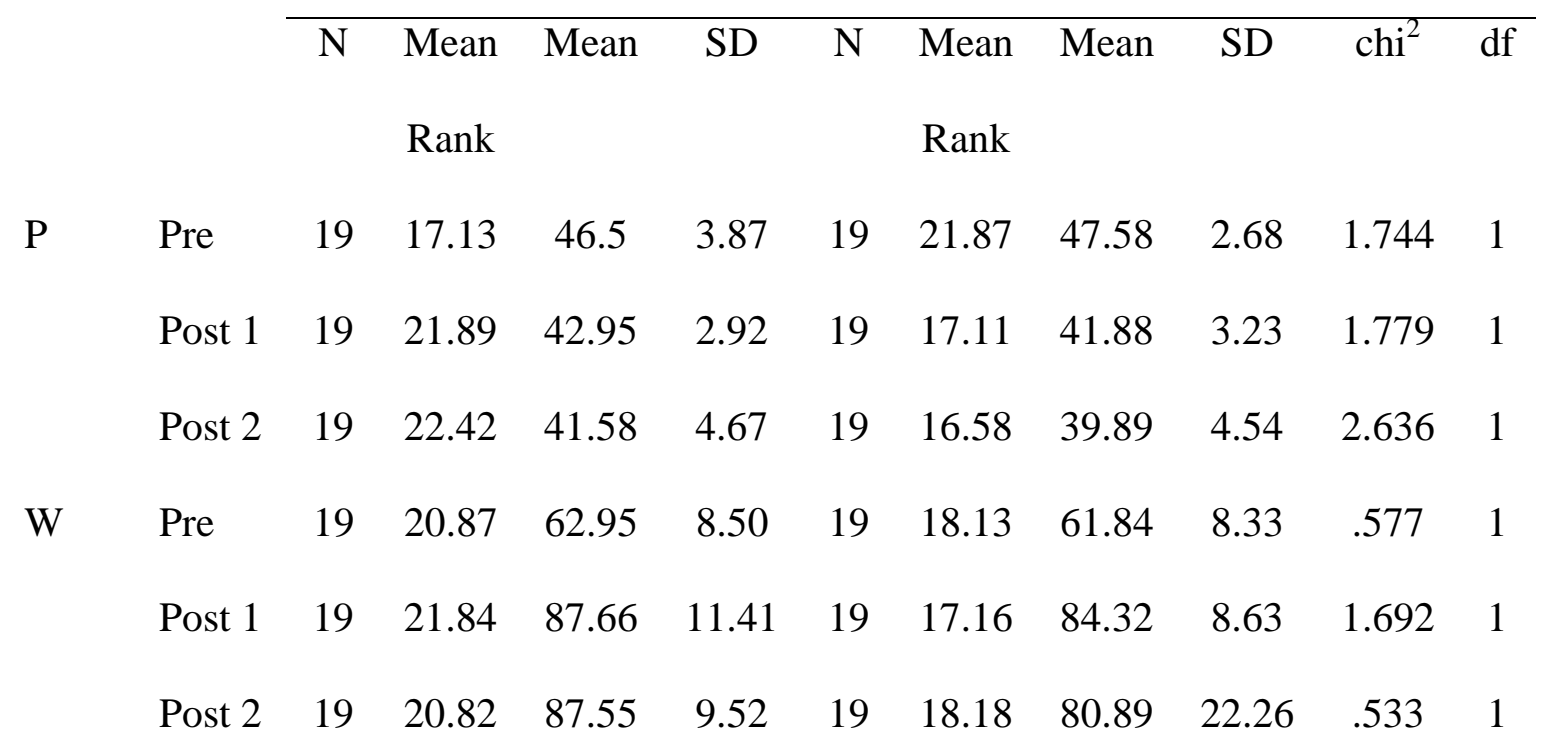

Note. $\mathrm{P}=$ Practical (laboratory) examinations. $\mathrm{W}=$ Written examinations. 
Table G7 Mann-Whitney $u$ Analysis of Final Anatomy Course Grade Average

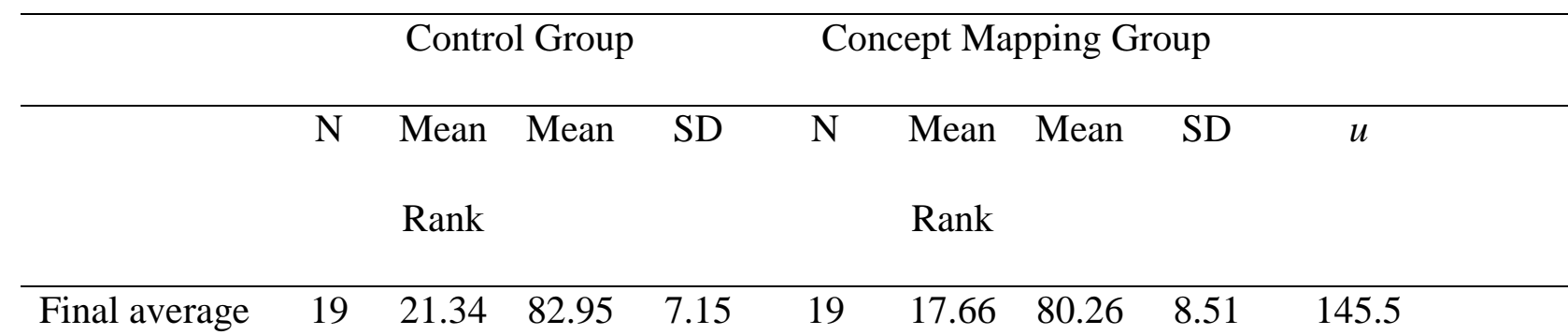

Note. Final average $=$ Average of instructor-generated tests of anatomy knowledge used to establish the final grade for the fall anatomy course.

Table G8 2x2 ANOVA with Repeated Measures for Researcher-constructed Kinesiology Test

$\begin{array}{lllll}\text { Source } & \text { SS } & \text { df } & \text { MS } & F\end{array}$

Between subjects

$\begin{array}{ccccc}\text { Group } & 24.93 & 1 & 24.93 & .472 \\ \text { Error } & 1480.15 & 28 & 52.86\end{array}$

Within subjects

$\begin{array}{rrccc}\text { Time } & 322.83 & 1 & 322.83 & 15.98 * \\ \text { Time * Group } & 10.83 & 1 & 1.83 & .536 \\ \text { Error } & 565.85 & 28 & 20.21 & \end{array}$

Note. $* p<.05$.

Table G9 Independent $t$ test Analysis for Final Kinesiology Course Grade Average

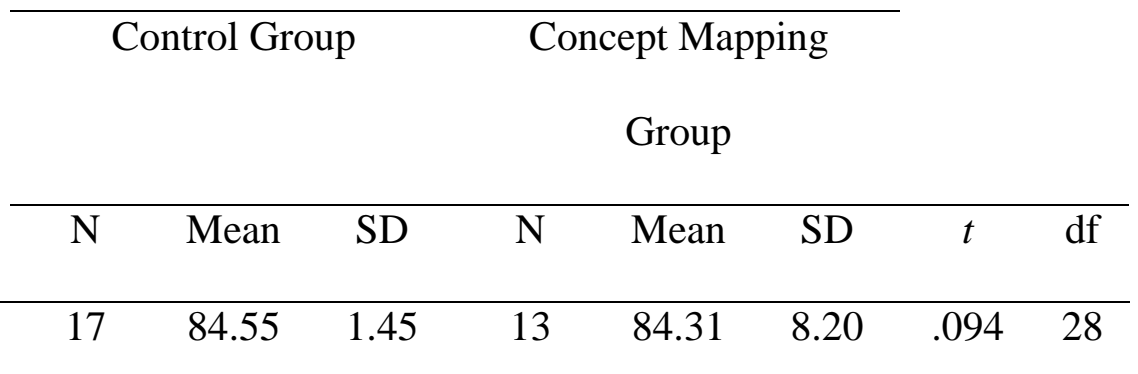


Table G10 2x3 ANOVA with Repeated Measures for LASSI Subscale Anxiety

\begin{tabular}{|c|c|c|c|c|}
\hline Source & SS & $\mathrm{df}$ & MS & $F$ \\
\hline \multicolumn{5}{|l|}{ Between subjects } \\
\hline Group & 76.44 & 1 & 76.44 & .572 \\
\hline Error & 3744.332 & 28 & 133.73 & \\
\hline \multicolumn{5}{|l|}{ Within subjects } \\
\hline Time & 98.90 & 2 & 49.45 & $6.19 *$ \\
\hline Time $*$ Group & .498 & 2 & .249 & .031 \\
\hline Error & 447.57 & 56 & 7.99 & \\
\hline
\end{tabular}

Note. $* p<.05$

Table G11 2x3 ANOVA with Repeated Measures for LASSI Subscale Attitude

\begin{tabular}{|c|c|c|c|c|}
\hline Source & SS & df & MS & $F$ \\
\hline \multicolumn{5}{|l|}{ Between subjects } \\
\hline Group & 10.14 & 1 & 10.14 & .385 \\
\hline Error & 736.99 & 28 & 26.32 & \\
\hline \multicolumn{5}{|l|}{ Within subjects } \\
\hline Time & 14.48 & 2 & 7.24 & 1.91 \\
\hline Time * Group & .613 & 2 & .307 & .081 \\
\hline Error & 212.50 & 56 & 3.80 & \\
\hline
\end{tabular}


Table G12 2x3 ANOVA with Repeated Measures for LASSI Subscale Concentration

\begin{tabular}{|c|c|c|c|c|}
\hline Source & SS & $\mathrm{df}$ & MS & $F$ \\
\hline \multicolumn{5}{|l|}{ Between subjects } \\
\hline Group & 6.41 & 1 & 6.41 & .102 \\
\hline Error & 1753.69 & 28 & 62.63 & \\
\hline \multicolumn{5}{|l|}{ Within subjects } \\
\hline Time & 41.61 & 1.57 & 26.54 & $4.34^{*}$ \\
\hline Time $*$ Group & 5.69 & 1.57 & 3.63 & .607 \\
\hline Error & 262.71 & 43.90 & 5.98 & \\
\hline
\end{tabular}

Note. ${ }^{*} p<.05$. Greenhouse-Geisser calculation used because sphericity requirement was not met.

Table G13 2x3 ANOVA with Repeated Measures for LASSI Subscale Information Processing

\begin{tabular}{|c|c|c|c|c|}
\hline Source & SS & $\mathrm{df}$ & MS & $F$ \\
\hline \multicolumn{5}{|l|}{ Between subjects } \\
\hline Group & 134.57 & 1 & 134.57 & 2.35 \\
\hline Error & 1602.06 & 28 & 57.22 & \\
\hline \multicolumn{5}{|l|}{ Within subjects } \\
\hline Time & 4.81 & 1.47 & 3.26 & .311 \\
\hline Time $*$ Group & 5.54 & 1.47 & 3.08 & .294 \\
\hline Error & 432.50 & 41.26 & 10.48 & \\
\hline
\end{tabular}

Note. Greenhouse-Geisser calculation used because sphericity assumption was not met. 
Table G14 2x3 ANOVA with Repeated Measures for LASSI Subscale Motivation

\begin{tabular}{|c|c|c|c|c|}
\hline Source & SS & $\mathrm{df}$ & MS & $F$ \\
\hline \multicolumn{5}{|l|}{ Between subjects } \\
\hline Group & 5.34 & 1 & 5.34 & .171 \\
\hline Error & 877.28 & 28 & 31.33 & \\
\hline \multicolumn{5}{|l|}{ Within subjects } \\
\hline Time & 24.19 & 2 & 12.10 & $5.35 *$ \\
\hline Time * Group & .190 & 2 & $9.51 \mathrm{E}-02$ & .042 \\
\hline Error & 126.72 & 56 & 2.26 & \\
\hline
\end{tabular}

Table G15 ANCOVA for LASSI Subscale Selecting Main Ideas

\begin{tabular}{|c|c|c|c|c|}
\hline Source & $\mathrm{SS}$ & df & MS & $F$ \\
\hline \multicolumn{5}{|l|}{ Between subjects } \\
\hline Pretest & 150.08 & 1 & 150.08 & $23.58 *$ \\
\hline Group & 3.68 & 1 & 3.68 & .579 \\
\hline Error & 171.86 & 27 & 6.37 & \\
\hline
\end{tabular}

Within subjects

$\begin{array}{rcccr}\text { Time } & 1.45 & 1 & 1.45 & .949 \\ \text { Time * Pretest } & 2.28 & 1 & 2.28 & 1.49 \\ \text { Time * Group } & 3.43 \mathrm{E}-02 & 1 & 3.43 \mathrm{E}-02 & .022 \\ \text { Error } & 41.20 & 27 & 1.53 & \end{array}$

Note. $* p<.05$. Pretest scores on LASSI Subscale Selecting Main Ideas was used as a covariate. 
Table G16 2x3 ANOVA with Repeated Measures for LASSI Subscale Self Testing

\begin{tabular}{|c|c|c|c|c|}
\hline Source & SS & df & MS & $F$ \\
\hline \multicolumn{5}{|l|}{ Between subjects } \\
\hline Group & 10.97 & 1 & 10.97 & .290 \\
\hline Error & 1059.36 & 28 & 37.83 & \\
\hline \multicolumn{5}{|l|}{ Within subjects } \\
\hline Time & 8.12 & 2 & 4.06 & .830 \\
\hline Time * Group & 4.92 & 2 & 2.46 & .503 \\
\hline Error & 274.05 & 56 & 4.89 & \\
\hline
\end{tabular}

Table G17 2x3 ANOVA with Repeated Measures for LASSI Subscale Study Aids

\begin{tabular}{|c|c|c|c|c|}
\hline Source & SS & $\mathrm{df}$ & MS & $F$ \\
\hline \multicolumn{5}{|l|}{ Between subjects } \\
\hline Group & 2.614 & 1 & 2.614 & .042 \\
\hline Error & 1732.32 & 28 & 61.87 & \\
\hline \multicolumn{5}{|l|}{ Within subjects } \\
\hline Time & 23.84 & 2 & 11.92 & 1.80 \\
\hline Time $*$ Group & 4.46 & 2 & 2.23 & .337 \\
\hline Error & 370.80 & 56 & 6.62 & \\
\hline
\end{tabular}


Table G18 2x3 ANOVA with Repeated Measures for LASSI Subscale Test Strategies

\begin{tabular}{|c|c|c|c|c|}
\hline Source & $\mathrm{SS}$ & $\mathrm{df}$ & $\mathrm{MS}$ & $F$ \\
\hline \multicolumn{5}{|l|}{ Between subjects } \\
\hline Group & 60.28 & 1 & 60.28 & 1.562 \\
\hline Error & 1080.88 & 28 & 38.60 & \\
\hline \multicolumn{5}{|l|}{ Within subjects } \\
\hline Time & 30.74 & 2 & 15.37 & $3.50 *$ \\
\hline Time * Group & 7.14 & 2 & 3.57 & .813 \\
\hline Error & 245.73 & 56 & 4.39 & \\
\hline
\end{tabular}

Note. $* p<.05$.

Table G19 2x3 ANOVA with Repeated Measures for LASSI Subscale Time Management

\begin{tabular}{|c|c|c|c|c|}
\hline Source & $\mathrm{SS}$ & $\mathrm{df}$ & MS & $F$ \\
\hline \multicolumn{5}{|l|}{ Between subjects } \\
\hline Group & .130 & 1 & .130 & .002 \\
\hline Error & 2118.35 & 27 & 78.46 & \\
\hline \multicolumn{5}{|l|}{ Within subjects } \\
\hline Time & 6.58 & 2 & 3.29 & .775 \\
\hline Time * Group & 13.06 & 2 & 6.53 & 1.54 \\
\hline Error & 229.01 & 54 & 4.24 & \\
\hline
\end{tabular}


Table G20 Descriptive Statistics for LASSI

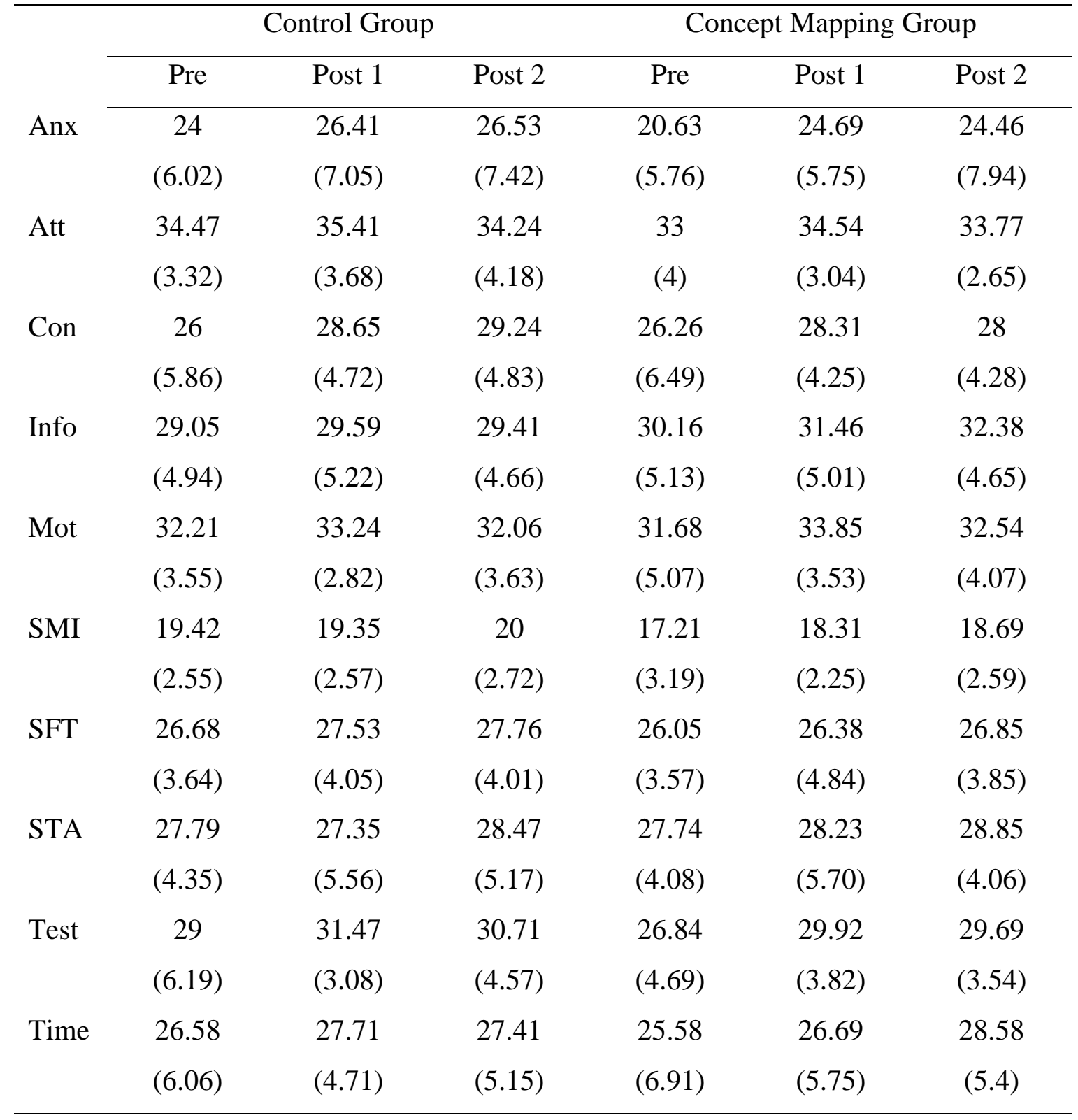

Note. $\mathrm{N}=19$ for pretest for both groups. For posttests $\mathrm{N}=17$ for control group and $\mathrm{N}=13$ for concept mapping group. Anx $=$ Anxiety. Att $=$ Attitude. Con $=$ Concentration. Info = Information Processing. Mot = Motivation. SMI = Selecting Main Ideas. SFT = Self Testing. STA = Study Aids. Test $=$ Test Strategies. Time $=$ Time Management. Standard deviations are in parentheses. 
Table G21 2x2x2 ANOVA with Repeated Measures for Kinesiology High Items versus Low Items by Group

\begin{tabular}{|c|c|c|c|c|}
\hline Source & SS & $\mathrm{df}$ & MS & $F$ \\
\hline \multicolumn{5}{|l|}{ Within Subjects } \\
\hline Time & .268 & 1 & .268 & $14.890 *$ \\
\hline Time*Group & 8.962E-03 & 1 & $8.962 \mathrm{E}-03$ & .498 \\
\hline Error (Time) & .504 & 28 & $1.80 \mathrm{E}-02$ & \\
\hline Item & .626 & 1 & .626 & $72.126 *$ \\
\hline Item*Group & $5.047 \mathrm{E}-02$ & 1 & $5.047 \mathrm{E}-02$ & $5.811 *$ \\
\hline Error (Item) & .243 & 28 & 8.684E-03 & \\
\hline Time*Item & 2.284E-03 & 1 & $2.284 \mathrm{E}-03$ & .297 \\
\hline Time*Item*Group & $6.210 \mathrm{E}-05$ & 1 & $6.210 \mathrm{E}-05$ & .008 \\
\hline Error (Time*Item) & .216 & 28 & 7.699E-03 & \\
\hline \multicolumn{5}{|l|}{ Between Subjects } \\
\hline Group & $3.466 \mathrm{E}-02$ & 1 & $3.466 \mathrm{E}-02$ & .776 \\
\hline Error & 1.25 & 28 & 4.465E-02 & \\
\hline
\end{tabular}

Note. $p<.05$. 
Table G22 Descriptive Statistics for Kinesiology High Items versus Low Items by Per cent Control Group Concept Mapping Group

$$
(n=17) \quad(n=13)
$$

Low level items High level items Low level items High level items

\begin{tabular}{lllll}
\hline Test 1 & $.497(.173)$ & $.400(.021)$ & $.554(.097)$ & $.377(.079)$ \\
Test 2 & $.582(.184)$ & $.471(.146)$ & $.677(.156)$ & $.480(.132)$
\end{tabular}

Note. Standard deviations are within parentheses. 


\section{Appendix H: Example of Coded Transcript from Interview (Inductive Analysis)}

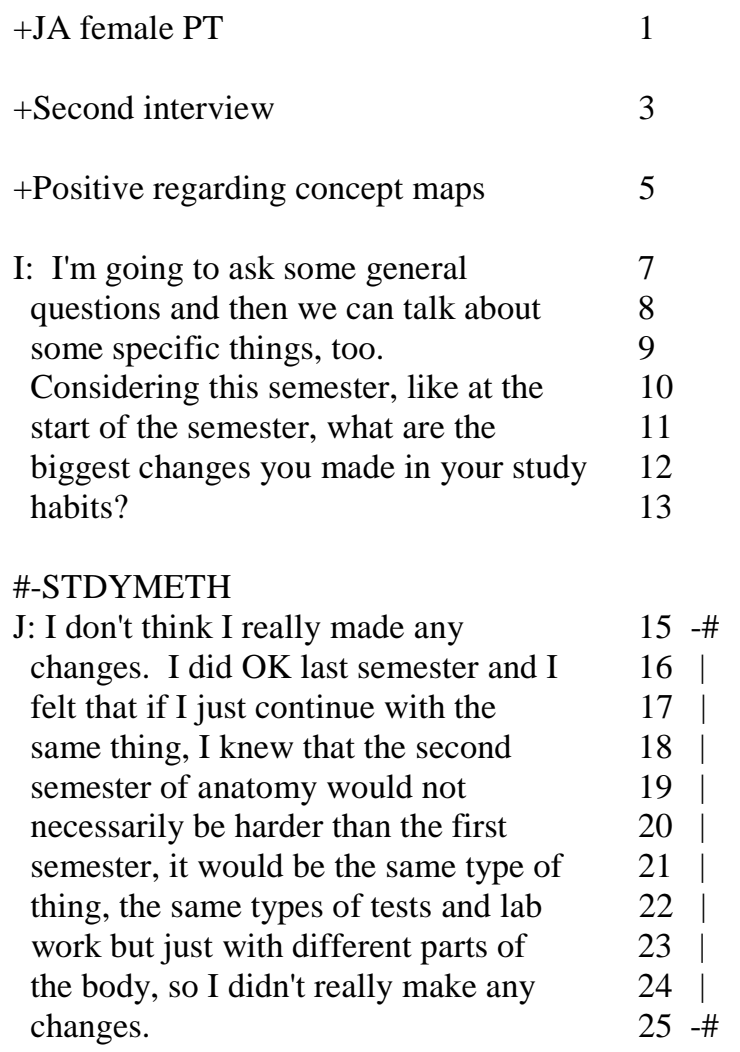

\#-TRANSFER

I: How does Kinesiology fit into the 27M -\# mix?

J: I really, I have to say I really like the class. It's nice that they kind of compliment each other, you know. You're not totally learning new material with Kinesiology. Recalling of some anatomy. It's just another dimension of it. So I think it's pretty good. I think PT's in a way have an advantage with it because we have Mr. X for class and for lab so it perfectly fits together. I mean there's no difference and whatever we learn in class we just carry right on $\quad 42$ into the lab. But I know that's 43 really not the same for OT's at least, $\quad 44$ and any kind of problems we are having 45 in lecture, we have the opportunity 46 ask those in lab so I think it allows $\quad 47$ us to do well in there.

I: What about your study habits? Do 50 
you study for Kinesiology the same way 51

that you do for anatomy? 52

\#-STDYMETH

J: I really do, just because they both 54 -\#

have kind of a course manual, and I 55

write things in during class, just $\quad 56$

like I do in anatomy and use the book. $\quad 57$

I don't really read the book word for $\quad 58$

word; I use it for clarification on 59

certain matters and also for the 60

figures. I think the figures are 61

really good. But generally I study 62 |

the same way. 63 -\#

I: Have you run into anything in 65

Kinesiology that gives you trouble? 66

\section{\#-TESTPREP}

$\mathrm{J}$ : I wouldn't say the material is $\quad 68 \mathrm{M}-\#$

necessarily hard. It is sometimes 69

more in depth. It just depends what $\quad 70$

we are covering, certain ligaments, 71

especially with motions and things 72

like that that we really didn't learn 73

as much in anatomy. What was the 74

question again? I was thinking, oh, 75

was there anything I found hard. $\quad 76$

(Yeah, was there anything difficult?) 77

No, the only thing is the test format 78

really makes you think. But as far as 79

the content, no, the style of the 80

tests is always the K style question, $\quad 81$

and that is hard. So you have to 82

really know your stuff and you have to 83 |

know your choices. 84 -\#

I: Yes, that's true for K questions on $\quad 86$

lots of topics. How about when you are 87

getting a new topic in Kinesiology, $\quad 88$

how do you think about learning the $\quad 89$

new information? Like, how do you plan 90

it out in terms of what you are going 91

to do with it? 92

\#-TRANSFER \$-OVERWHELM \%-METACOG

$\mathrm{J}$ : With everything that we have learned $\quad 94 \mathrm{M}-\#-\$-\%$

in Kinesiology so far we've covered it 95 |||

in anatomy first, so, I have some kind 96 |||

of background information. And I, you 97 |||

know he starts teaching different 98 \|ा

motions and all kinds of things that 99 ||

are related to the new topic. I start $100 \quad \|$

to get overwhelmed, but I think, wait 101 ||

a second, I know the bases here, we 102 ||

are just learning it in a different 103 || 
way, and adding a different dimension. So, I think they really complement each other. And I think having it this semester is really a good time too, so I guess they used to have it 4 th year or something. I think it really fits in great now. A lot of the clinical stuff we don't really know, but we run across that in lab and he teaches us some things. It's really good.

104
105
106
107
108
109
110
111
112
113
114

I: What about with anatomy, you learn 116 something in class and you go into the 117 lab and there it is. What about with 118 Kinesiology? Isn't there sometimes 119 people have a hard time picturing $\quad 120$ things?

\section{\#-KINES \#-STDYMETH \$-MOVEMENT}

J: Right, and I think, I find myself 123 -\#-\$

getting up and actually moving like 124 ||

when we did some things with the hip. 125 ||

The anterior pelvic tilt, posterior 126 ||

and you're thinking wait, how is that 127 ||

really moving like that? But I think 128 ||

the lab helps with that too. We joke 129 ||

around, all right, who's going to get 130 ||

up and do this motion or whatever, but 131 ||

that, I think that helps. And I would 132 |-\$

use the book more for that kind of 133

thing because sometimes when you are 134

writing things down in class on the 135

course manual, you don't catch every $\quad 136$

bit, and you might totally miss 137

something. So I would use the book 138 |

for that.

$139-\#$

I: Have you used any concept maps for $\quad 141$

Kinesiology? 142

J: No. $\quad 144$

I: What kinds of things do think would 146

make it so that concept maps would be 147

like a good way to study for $\quad 148$

Kinesiology? 149

\#-CMAP \#-TESTPREP \#-STDYMETH \#-TIMING

J: I don't know. I think you could 151M -\#

really use them with how the course is 152 |

now. I just end up, I feel like I run 153

out of time a lot. And I instead go 154

back and make my notes more complete. 155

But I could just as easily do the 156

concept map thing, I just always think 157 
I: When you are getting ready for a $\quad 171$ test in Kinesiology, how do you see if 172 you're ready? 173

\section{\#-STDYMETH \#-TESTPREP}

J: I'd almost like talk to myself. It's really weird, but I don't find myself falling into that same pattern of just looking at notes over and over and over again and just letting myself

I: So you were done studying Kines 195 ahead of time? 196

J: Yeah, definitely, the day before, I 198 would only look at a couple of things 199 that I really needed to look at. 200

I: How did you do that? 202

J: How with Kines? 204

I: Yes. 206

\#-STDYMETH \#-UPKEEP \$-COERC \$-TIMING \$-HABIT

J: Um, I make myself go back after 208 -\#-\$

class. And even if it's half an hour, 209 ||

just so I don't totally forget the 210 \| 


name of a ligament or don't forget
like when we learned valgus and varus
forces that was really strange at

I: When did you develop that habit? 244

J: This year. 246

I: You didn't do that in high school, $\quad 248$

or in the first two years? 249

\$-PREVHABIT \$-METACOG

J: No, my study habits now are so $\quad 251 \quad-\$$

different than high school. I 252 |

\#-STDYMETH \#-TESTPREP

actually have study habits, and I 253 -\# |

don't want to say that I didn't study 254 ||

in high school, but I don't have the 255 ||

same type of planned schedule that I 256 ||

do now where I make a list and try to 257 ||

do something not necessarily for a 258 ||

certain period of time, but I know 259 ||

that I need to work on anatomy until I 260 ||

feel okay I feel comfortable enough 261 ||

with this I can put it down and then 262 ||

pick up something else. 263 -\#-\$ 
I: How did you know you had to change 265

your study habits?

\#-MOTIVATN \#-FEAR

J: Because I want to do really well and 268 -\#

like I said in our last interview I 269

said I almost came in scared and that 270

fear kind of made me "I better study 271

this....I better study until I know it, $\quad 272$

I don't want to be up all hours of the 273

night", and I make myself go to bed so 274

I know I'm not going to go to bed 275

later than 12:30 so I need to look at 276 ।

this now. 277 -\#

I: With Kinesiology, how do you 279

organize the information when you $\quad 280$

study it? 281

\#-STDYMETH

$\mathrm{J}$ : I follow the flow of the notes 283M -\#

basically. And then again, some 284 |

things are so much easier to grasp for 285

me, so I'll put like a little mark or 286

star beside something I need to come 287

back to, and then I'll back-track, but 288 ।

otherwise I just kind of go with it. 289 -\#

I: Do you ever, say you are starting to 291

studying the elbow, do you ever go 292

back and compare it to the shoulder or 293

something like that, or do you just 294

kind of keep all those..... 295

\#-CONNECTNS \#-STDYMETH

J: I try to keep, in my mind like, I 297 -\#

don't always just flip back and forth 298 |

and say "this is this kind of joint, 299

what's this kind of joint" I know 300

that's something that you have to keep 301

in your mind to be able to recall, $\quad 302$

really quickly. What was the question 303

again? (About whether or not you 304

compare like certain parts to other $\quad 305$

parts.) I think that as we go along, 306

I can see certain similarities and $\quad 307$

certain differences like presence of $\quad 308$

like articular cartridge, or like $\quad 309$

joint capsule, just certain things $\quad 310$

like "oh, that's kind of like how it 311

is at the elbow, or how it is at the $\quad 312$

knee, and also with the muscles and 313

motion, I think, OK, what flexes the 314

knee but what flexes the elbow, and I 315

do things like that, but I think 316

that's about it probably. 317 -\# 
I: Is there anything else that you can $\quad 319$

think of about Kinesiology that might $\quad 320$

be different from anatomy? Would you 321

have had such an easy time in 322

Kinesiology if you hadn't had anatomy 323

yet?

\#-TRANSFER

$\mathrm{J}$ : It would be really hard for me I 326M -\#

think because I have had no anatomy. $\quad 327$

I never even had it in high school, so $\quad 328$

to take Kinesiology, I probably 329

wouldn't be able to get over the names $\quad 330$

of the bones and the muscles let alone $\quad 331$

what actually is going on at the 332

joint, so that would be very hard for 333

me. But having anatomy and as much 334

anatomy as we had was perfect because 335

we started with the shoulder and $\quad 336$

general concepts first and then we $\quad 337$

went to the shoulder and things like $\quad 338$

that and that was, we spent a lot of 339

time on the shoulder even though we $\quad 340$

had done that way back in anatomy, 341

that was still something we could 342 |

build upon, because we did it before. 343 -\#

I: When you were asking about the 345

muscle function earlier, that's going 346

to be for the fall in Eval Methods, so 347

that's when you are going to have a 348

good idea about the Kinesiology 349

anatomy should make muscle testing a $\quad 350$

lot easier. $\quad 351$

\#-EXPECTATN

J: Right, I can see that. My roommate 353 -\#

was doing some muscle testing on me 354 |

and I could see some things that I 355

could really make sense of it, not 356

evening learning muscle testing, but $\quad 357$

what we've learned so far it didn't 358

seem something that wasn't really that 359 |

bad. It seemed kind of neat actually. $\quad 360$-\#

I: So everything you learn from here on $\quad 362$

out is not going to be completely new 363

to you? 364

\#-OVERWHELM \#-EXPECTATN \#-FEAR

J: I guess not, I don't know, maybe I 366 -\#

need to think of it that was because I 367

think "oh my gosh, if I learn as much 368

next year, it's all new, how am I 369

going to be able to retain all of $\quad 370$ 
this, but I guess it's just, you are

I: If you were to have all next year be $\quad 375$ about French Literature, then you 376 might have to worry about retaining it $\quad 377$ all.

J: Yeah, and I think if maybe I would $\quad 380$ change my major or something I think 381 maybe that would be easier, but yet it $\quad 382$ would all be new. I mean changing 383 your major to education your business $\quad 384$ I don't have any background in that. $\quad 385$ So, I think anything would be hard. $\quad 386$ Anything is hard at first. $\quad 387$

I: So you think you are going to stick $\quad 389$ with what you have? 390

J: Yeah, I'm not changing my major now. 392

+Extra questions with answers in written 394 format after the participant had read 395 the transcript. 396

I: What would you say is the biggest 398 change in your thinking over the past 399 year? 400

\section{\#-MOTIVATN}

J: That getting As in subjects means 402 -\# everything, when in actuality it 403 doesn't. I have tried to focus on how $\quad 404$ to be a good clinician. I try not to 405 focus only on the material we have 406 learned, but instead on how I can use 407 | it and be the best PT possible. 408 -\# 
Appendix I: Example Matrix for Logical Analysis (Research Question Six)

\begin{tabular}{|c|c|c|c|c|c|c|}
\hline & $\mathrm{CG}$ & DK & GD & GJ & JA & SJ \\
\hline $\begin{array}{l}\text { Overwhelm/ } \\
\text { Expectation }\end{array}$ & $\begin{array}{l}\text { Our expectations for } \\
\text { third year was that it } \\
\text { was going to be } \\
\text { hectic. And that } \\
\text { there would be a lot } \\
\text { of work that you } \\
\text { would have to work } \\
\text { through and pretty } \\
\text { much that came } \\
\text { true. Like trying to } \\
\text { balance and trying } \\
\text { to find a balance } \\
\text { between different } \\
\text { subjects. It was a lot } \\
\text { different from } \\
\text { sophomore year. } \\
\text { [CG1 Lines: } 39-47 \text { ] } \\
\text { We expected it. We } \\
\text { expected much } \\
\text { worse actually. I: } \\
\text { How could it have } \\
\text { been worse? C: I } \\
\text { don't know. Like, all } \\
\text { of last year while } \\
\text { we were taking our, } \\
\text { they were easier } \\
\text { classes, they were } \\
\text { core classes, then } \\
\text { we'd hear from like } \\
\text { the third years, like } \\
\text { oh my god, there's } \\
\text { so much work! Or } \\
\text { whatever. And we } \\
\text { expected that but we }\end{array}$ & $\begin{array}{l}\text { I: How was last } \\
\text { semester different } \\
\text { from previous } \\
\text { years? } \\
\text { D: Shocking. } \\
\text { I: Shocking, in what } \\
\text { way? } \\
\text { D: I, um, a lot of } \\
\text { new information, a } \\
\text { lot more } \\
\text { information. Wasn't } \\
\text { used to the content, } \\
\text { you know? Kind of } \\
\text { overwhelming in a } \\
\text { sense. } \\
\text { (DK 17-27) }\end{array}$ & $\begin{array}{l}\text { I didn't expect to be } \\
\text { as rigorous as it is. } \\
\text { Bounce from one } \\
\text { thing to the next. I'm } \\
\text { trying to... it's hard } \\
\text { to stay ahead of the } \\
\text { game with that } \\
\text { many classes, with } \\
\text { that much material } \\
\text { that's being } \\
\text { presented. Even } \\
\text { though it's not a lot } \\
\text { really, it's like } \\
\text { average with } 16 \\
\text { credits, but there's a } \\
\text { lot of material so it } \\
\text { seems like your } \\
\text { bouncing from test } \\
\text { to test. And just } \\
\text { really, you're not } \\
\text { really, really really } \\
\text { playing catch up. } \\
\text { You're always } \\
\text { behind and there's } \\
\text { always something } \\
\text { looming the next } \\
\text { week, so. I guess it's } \\
\text { tough, it is more } \\
\text { rigorous than I } \\
\text { expected it to be. } \\
\text { [GD1 Lines: } 64-79 \text { ] }\end{array}$ & $\begin{array}{l}\text { Well, um, at first I } \\
\text { didn't expect the } \\
\text { amount of work. } \\
\text { Like I knew it was } \\
\text { going to be a lot of } \\
\text { work, but I never } \\
\text { expected that it was } \\
\text { going to be as much } \\
\text { as it really was. } \\
\text { And, so, from that } \\
\text { standpoint, I was } \\
\text { unprepared and I } \\
\text { thought I could go } \\
\text { about like my } \\
\text { normal study habits. } \\
\text { And my normal } \\
\text { study habits often } \\
\text { involve waiting } \\
\text { until a couple of } \\
\text { days before the test, } \\
\text { before I start. And, } \\
\text { so that's what I did } \\
\text { for the first test and } \\
\text { I didn't do so swift. } \\
\text { And, then I realized } \\
\text { that I had to start } \\
\text { sooner, but it just } \\
\text { like so happened } \\
\text { that like with the } \\
\text { next test there was a } \\
\text { round of other tests } \\
\text { and the same thing } \\
\text { sort of happened. I } \\
\text { was a little bit } \\
\text { better, like maybe I }\end{array}$ & $\begin{array}{l}\text { With everything that } \\
\text { we have learned in } \\
\text { Kinesiology so far } \\
\text { we've covered it in } \\
\text { anatomy first, so, I } \\
\text { have some kind of } \\
\text { background } \\
\text { information. And I, } \\
\text { you know he starts } \\
\text { teaching different } \\
\text { motions and all } \\
\text { kinds of things that } \\
\text { are related to the } \\
\text { new topic. I start to } \\
\text { get overwhelmed, } \\
\text { but I think, wait a } \\
\text { second, I know the } \\
\text { bases here, we are } \\
\text { just learning it in a } \\
\text { different way, and } \\
\text { adding a different } \\
\text { dimension. [JA2 } \\
\text { Lines: } 94-104] \\
\text { Okay, I knew that } \\
\text { last, like beginning } \\
\text { last semester it } \\
\text { would be my most } \\
\text { difficult semester } \\
\text { that I've had so far. } \\
\text { And I have to say I } \\
\text { was really nervous. } \\
\text { I had never had any } \\
\text { kind of anatomy in } \\
\text { high school or }\end{array}$ & $\begin{array}{l}\text { It was a kick in the } \\
\text { butt, basically. It } \\
\text { was, um, I don't } \\
\text { know that it was } \\
\text { harder than I } \\
\text { expected, but I had } \\
\text { to like, my way of } \\
\text { studying had to be } \\
\text { completely } \\
\text { different. I think a } \\
\text { lot more } \\
\text { information all at } \\
\text { once, than I } \\
\text { expected, like I } \\
\text { knew it was going } \\
\text { to be a lot, I just } \\
\text { didn't realize that it } \\
\text { would be so much, } \\
\text { so concentrated. } \\
\text { [SJ1 Lines: 25-33] }\end{array}$ \\
\hline
\end{tabular}




\begin{tabular}{|c|c|c|c|c|c|c|}
\hline & CG & DK & GD & GJ & JA & SJ \\
\hline & $\begin{array}{l}\text { raised the level in } \\
\text { our heads, so it } \\
\text { wasn't as bad. [CG1 } \\
\text { Lines: 51-63] }\end{array}$ & & & $\begin{array}{l}\text { had an extra day or } \\
\text { two, but I still... } \\
\text { Like, my grade } \\
\text { improved, but not as } \\
\text { much as I had } \\
\text { wanted it to. So } \\
\text { then, the third test, } \\
\text { well I guess the } \\
\text { final, I started } \\
\text { earlier and I did do } \\
\text { better on the final. } \\
\text { But, I just, I mean, I } \\
\text { totally didn't expect } \\
\text { the amount of } \\
\text { information that it } \\
\text { was. [GJ1 Lines: } \\
\text { 22-48] }\end{array}$ & $\begin{array}{l}\text { physiology or } \\
\text { anything like that. I } \\
\text { took advanced } \\
\text { chemistry and that } \\
\text { was about it so I } \\
\text { knew that coming in } \\
\text { I felt disadvantaged } \\
\text { that I never had that } \\
\text { kind of experience. } \\
\text { So I knew that I [JA } \\
1 \text { Lines: } 15-25]\end{array}$ & \\
\hline Apprehension & & $\begin{array}{l}\text { Overall it was good. } \\
\text { I don't know if it's } \\
\text { for me personally if } \\
\text { it's going to be } \\
\text { another way to } \\
\text { study. Because I } \\
\text { don't, it may have } \\
\text { helped, it may not } \\
\text { have, I just don't, I } \\
\text { guess I'm so a } \\
\text { creature of habit that } \\
\text { I'm so used to doing } \\
\text { everything else that } \\
\text { I'm really afraid to } \\
\text { start something new. } \\
\text { So I don't, I think } \\
\text { it's a good idea and I } \\
\text { think it could help } \\
\text { me study if I was } \\
\text { open to that kind of } \\
\text { thing. [FOCGRP } \\
\text { Lines: } 1410-1420]\end{array}$ & $\begin{array}{l}\text { I like it. Um, I think } \\
\text { it's good. It really, I } \\
\text { guess it's kind of not } \\
\text { what you had in } \\
\text { mind. (laughs) from } \\
\text { my perspective but } \\
\text { um, it did, it } \\
\text { definitely did help } \\
\text { me and um I think it } \\
\text { helps. It must work! } \\
\text { I: Why do you say } \\
\text { that? G: Well, } \\
\text { because Gertie does } \\
\text { pretty good and she } \\
\text { uses it a lot! And, } \\
\text { um, I mean I } \\
\text { couldn't bring } \\
\text { myself to do that. I } \\
\text { just, you know, the } \\
\text { way she, if she truly } \\
\text { does study } \\
\text { specifically from }\end{array}$ & & & $\begin{array}{l}\text { I don't know, I don't } \\
\text { know whether it's } \\
\text { just kind of like, } \\
\text { well that's what I've } \\
\text { been doing, so that's } \\
\text { what I'm most } \\
\text { comfortable with so, } \\
\text { also I: You would } \\
\text { be afraid to.. S: } \\
\text { Right. Yeah, it's } \\
\text { probably more like } \\
\text { paranoia that if I } \\
\text { don't do this and I } \\
\text { do bad, is that why? } \\
\text { Not necessarily like } \\
\text { any other reason. } \\
\text { (inaudible) } \\
\text { [FOCGRP Lines: } \\
\text { 862-885] } \\
\text { I think I was just, } \\
\text { there was just so }\end{array}$ \\
\hline
\end{tabular}




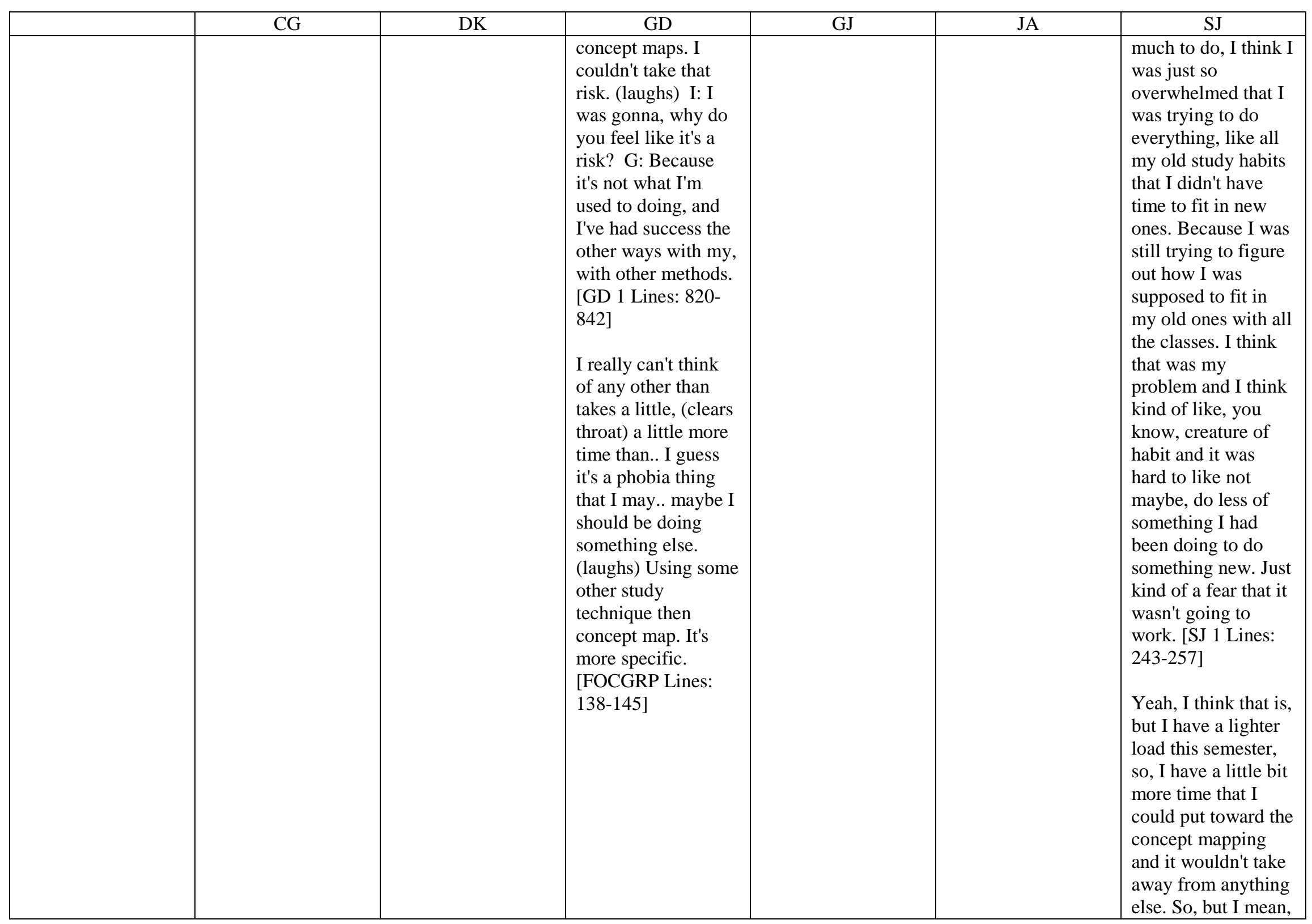




\begin{tabular}{|c|c|c|c|c|c|c|}
\hline & $\mathrm{CG}$ & DK & GD & GJ & JA & SJ \\
\hline & & & & & & $\begin{array}{l}\text { yeah, that was my } \\
\text { biggest problem last } \\
\text { semester was like } \\
\text { the change in } \\
\text { studying and just } \\
\text { like afraid that it } \\
\text { was going to take } \\
\text { away something that } \\
\text { has already been } \\
\text { working. So, but } \\
\text { now, I'm pretty sure } \\
\text { it will help so it's } \\
\text { kind of not, it's not } \\
\text { so scary now cause } \\
\text { if you know it's } \\
\text { going to help, it's } \\
\text { okay to have that } \\
\text { take up time, you } \\
\text { know? So. [SJ } 1 \\
\text { Lines: 435-449] }\end{array}$ \\
\hline Metacognition & $\begin{array}{l}\text { I think that they are } \\
\text { good for active } \\
\text { learning. Like if you } \\
\text { use it a certain way. } \\
\text { It depends on how } \\
\text { you use it I guess. } \\
\text { And some people } \\
\text { can just look at the } \\
\text { map and do it, but } \\
\text { it's easier if it's } \\
\text { hands-on, I stay } \\
\text { more awake than if } \\
\text { I'm sitting there like, } \\
\text { honestly, sitting } \\
\text { there memorizing, } \\
\text { like this is such and } \\
\text { such, and you are } \\
\text { like oh, I know it, } \\
\text { but you don't! You }\end{array}$ & $\begin{array}{l}\text { I didn't have any } \\
\text { trouble with the } \\
\text { software, but on the } \\
\text { other hand I have } \\
\text { never concept } \\
\text { mapped, done any } \\
\text { concept mapping } \\
\text { before. So it was a } \\
\text { new idea to learn. } \\
\text { A new process. And } \\
\text { I don't know if it, } \\
\text { hopefully I'll benefit } \\
\text { from it, but like said } \\
\text { before, I think I'm } \\
\text { better off whenever } \\
\text { it comes to reading } \\
\text { notes and not even } \\
\text { necessarily } \\
\text { memorizing but just }\end{array}$ & $\begin{array}{l}\text { So, and that's } \\
\text { typically how I do } \\
\text { study. I don't, I don't } \\
\text { memorize. Now I } \\
\text { don't memorize } \\
\text { things, small points, } \\
\text { little detailed stuff. I } \\
\text { just try to look at the } \\
\text { general concepts } \\
\text { behind it and I try to } \\
\text { relate the general } \\
\text { concepts to other } \\
\text { things. And if I get } \\
\text { the general concept } \\
\text { I'm fine. [GD } 1 \\
\text { Lines: 133-141] } \\
\text { Yeah, yeah. I } \\
\text { change all the time. }\end{array}$ & $\begin{array}{l}\text { So, I just think that } \\
\text { as far as how I } \\
\text { studied before, like I } \\
\text { mean, this is just } \\
\text { going to be harder I } \\
\text { think for me. I: Do } \\
\text { you... So it won't } \\
\text { be, um, on account } \\
\text { of doing the concept } \\
\text { maps, you'll be a } \\
\text { step ahead. You'll } \\
\text { feel like you have to } \\
\text { go back to the } \\
\text { beginning. G: I'm } \\
\text { going to feel like I } \\
\text { have to do double } \\
\text { the work I think. } \\
\text { Just 'cause I do } \\
\text { things at the last }\end{array}$ & $\begin{array}{l}\text { It was really } \\
\text { different, but it was } \\
\text { pretty easy to work } \\
\text { in. First of all I was } \\
\text { looking for } \\
\text { something to kind of } \\
\text { give me an edge to } \\
\text { kind of really help } \\
\text { me to better } \\
\text { understand what } \\
\text { was presented in } \\
\text { class and what I had } \\
\text { in my notes. [JA } 1 \\
\text { Lines: 365-3xx] } \\
\text { I guess not, I don't } \\
\text { know, maybe I need } \\
\text { to think of it that }\end{array}$ & $\begin{array}{l}\text { If it's, if that's } \\
\text { appropriate, um, I } \\
\text { just write, well I } \\
\text { don't know if that } \\
\text { would be visual } \\
\text { learning, but I just I } \\
\text { tend to write a lot. } \\
\text { Like, I'm not, I don't } \\
\text { just read. Like I try } \\
\text { to, I guess not } \\
\text { maybe a visual } \\
\text { learner but I'm an } \\
\text { active learner. Like I } \\
\text { can't just sit there } \\
\text { and read the notes } \\
\text { over and over, I } \\
\text { have to like, recopy } \\
\text { them or take notes } \\
\text { from the notes or }\end{array}$ \\
\hline
\end{tabular}




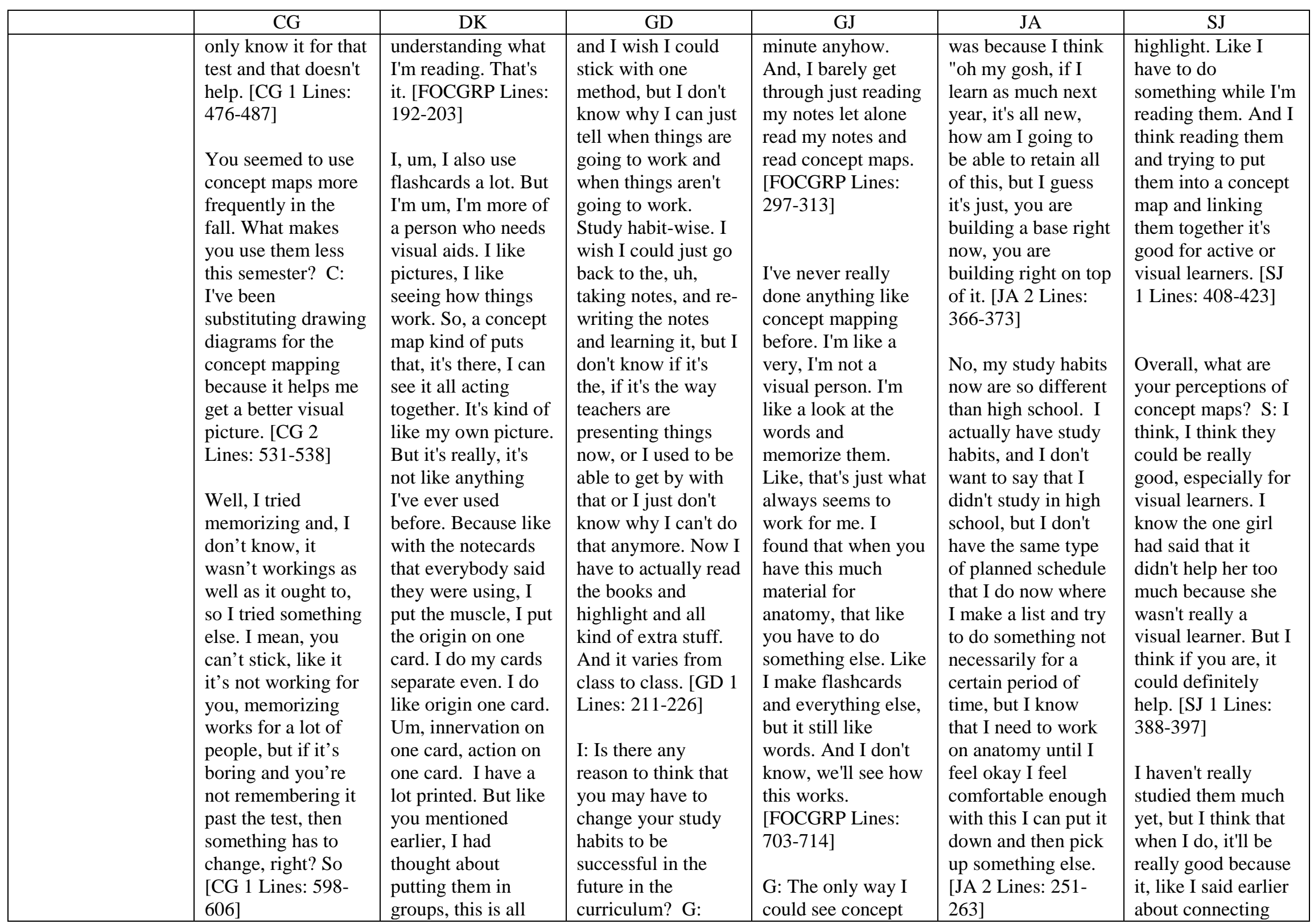




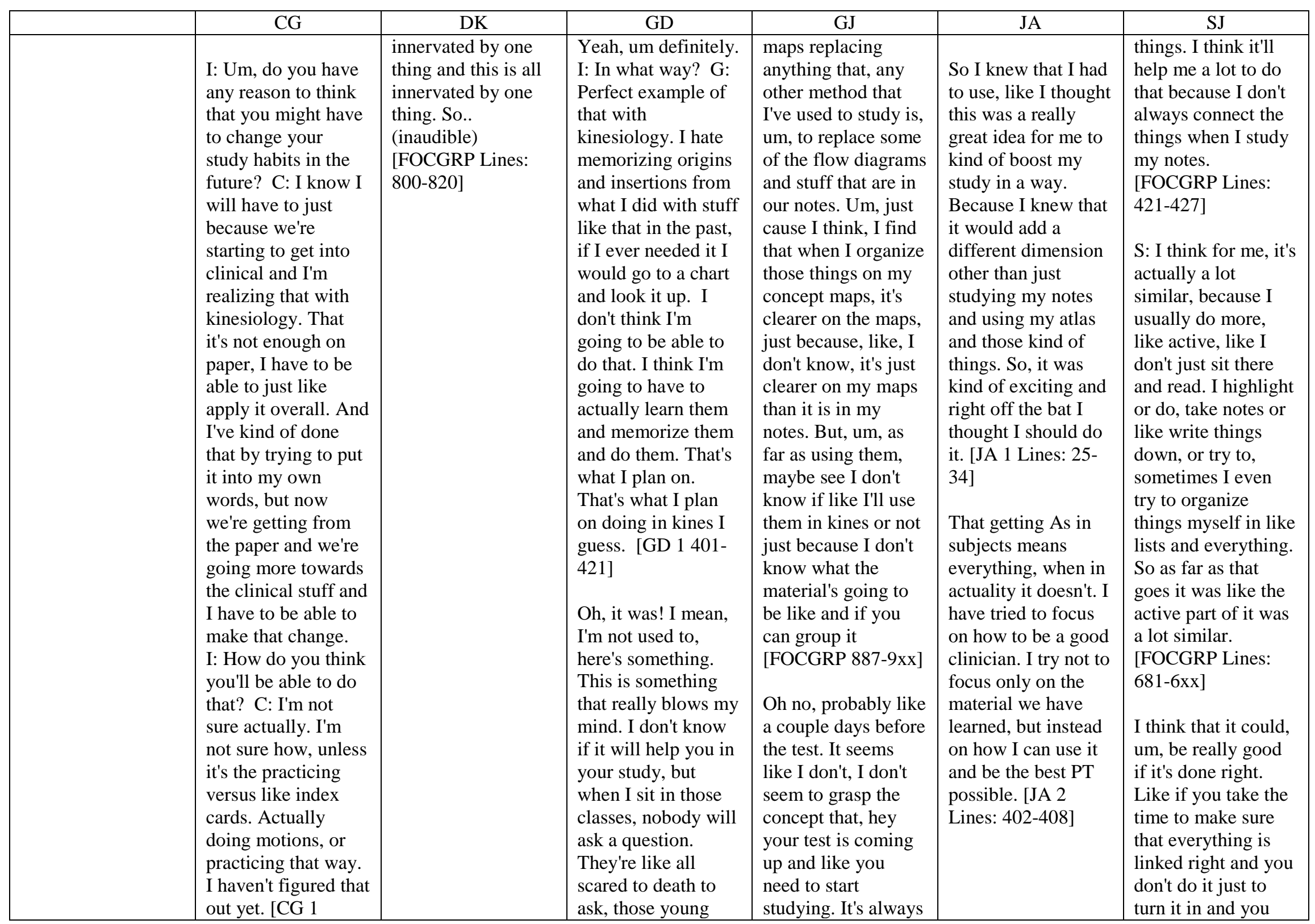




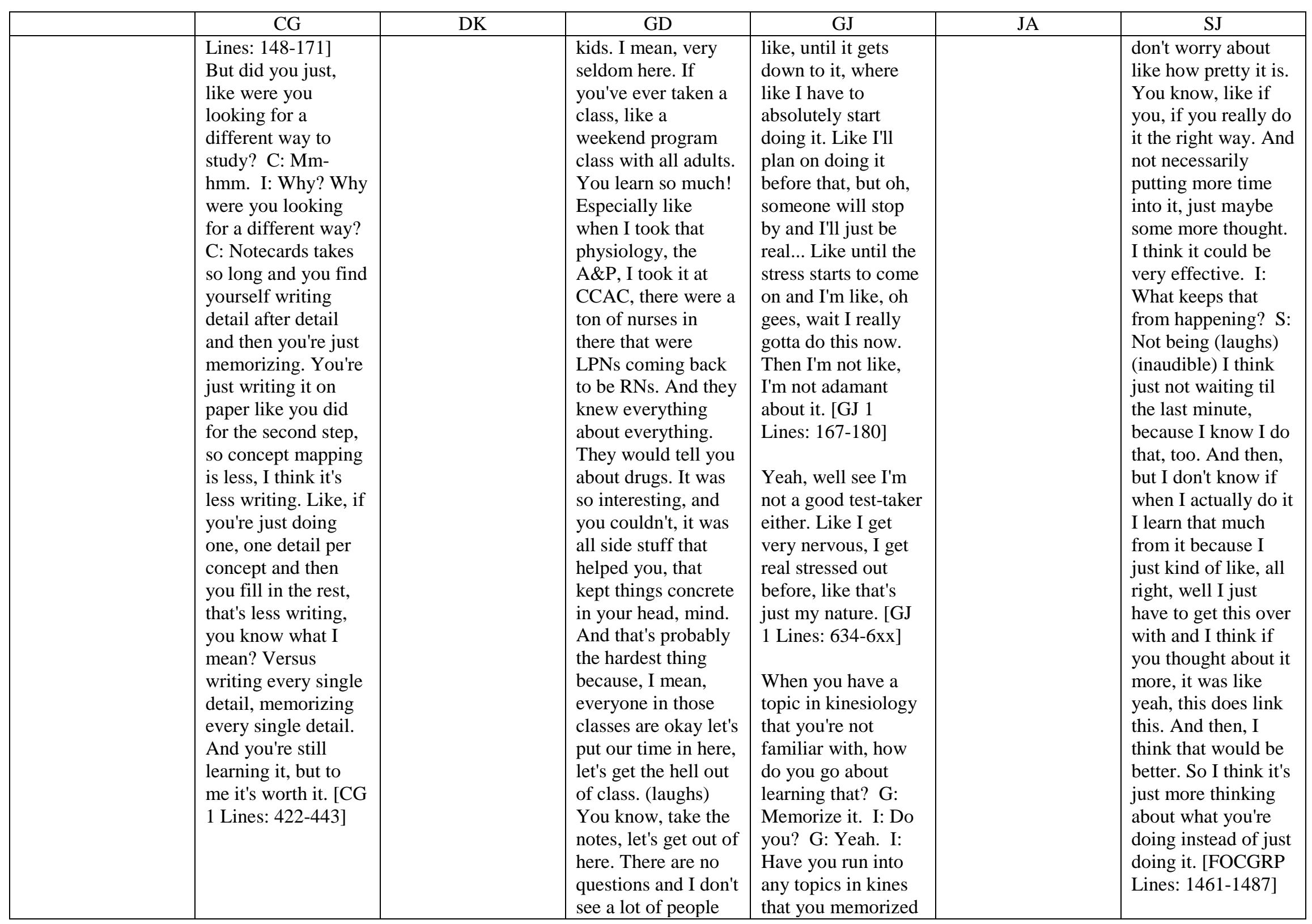




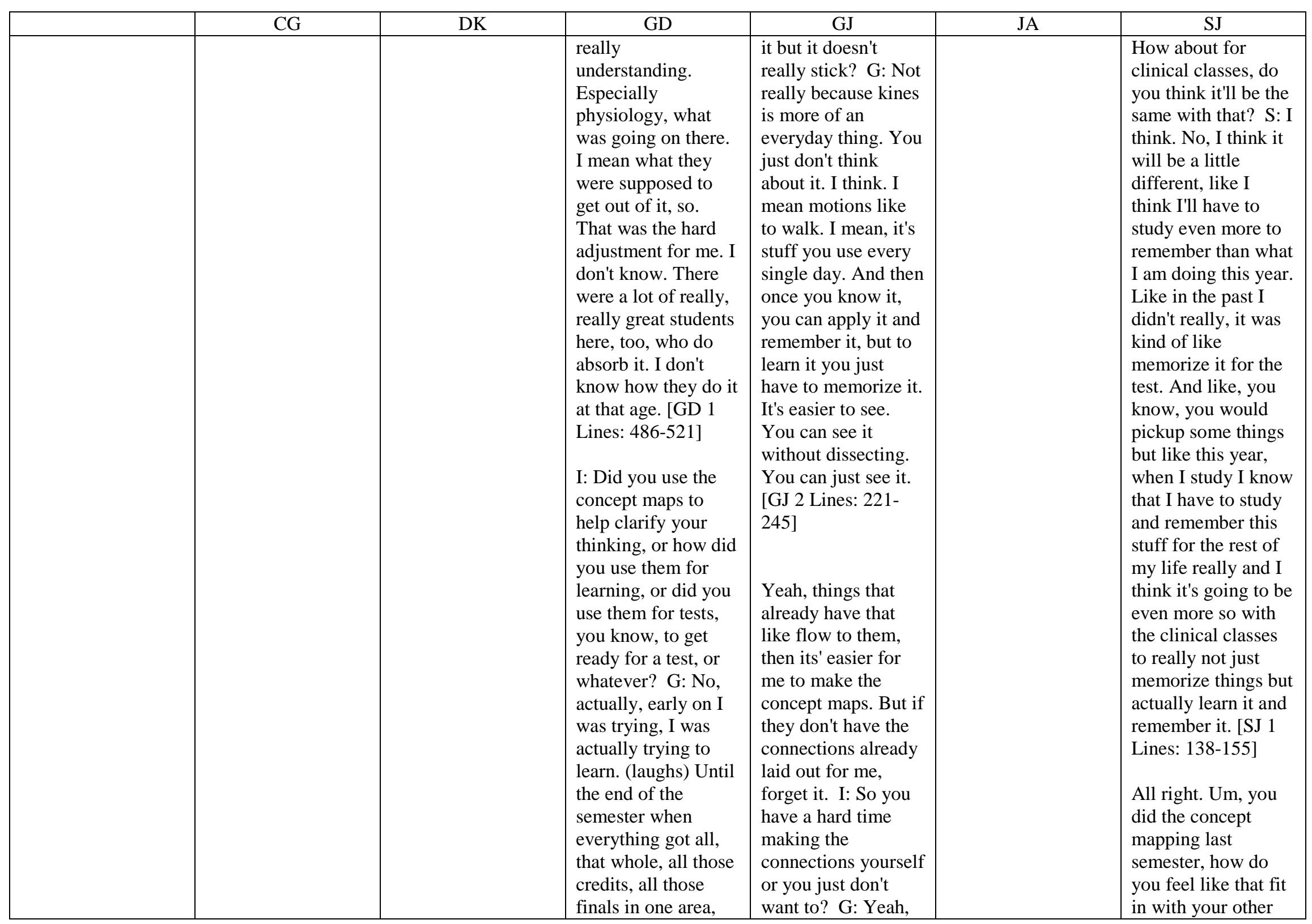




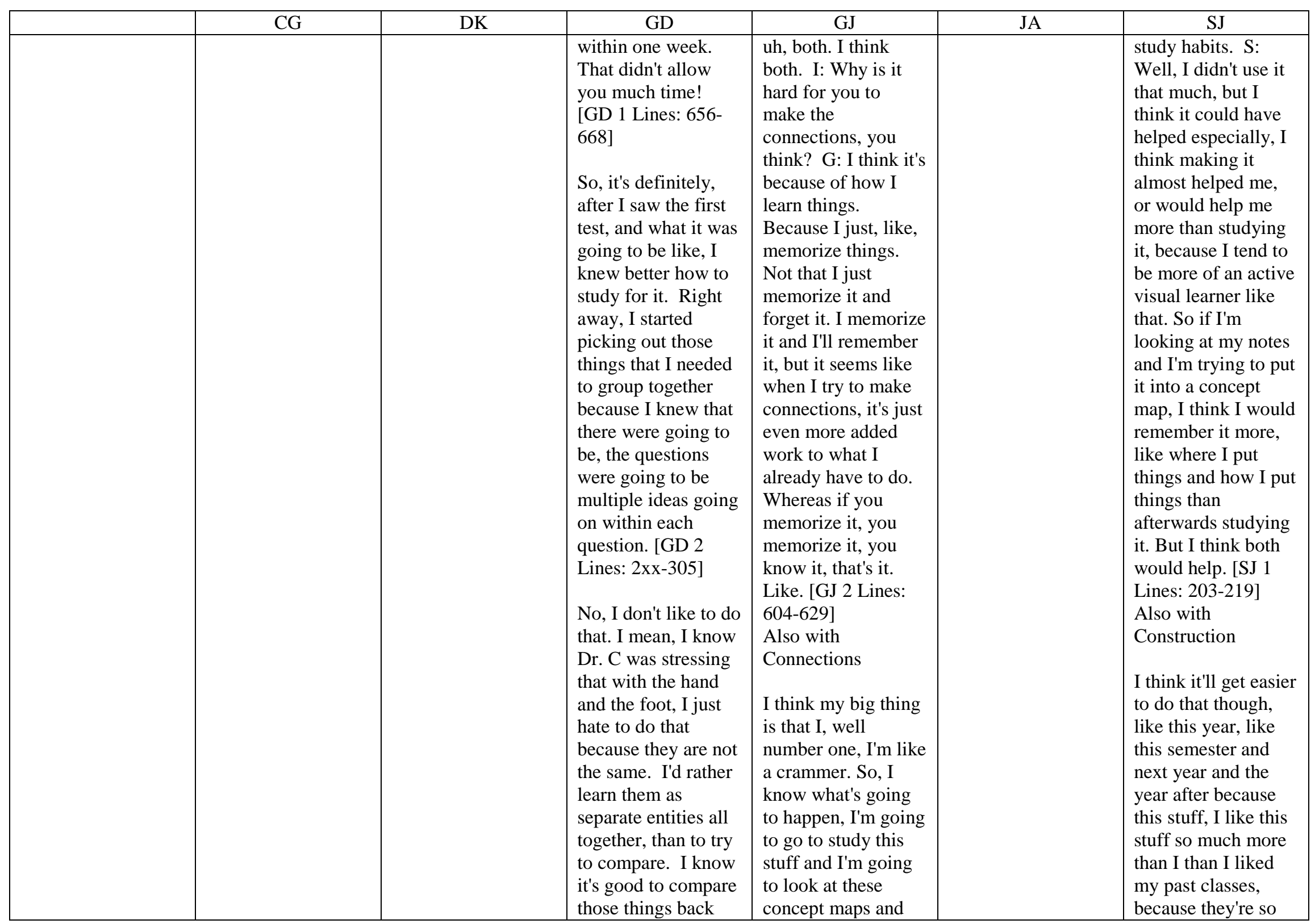




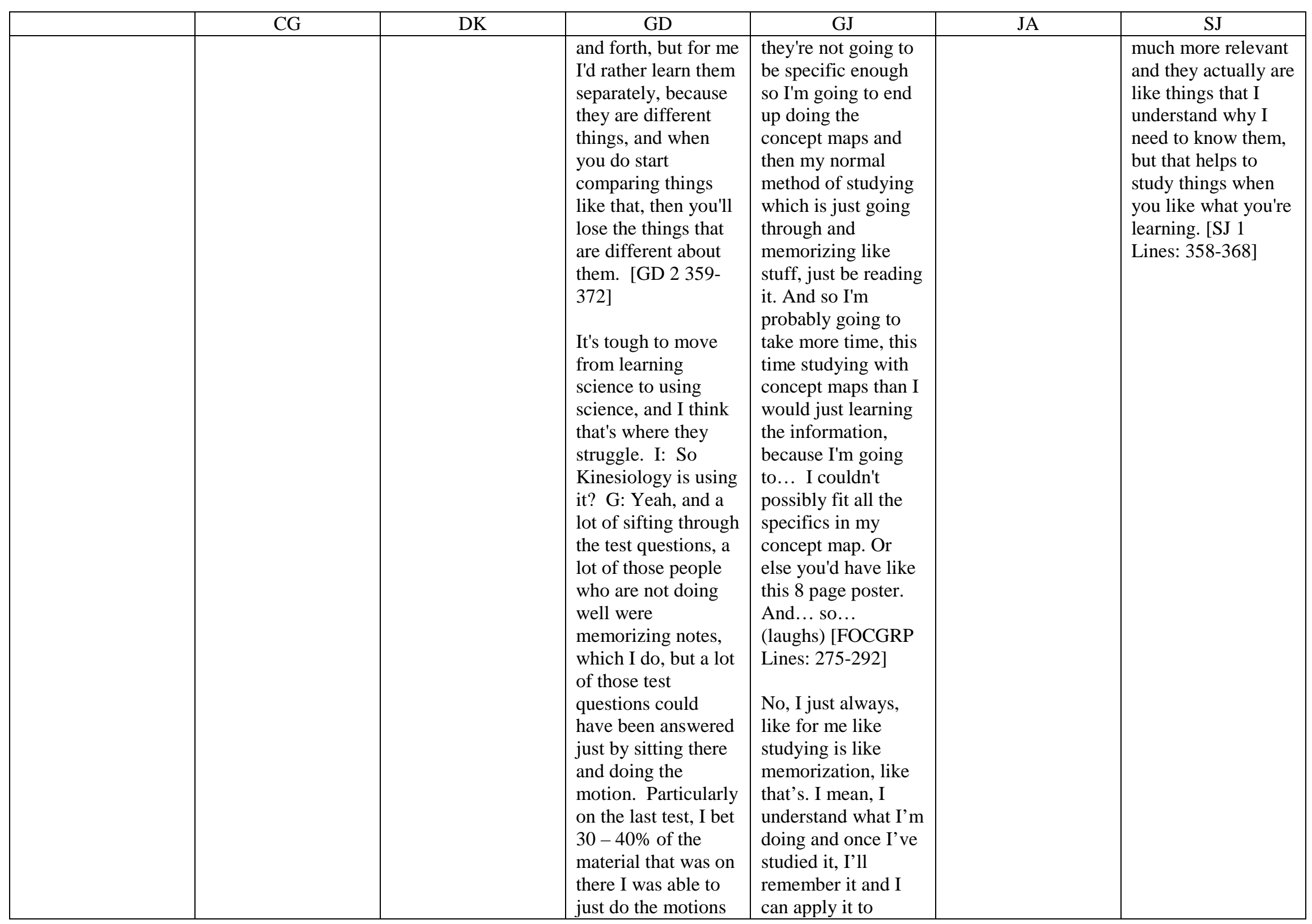




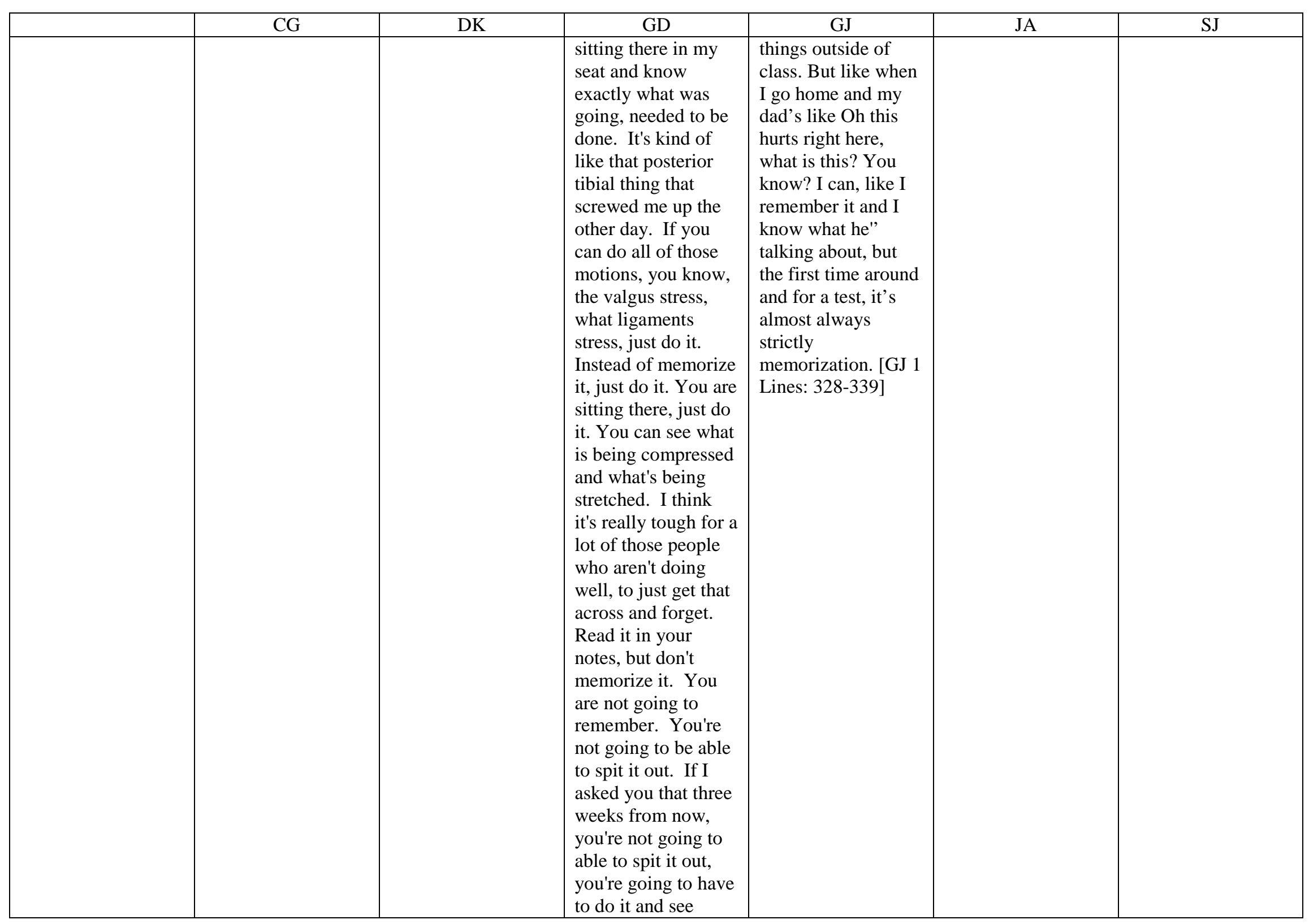




\begin{tabular}{|c|c|c|c|c|c|c|}
\hline & $\mathrm{CG}$ & DK & GD & GJ & JA & SJ \\
\hline & & & $\begin{array}{l}\text { what's happening. I } \\
\text { think that's where a } \\
\text { lot of problems } \\
\text { occur. [GD } 2 \text { Lines: } \\
\text { 708-746] }\end{array}$ & & & \\
\hline Habit & & $\begin{array}{l}\text { Yes. I, um, probably } \\
\text { before this I used to } \\
\text { study a week in } \\
\text { advance at top And } \\
\text { that would, like I'd } \\
\text { do the readings, and } \\
\text { I'd make flashcards } \\
\text { but never as much } \\
\text { studying. I'd slack } \\
\text { off some things. I: } \\
\text { So do you feel that } \\
\text { it's just mainly a } \\
\text { difference not so } \\
\text { much in your } \\
\text { approach or your } \\
\text { method so much as } \\
\text { the amount of time? } \\
\text { D: Yeah, definitely. } \\
\text { I mean I still take } \\
\text { the same approach } \\
\text { when I used to study } \\
\text { before. I used to, } \\
\text { flash cards, readin } \\
\text { notes, but now it's } \\
\text { more time, it's mo } \\
\text { energy so to speak. } \\
\text { [DK Lines: } 233- \\
\text { 254] } \\
\text { Um, you made } \\
\text { mention too, about, } \\
\text { just kind of the time } \\
\text { factor. Did, um, and } \\
\text { lot of people, pretty }\end{array}$ & $\begin{array}{l}\text { Really didn't have, } \\
\text { like in my } \\
\text { undergraduate, I } \\
\text { really didn't have } \\
\text { too much, too many } \\
\text { problems. I really } \\
\text { didn't have to study } \\
\text { that much. If I went } \\
\text { to class and took } \\
\text { notes, rewrote my } \\
\text { notes, that was } \\
\text { usually sufficient to } \\
\text { get by with a B or } \\
\text { so. So I really didn't } \\
\text { have to study too } \\
\text { much. [GD } 1 \text { Lines: } \\
\text { 88-95] } \\
\text { Concept mapping } \\
\text { really doesn't } \\
\text { compare to any } \\
\text { other study method I } \\
\text { ever used so. Really } \\
\text { we'll see how it } \\
\text { works out but, um, } \\
\text { yeah I really never } \\
\text { did too much like } \\
\text { that. I guess it was } \\
\text { all reading notes, } \\
\text { memorizing notes, } \\
\text { using flash cards or } \\
\text { whatever else. } \\
\text { Whatever else, } \\
\text { technique may be }\end{array}$ & & $\begin{array}{l}\text { So it sounds like the } \\
\text { notes are a habit. J: } \\
\text { Yeah, it is such a } \\
\text { habit, to think, to try } \\
\text { to be independent of } \\
\text { those is really } \\
\text { difficult. [JA } 2 \\
\text { Lines: 164-169] } \\
\text { I don't know. I } \\
\text { think you could } \\
\text { really use them with } \\
\text { how the course is } \\
\text { now. I just end up, I } \\
\text { feel like I run out of } \\
\text { time a lot. And I } \\
\text { instead go back and } \\
\text { make my notes } \\
\text { more complete. But } \\
\text { I could just as easily } \\
\text { do the concept map } \\
\text { thing, I just always } \\
\text { think let's just get } \\
\text { my complete set of } \\
\text { notes. I just always } \\
\text { think that way first. } \\
\text { But instead I guess I } \\
\text { could just take a } \\
\text { concept and run } \\
\text { with it on a concept } \\
\text { map too. [JA } 2 \\
\text { Lines: } 151-162 \text { ] }\end{array}$ & $\begin{array}{l}\text { Well, it was a lot } \\
\text { more like constant } \\
\text { work than I had } \\
\text { expected and I think } \\
\text { only because I never } \\
\text { had a class that } \\
\text { required like } \\
\text { constant studying. } \\
\text { Like usually it was } \\
\text { like, you know a } \\
\text { week before the test } \\
\text { and, like I mean I } \\
\text { would do homework } \\
\text { and do the readings } \\
\text { but, like I never had } \\
\text { to review my notes } \\
\text { everyday. And that } \\
\text { was that kind of } \\
\text { opened my eyes a } \\
\text { little bit. [SJ } 1 \\
\text { Lines: } 39-49 \text { ] }\end{array}$ \\
\hline
\end{tabular}




\begin{tabular}{|c|c|c|c|c|c|c|}
\hline & CG & DK & GD & GJ & JA & SJ \\
\hline & & $\begin{array}{l}\text { much concept map } \\
\text { was something they } \\
\text { did on top of what } \\
\text { they were already } \\
\text { doing and I just } \\
\text { wondered what, } \\
\text { how you felt about } \\
\text { that D: Um, it was } \\
\text { definitely added to } \\
\text { what I was doing. I } \\
\text { didn't, like I didn't } \\
\text { cut out any of my } \\
\text { other studying } \\
\text { habits because I } \\
\text { didn't stop doing } \\
\text { anything i place of } \\
\text { it. Um, I don't } \\
\text { necessarily think I'll } \\
\text { use it in the future to } \\
\text { replace anything. } \\
\text { [DK Lines: 545- } \\
\text { 558] }\end{array}$ & $\begin{array}{l}\text { available. So.. } \\
\text { [FOCGRP Lines: } \\
\text { 723-731] }\end{array}$ & & & $\begin{array}{l}\text { to, if it works. } \\
\text { [FOCGRP Lines: } \\
\text { 854-860] } \\
\text { So, um, how are, } \\
\text { what are your } \\
\text { typical study habits? } \\
\text { S: I usually read the } \\
\text { assignment. It } \\
\text { depends on the } \\
\text { class, like how } \\
\text { much, like the } \\
\text { teacher actually } \\
\text { takes from the book. } \\
\text { But I try to take } \\
\text { really good notes } \\
\text { and I would like to } \\
\text { study them more } \\
\text { often. I don't } \\
\text { necessarily, but I do } \\
\text { a lot of um, like I } \\
\text { make a lot of lists } \\
\text { about like what I } \\
\text { need to know, what } \\
\text { I need to study and I } \\
\text { rewrite things a lot. } \\
\text { Not necessarily } \\
\text { notes but like I'll } \\
\text { take notes from my } \\
\text { notes sometimes. } \\
\text { And I do a lot of } \\
\text { highlighting. It's } \\
\text { kind of like more } \\
\text { active studying. I } \\
\text { don't just sit there } \\
\text { and read. [SJ 1 } \\
\text { Lines: 66-83] }\end{array}$ \\
\hline CMAP \& COERCE & & & & $\begin{array}{l}\text { Like other people } \\
\text { have been saying }\end{array}$ & $\begin{array}{l}\text { Yeah, and generally } \\
\text { I have to say that I }\end{array}$ & \\
\hline
\end{tabular}




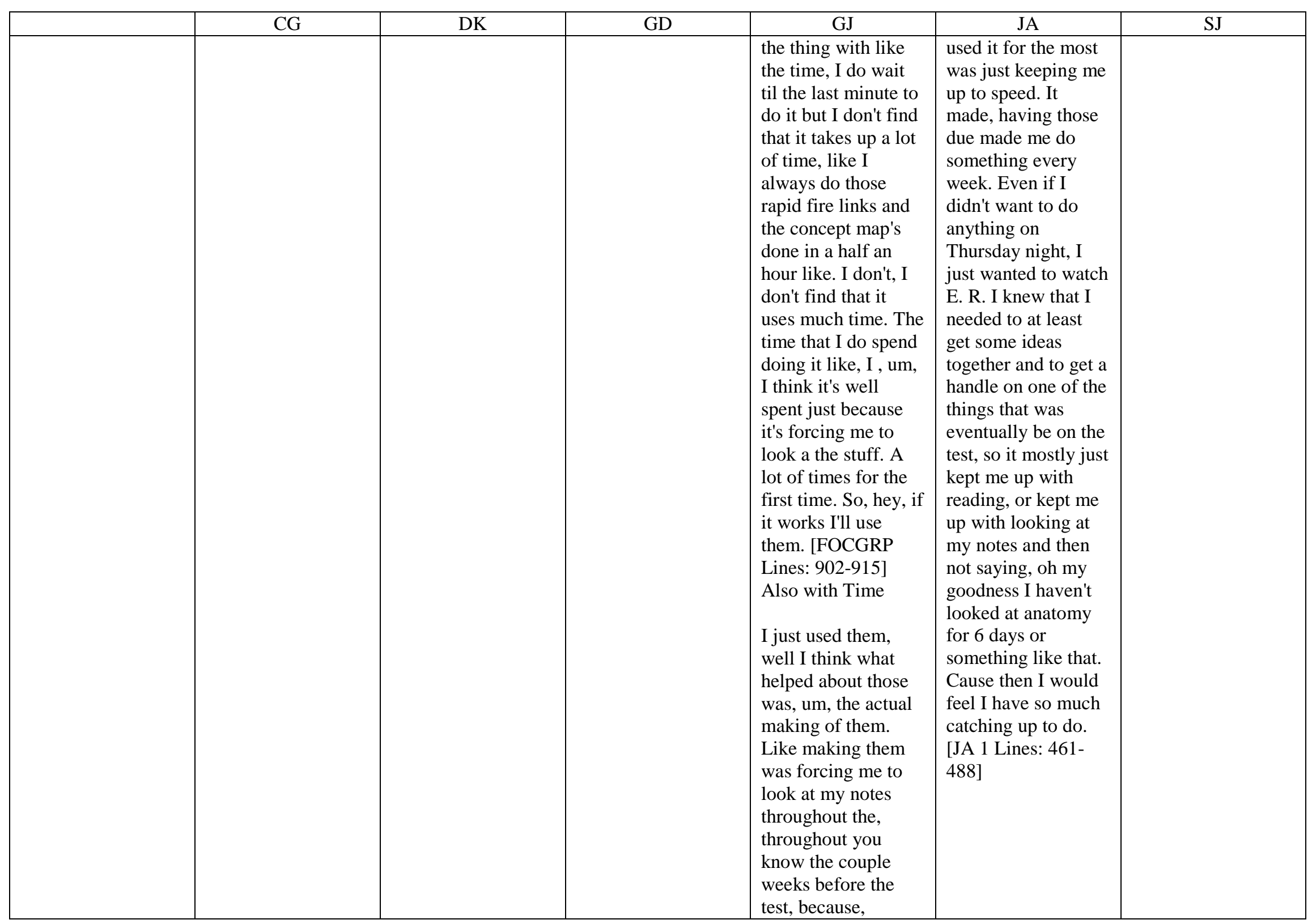




\begin{tabular}{|c|c|c|c|c|c|c|}
\hline & $\mathrm{CG}$ & DK & GD & GJ & JA & SJ \\
\hline & & & & $\begin{array}{l}\text { usually I wouldn't } \\
\text { look at it at all. And } \\
\text { that forced me to at } \\
\text { least become you } \\
\text { know familiar with } \\
\text { terms, and a general } \\
\text { idea of function and } \\
\text { whatever and so I } \\
\text { think that helped } \\
\text { me. But then, as far } \\
\text { as actually [GJ } 1 \\
\text { Lines: 283-299] } \\
\text { Other than, just like, } \\
\text { I think this study's } \\
\text { good from the } \\
\text { standpoint that it } \\
\text { makes you set goals, } \\
\text { like for yourself and } \\
\text { just how, what do } \\
\text { you want to } \\
\text { accomplish this } \\
\text { week and stuff like } \\
\text { that. [GJ } 1 \text { Lines } \\
698-703 \text { ] }\end{array}$ & & \\
\hline NOTECARD & $\begin{array}{l}\text { Notecards takes so } \\
\text { long and you find } \\
\text { yourself writing } \\
\text { detail after detail } \\
\text { and then you're just } \\
\text { memorizing. You're } \\
\text { just writing it on } \\
\text { paper like you did } \\
\text { for the second step, } \\
\text { so concept mapping } \\
\text { is less, I think it's } \\
\text { less writing. Like, if } \\
\text { you're just doing } \\
\text { one, one detail per }\end{array}$ & $\begin{array}{l}\text { Flash cards I'll } \\
\text { probably do the rest } \\
\text { of my life. I: Why } \\
\text { do you think that? } \\
\text { D: They've always } \\
\text { worked. I well, not } \\
\text { that they really } \\
\text { worked, but, kind of } \\
\text { like a comfort with } \\
\text { them. Something I' } \\
\text { always used. [DK } \\
\text { Lines: } 2 x x-288] \\
\text { Well, I mean, when }\end{array}$ & $\begin{array}{l}\text { Yeah, I hate to make } \\
\text { it sound like I use } \\
\text { flash cards all the } \\
\text { time, too, because I } \\
\text { don't. It's just that it } \\
\text { seemed like the best } \\
\text { method for learning } \\
\text { anatomy. For } \\
\text { learning, not even } \\
\text { for learning } \\
\text { anatomy though, } \\
\text { just specifically for } \\
\text { a muscle, its } \\
\text { origin,its insertion, }\end{array}$ & $\begin{array}{l}\text { Last year a little bit } \\
\text { and this year I } \\
\text { started doing like } \\
\text { some flashcards, but } \\
\text { I found out from last } \\
\text { semester that's just } \\
\text { too much } \\
\text { information to put } \\
\text { on flashcards. Like } \\
\text { the time I spent } \\
\text { making the } \\
\text { flashcards would } \\
\text { have been better } \\
\text { spent just studying }\end{array}$ & $\begin{array}{l}\text { And I have to say, } \\
\text { one thing I don't do } \\
\text { this year, that I did } \\
\text { in the past is make } \\
\text { notecards. I just } \\
\text { found that there's } \\
\text { too much } \\
\text { information that I } \\
\text { get too caught up in } \\
\text { putting words on } \\
\text { cards and not } \\
\text { studying what I } \\
\text { already have [JA } 1 \\
\text { Lines: 191-197] }\end{array}$ & $\begin{array}{l}\text { I think for me, it's } \\
\text { actually a lot } \\
\text { similar, because I } \\
\text { usually do more, } \\
\text { like active, like I } \\
\text { don't just sit there } \\
\text { and read. I highlight } \\
\text { or do, take notes or } \\
\text { like write things } \\
\text { down, or try to, } \\
\text { sometimes I even } \\
\text { try to organize } \\
\text { things myself in like } \\
\text { lists and everything. }\end{array}$ \\
\hline
\end{tabular}




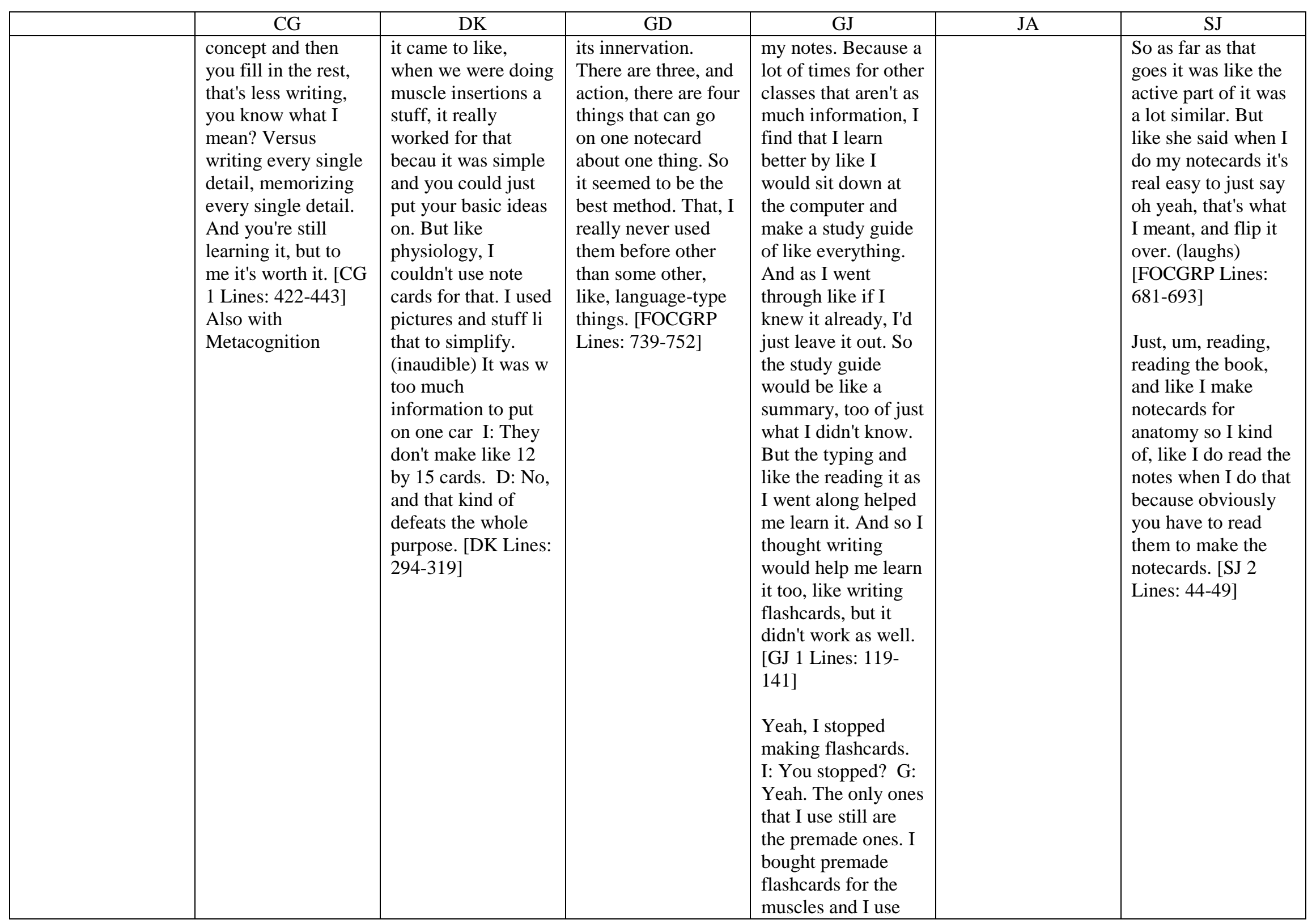




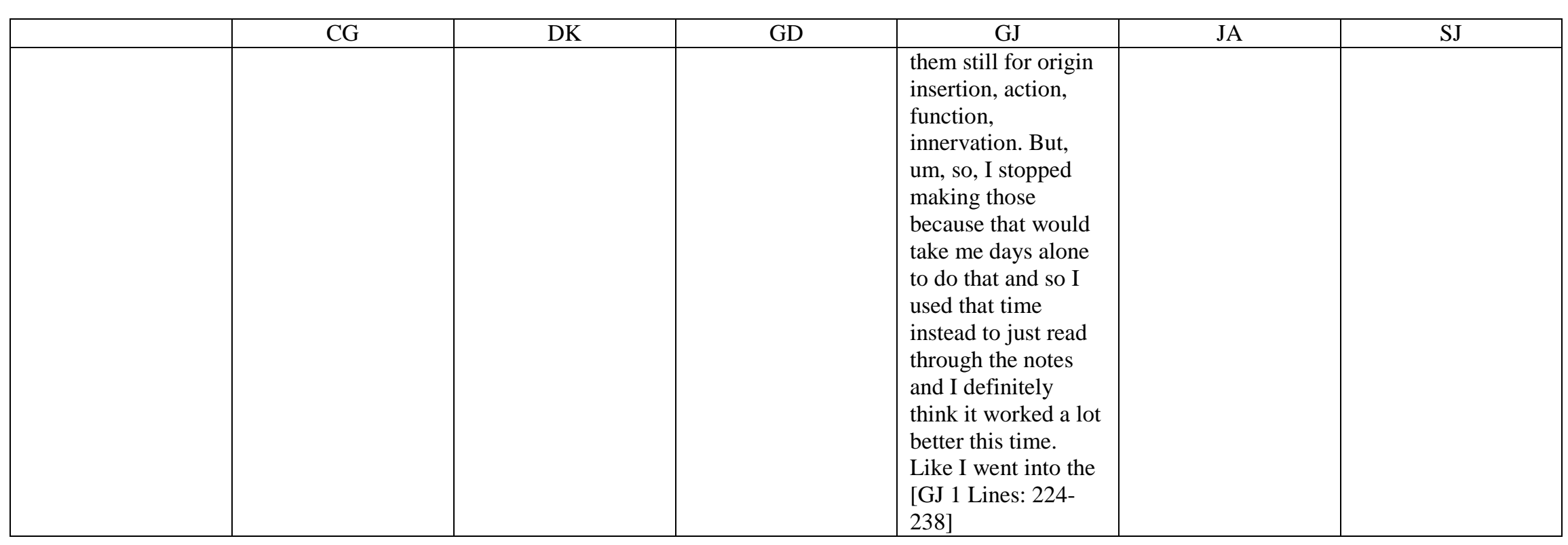




\section{Appendix J: Concept Map Examples From Participants}

The following concept maps have been modified from the original for better representation on these pages. They have been modified by 1) changing the fill color of all symbols to white, and 2) eliminating the shadow feature of the symbols. In some cases the concept maps have been recreated by the investigator, but the structure of the concept map was not altered.

\section{Figure J1Concept map constructed by JA (meaningful learner)}

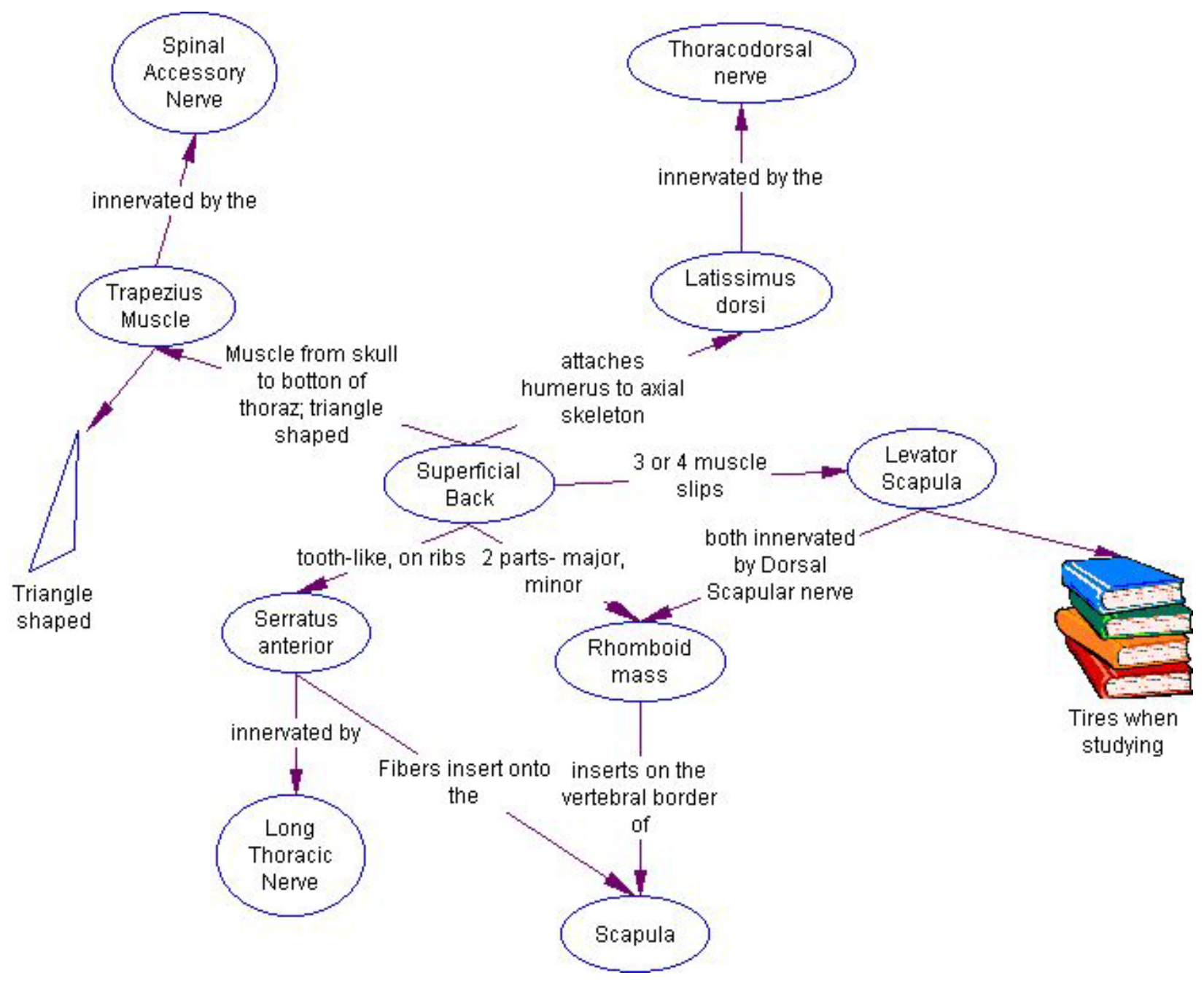


Figure J2 Concept map by GD (meaningful learner)

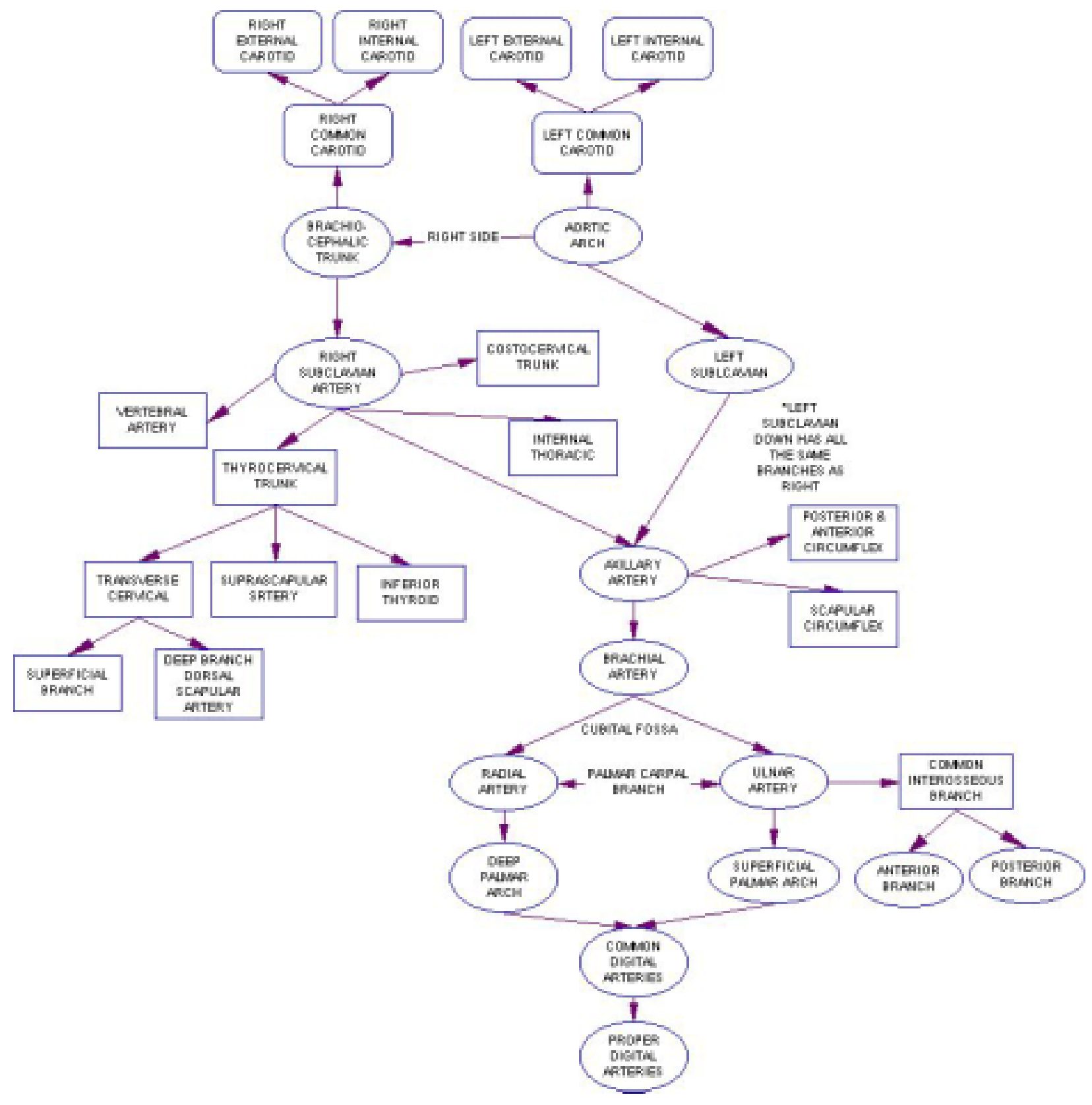


Figure J3 Concept map by SJ (meaningful learner)

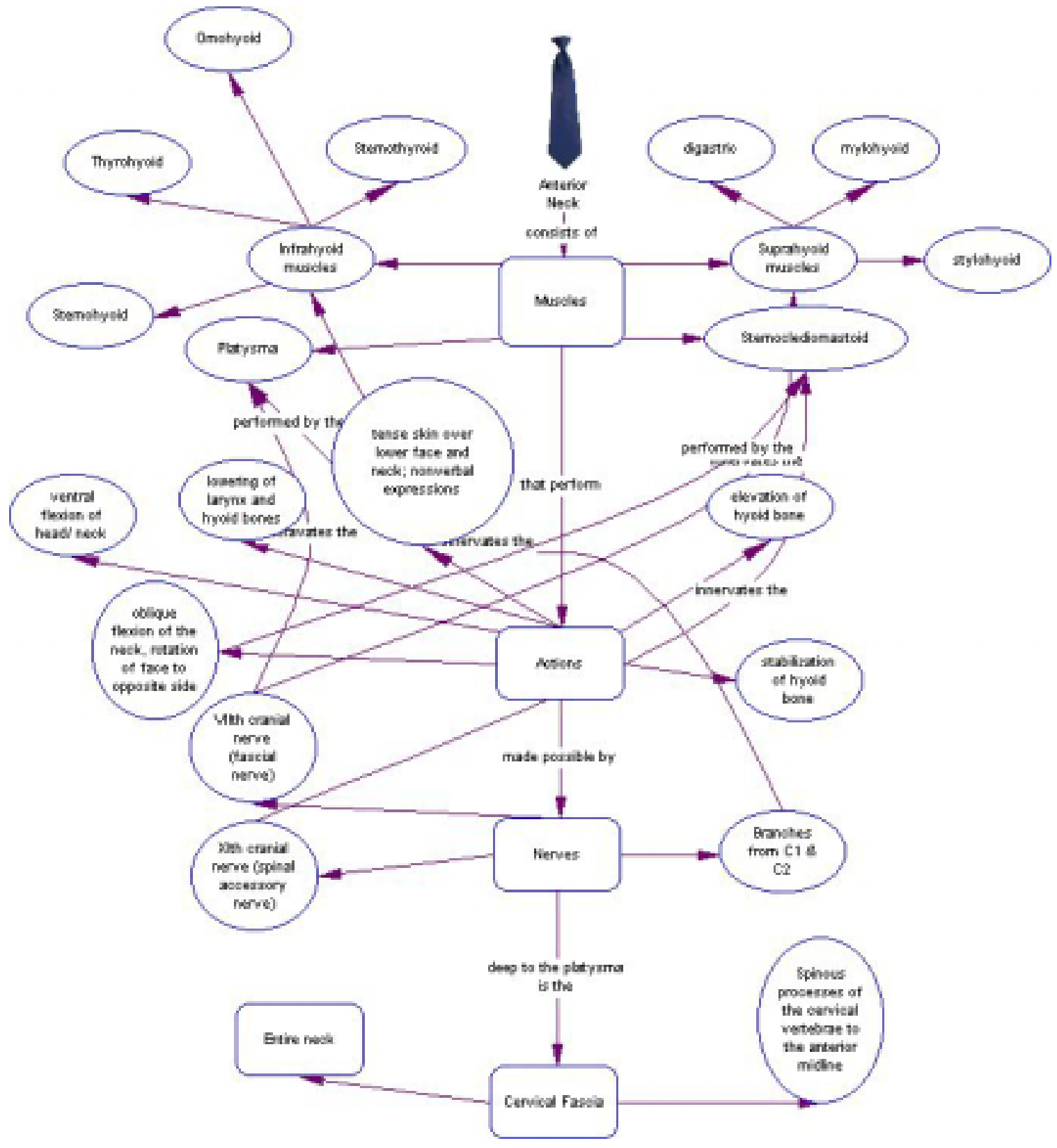


Figure J4 Concept Map created by CG (meaningful learner)

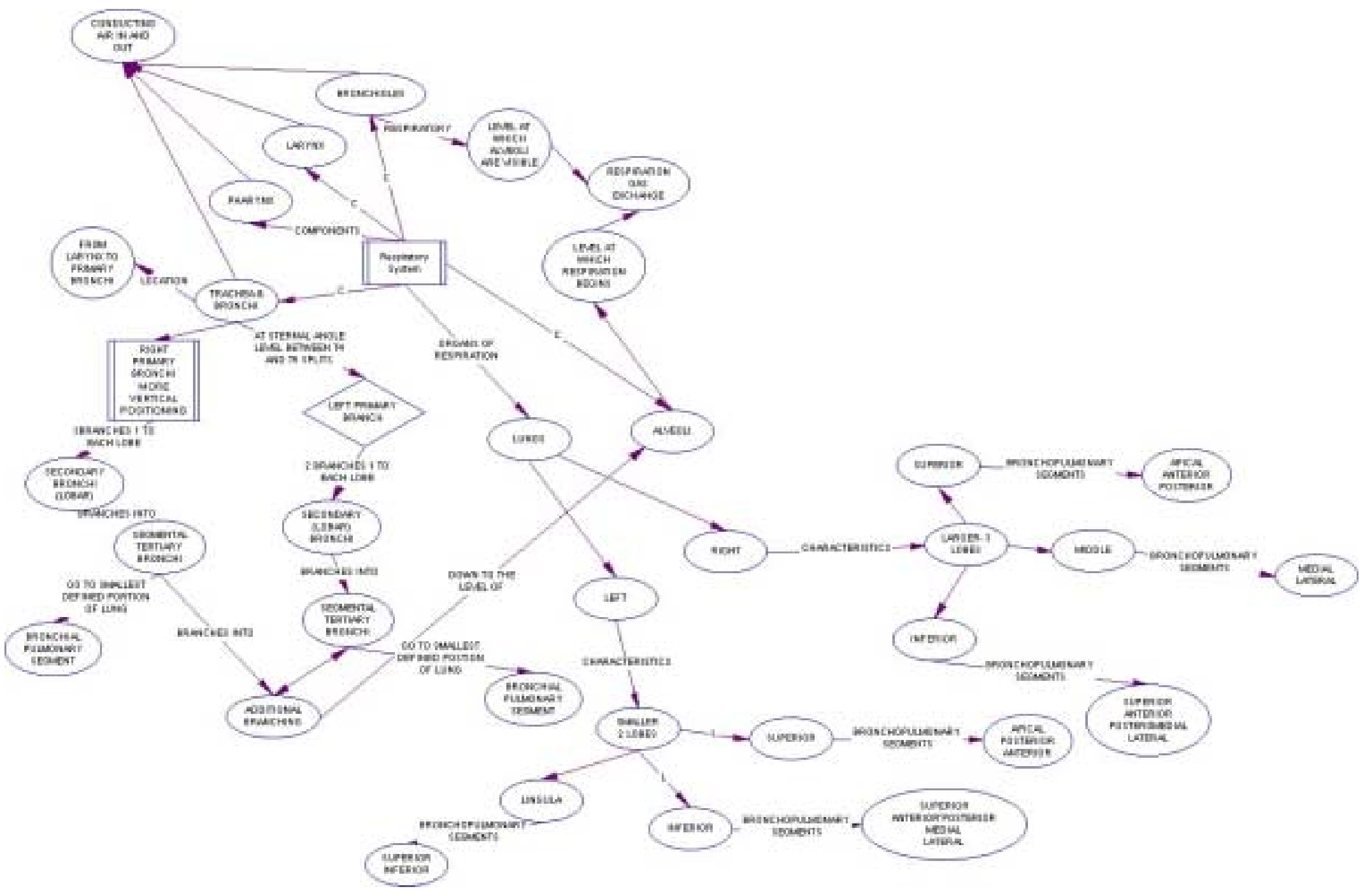


Figure J5 Concept Map created by GJ (rote learner)

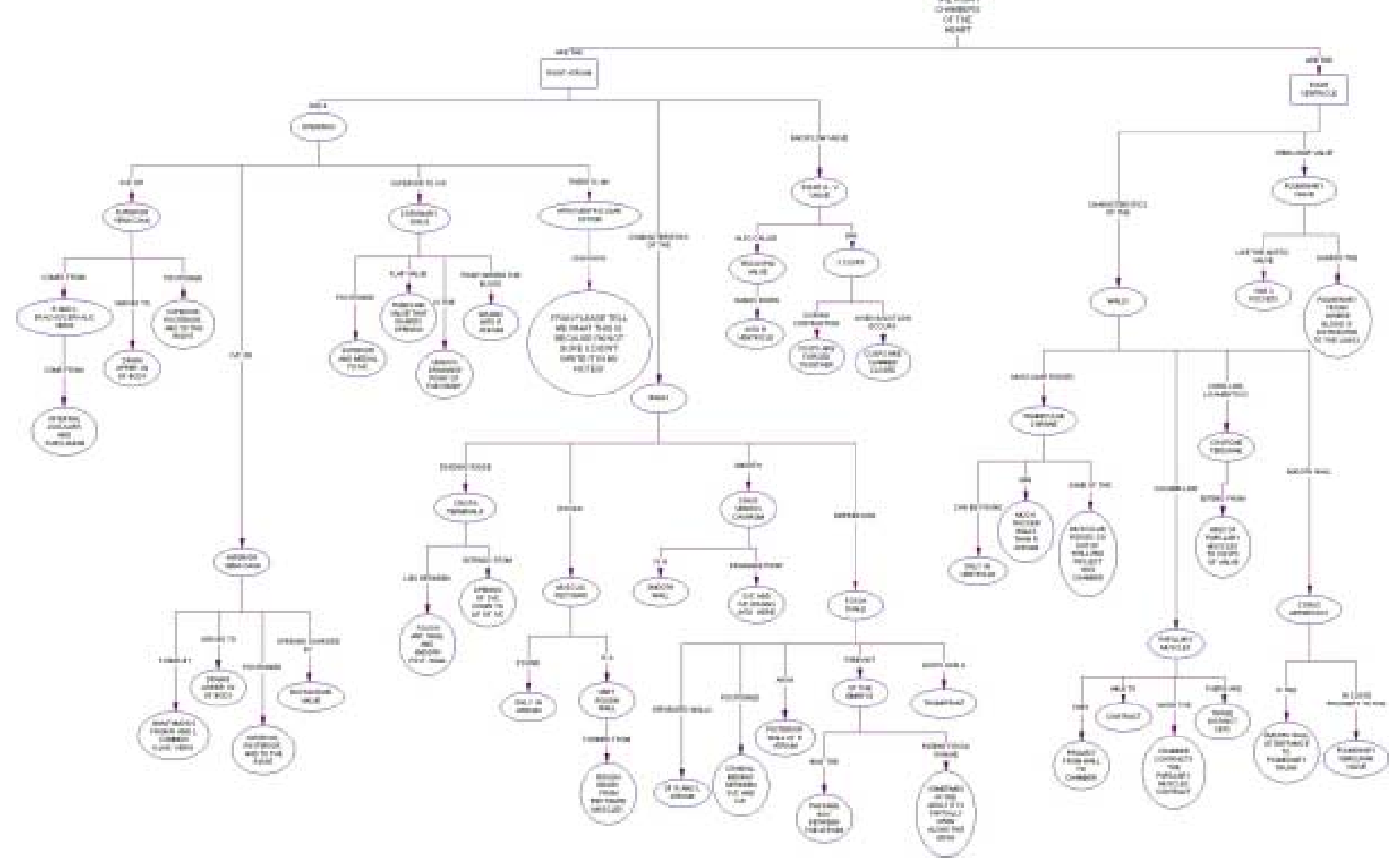


Figure J6 Concept map created by DK (rote learner)

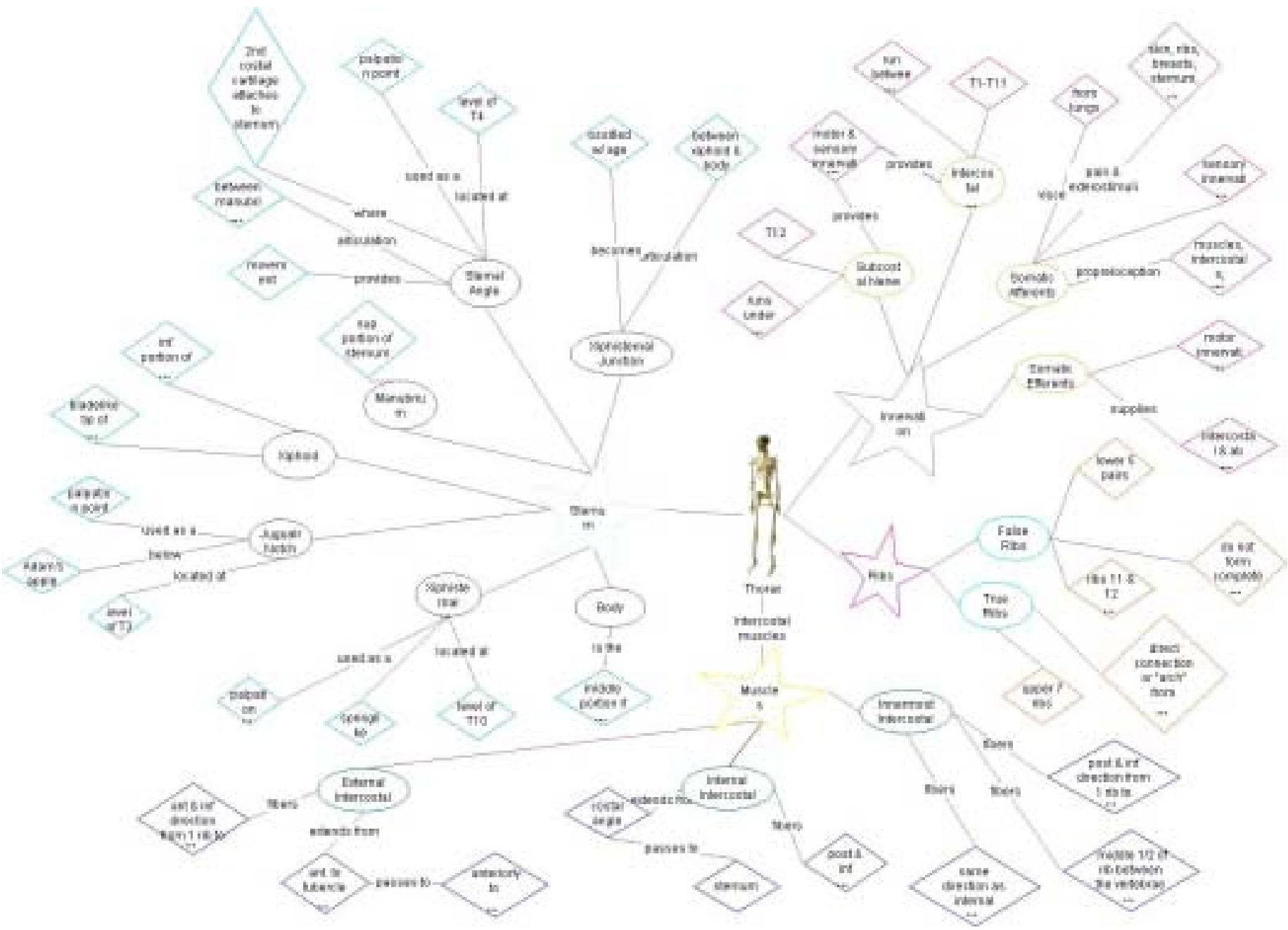

